Portland State University

PDXScholar

\title{
Can Tidal Perturbations Associated with Sea Level Variations in the Western Pacific Ocean be used to Understand Future Effects of Tidal Evolution?
}

\author{
Adam T. Devlin \\ Portland State University \\ David A. Jay \\ Portland State University, djay@pdx.edu \\ Stefan A. Talke \\ Portland State University, talke@pdx.edu \\ Edward D. Zaron \\ Portland State University, ezaron@pdx.edu
}

Follow this and additional works at: https://pdxscholar.library.pdx.edu/cengin_fac

Part of the Civil Engineering Commons, and the Environmental Engineering Commons Let us know how access to this document benefits you.

\section{Citation Details}

Devlin, Adam T.; Jay, David A.; Talke, Stefan A.; and Zaron, Edward D., "Can Tidal Perturbations Associated with Sea Level Variations in the Western Pacific Ocean be used to Understand Future Effects of Tidal Evolution?" (2014). Civil and Environmental Engineering Faculty Publications and Presentations. 173. https://pdxscholar.library.pdx.edu/cengin_fac/173

This Post-Print is brought to you for free and open access. It has been accepted for inclusion in Civil and Environmental Engineering Faculty Publications and Presentations by an authorized administrator of PDXScholar. Please contact us if we can make this document more accessible: pdxscholar@pdx.edu. 


\section{Can tidal perturbations associated with sea level variations in the western Pacific Ocean be used to understand future effects of tidal evolution?}

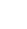

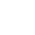

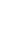

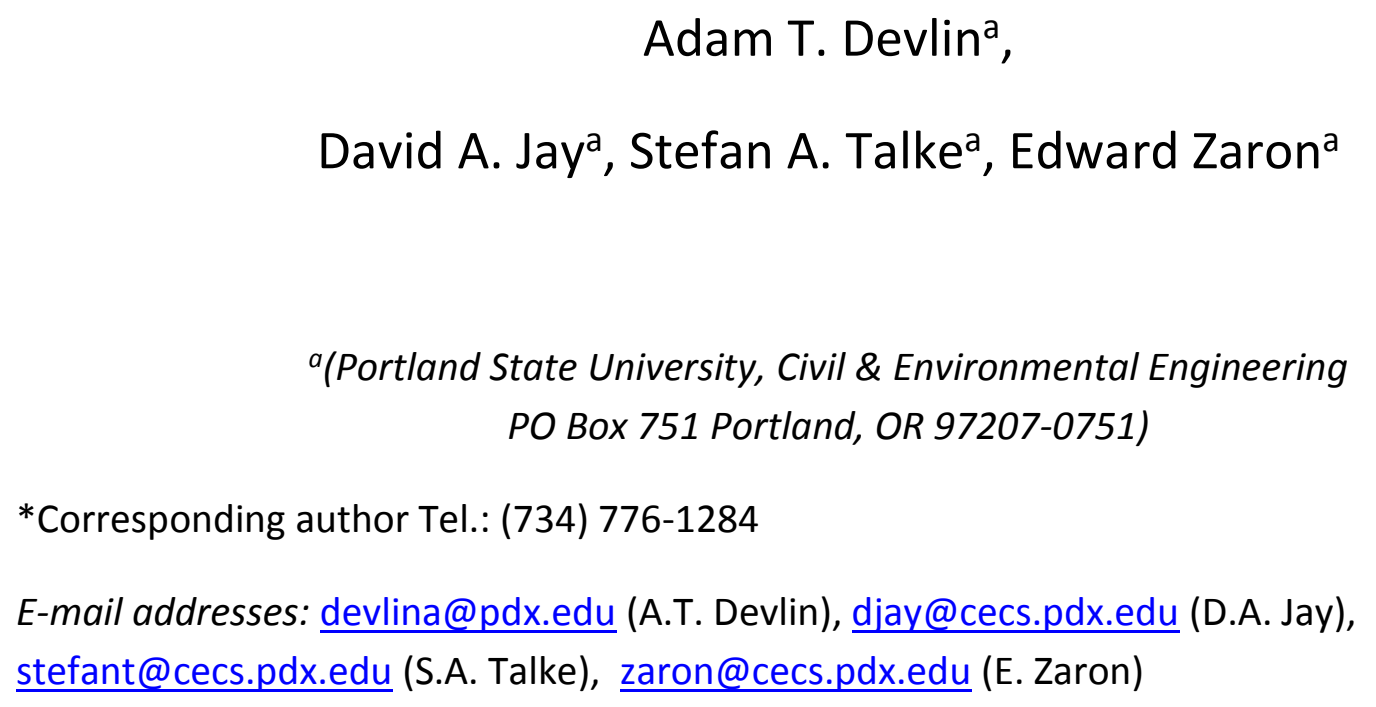

\section{April 2014}

Submitted to:

Ocean Dynamics

\section{Keywords:}

Astronomical tides; Western tropical Pacific; sea level variability; tidal anomaly trends; climate change; resonant triads 


\section{Abstract}

23 This study examines connections between mean sea level (MSL) variability and diurnal and semidiurnal tidal constituent variations at 17 open-ocean and 9 continental shelf tide gauges in the western tropical Pacific Ocean, a region showing anomalous rise in MSL over the last 20 years and strong interannual variability. Detrended MSL fluctuations are correlated with detrended tidal amplitude and phase fluctuations, defined as tidal anomaly trends (TATs), to quantify the response of tidal properties to MSL variation. About 20 significant amplitude and phase TATs are found for each of the two strongest tidal constituents, $\mathrm{K}_{1}$ (diurnal) and $\mathrm{M}_{2}$ (semidiurnal). Lesser constituents $\left(\mathrm{O}_{1}\right.$ and $\mathrm{S}_{2}$ ) show trends at nearly half of all gauges. Fluctuations in MSL shift amplitudes and phases; both positive and negative responses occur. Changing overtides suggest TATs are influenced by changing shallow water friction over the equatorial Western Pacific and the eastern coast of Australia (especially near the Great Barrier Reef). There is a strong connection between semidiurnal TATs at stations around the Solomon Islands and changes in thermocline depth, overtide generation, and the El Niño Southern Oscillation (ENSO). TATs for $\mathrm{O}_{1}, \mathrm{~K}_{1}$ and $\mathrm{M}_{2}$ are related to each other in a manner that suggests transfer of energy from $\mathrm{M}_{2}$ to the two diurnals via resonant triad interactions; these cause major tidal variability on sub-decadal time scales, especially for $\mathrm{M}_{2}$. The response of tides to MSL variability is not only spatially complex, it is frequency dependent; therefore, short-term responses may not predict long-term behavior.

\section{$\underline{\text { 1.Introduction }}$}

This study examines the connections between mean sea level (MSL) rise and variations in major diurnal and semidiurnal tidal constituent properties at open-ocean and continental shelf tide gauges in the Western Tropical Pacific Ocean, a region showing anomalous MSL rise over the last 20 years (Merrifield, 2011). Additionally, this domain exhibits large excursions of interannual sea level and tidal variability, especially during El Nino and La Nina events. We attempt to answer the question posed in the title, can we use the relations of the observed short-term MSL fluctuations to the short-term tidal variations to understand the future effects of tidal evolution, and to predict changes in total water level (MSL + tides) under higher MSL conditions? MSL rise rates have increased since ca. 1993 at 15 of 26 gauges used in this study, and the rate has increased at both deep ocean island stations and at continental shelf gauges (Figure 1; Tables 1a and 1b). This rapid increase in Western Pacific MSL rate of change provides an opportunity to seek connections between MSL rise and tidal evolution. If MSL rise is a primary driver of changes in the tides, as suggested by Arbic and Garrett (2010), then this area should exhibit unusually large rates of tidal evolution over the same time period, with a relatively simple spatial pattern. Alternatively, if changes in internal wave propagation (as in Hawaii, Colosi and Munk, 2006) are dominant, then smaller-scale, less spatially coherent tidal evolution would be expected. Shallow water frictional processes can also alter tidal constituents and may be altered by MSL variations (Amin, 1983), but this local process would not likely drive regional trends. Finally, the existence 
Pacific Island gauges suggests. Furthermore, the results of our analyses suggest that different processes are active in different parts of the frequency spectrum, and so the behavior of short-term fluctuations do not, in general, allow a clear prediction of what may be expected for long-term trends of tidal properties.

We examine the interactions of detrended tidal anomalies - the deviations from long-term trends in tidal constituent properties - in relation to detrended MSL anomalies (deviations from long-term MSL trends) as a means of diagnosing dynamical factors that might influence the longer-term evolution of tides. Specifically, we examine MSL anomalies and tidal anomalies at 26 tide gauges in the Western Pacific region, at both island gauges, and at nearby continental shelves. We focus on four constituents, the two largest semidiurnal (twice daily) constituents, $\mathrm{M}_{2}$ (twice daily lunar tide) and $\mathrm{S}_{2}$ (twice daily solar tide), and the two largest diurnal (once daily) components, $\mathrm{K}_{1}$ (lunisolar diurnal) and $\mathrm{O}_{1}$ (lunar diurnal). In addition, a subset of gauges with a minimum length-of-record (LOR) $\geq 40 \mathrm{yr}$ is used to determine whether any changes in tidal trends are associated with the onset of anomalous regional MSL rise in recent decades. We will compare the long-term linear trends of both MSL and tidal properties (amplitude and phase), as well as the shorter-term fluctuations of MSL anomalies and tidal property anomalies from these long term trends (LTTs). Under rapidly rising and warming sea level scenarios, tidal amphidromes may shift as MSL rises and stratification increases (Pugh, 2004, Müller 2010). Amphidromes may shift center position, amplify, and/or rotate. For all four tides, we will compare the changes in amplitudes and phases with changes in MSL in the context of possible amphidromic migrations.

We will also attempt to identify the mechanisms behind the observed trends in tidal properties in several ways. First, we consider non-linear, shallow-water overtides as a tool for understanding changing friction over continental shelves and in shallow water regions in relation to changing tides. Then we will compare the variations of tidal trends at select stations to fluctuations in regional thermocline depth. Finally, we will consider the possibility of a resonant triad interaction between the $\mathrm{K}, \mathrm{O}_{1}$, and $\mathrm{M}_{2}$ tides.

\section{2. Background}

\subsection{Changing sea level and changing tides}

Ocean tides are usually considered stationary in time because of their close relationship to astronomical forcing. However, recent work has shown that tides are evolving at diverse rates in different parts of the ocean without any apparent relationship to astronomical forcing (Woodworth, 2010). Changes in major tidal constituents such as $\mathrm{M}_{2}$, $\mathrm{S}_{2}, \mathrm{~K}_{1}$ and $\mathrm{O}_{1}$ are observed in the Eastern Pacific (Jay, 2009), the Gulf of Maine (Ray, 2006), and the North Atlantic (Ray, 2009; Müller et al., 2011). Changes in tidal range and datum levels along many parts of the US coast line (Flick et al., 2003) also indicate evolution of constituents. While several mechanisms have been suggested that are independent of mean sea level (MSL) rise (Jay 2009), MSL may influence or be correlated with tidal evolution in a variety of ways, both locally and on amphidromic scales, as well as over a multitude of frequency bands, from seasonal to multi-decadal. One possibility is that changes in continental shelf depth may influence tides on a basin scale (Arbic and Garrett, 2010, Arbic et al., 2009), through changing bed friction in shallow water. Rising MSL also alters tidal 
wavelength and wave speed in shallow water areas, and reduces energy dissipation due to the reduced effect of bottom friction (Pugh, 1987). Alternatively, MSL rise may coincide with changes in stratification and/or thermocline depth. These internal changes may alter the surface manifestation of internal tides in ways that are detectable at tide gauges, e.g., at Honolulu (Colosi and Munk, 2006). Finally, fluctuations in multiple constituents may be related via resonant triads (cf. Lamb, 2007). These factors, individually or in combination, could lead to a migration of the tidal amphidromes that would appear as a change in tidal properties at fixed observation stations.

The long-term global average trend in MSL is $1.7 \pm 0.3 \mathrm{mmyr}^{-1}$, as determined from tide gauge records (Church and White, 2006; 2011). Satellite observations show that the global MSL rise since 1993 has been $3.3 \pm 0.4$ mmyr $^{-1}$ (Nicholls and Cavenaze, 2010), suggesting a recent acceleration. However, MSL rise is spatially non-uniform. Five-year running means suggest that the MSL trend in the western Tropical Pacific has approached $+10 \mathrm{mmyr}^{-1}$ at some locations since 1993 (Merrifield, 2011). In contrast, MSL rise rates in the Northeastern Pacific have been below the global average over the same time period (National Research Council Ocean Science Board, 2012), with some places along the West Coast of the US having constant or slightly negative rates since 1980, partly due to prevailing wind patterns. While it is unlikely that the extreme rise rate in the western tropical Pacific will persist, and Bromirski et al. (2011) have suggested that a trend reversal along the US West Coast is imminent, such decadal-scale variations in MSL rise rates offer an opportunity to examine the connections between different parts of the water level spectrum, in this case, between tidal evolution and MSL.

MSL also exhibits fluctuations related to climate cycles. The El-Nino Southern Oscillation (ENSO) is a strong contributing factor to sea surface anomalies in the Pacific (Kohl et al. 2007; Lombard et al. 2009; Timmermann et al. 2010), and local, short-term MSL anomalies associated with ENSO are often much larger than long-term trends. The 1982-1983 and the 1997-1998 El Nino events gave rise to widespread MSL fluctuations, with some coastal localities showing yearly averaged MSL rises or falls of 200mm or more (Nerem et al, 1999; White et al, 2001). ENSO-related sea surface height ( $\mathrm{SSH}$ ) trends are, however, an order of magnitude too small (over a $\sim 15 \mathrm{yr}$ time period) and too transient to account for the observed MSL rise for the western tropical Pacific region (Merrifield, 2011). Instead, Merrifield argues that the unusually rapid MSL rise in the western tropical Pacific is correlated with changing wind stress patterns in the region from after 1993, corresponding roughly to the period of satellite observations. ENSO related sea level variability is difficult to remove entirely from MSL time series, due to its quasiperiodic behavior, and large geographical extent that the signal affects. Hamlington, et al. (2011) present a detailed study on the capture and removal of the ENSO signal and of modulated annual variability from global sea level records for 1950 through 2009, using cyclostationary empirical orthogonal function techniques, based on the methods of Church et al. (2004).

Predictions of future inundation due to extreme events must account for both MSL rise and changes in tidal properties. For example, Haigh et al. (2010) found that MSL rise rates of $+0.8-2.3$ mmyr $^{-1}$ in the English Channel were accompanied by smaller increases in high water elevation of $+0.1-0.3 \mathrm{mmyr}^{-1}$ (relative to MSL). A numerical model from Pickering et al. (2012) found that a $2 \mathrm{~m}$ increase in MSL increased the spring tidal range from $-0.49 \mathrm{~m}$ to 
$+0.35 \mathrm{~m}$, depending on location. Hence, changing tidal processes can either mitigate or exacerbate changes to extreme water levels caused by MSL rise (Horsburgh and Wilson, 2007). between the critical latitudes for the major tidal species, $\pm 30^{\circ}$ latitude for $K_{1}$ and, and $\pm 75^{\circ}$ for $M_{2}$. Ray and Mitchum (1997) report that time-series of the monthly variations of $\mathrm{M}_{2}$ and MSL were coherent at annual, inter-annual and intra-annual bands, and Mitchum and Chiswell (2000) note that higher amplitudes of $\mathrm{M}_{2}$ are associated with times of a deeper thermocline. Colosi and Munk (2006) conclude that the observed increase in the total $\mathrm{M}_{2}$ amplitude from $161 \mathrm{~mm}$ to $169 \mathrm{~mm}$ at Honolulu over the past century occurred because the internal $\mathrm{M}_{2}$ wave moved more closely into phase with the surface tide. This conclusion is dependent on the assumption that rising sea level is a proxy for a deeper thermocline, which then alters the phase and/or the amplitudes of the internal tide.

\section{$\underline{\text { 2.2 Resonant Triads-- Theory }}$}

Resonant triad interactions are a possible mechanism for coherent fluctuations of multiple tidal constituents. Resonant (and near-resonant) triad interactions, were first described in the context of light waves by Armstrong et al (1962), discussed generally by Bretherton (1964), and solutions for water waves are detailed by Craik (1985). Resonant internal wave triads arise from the (nonlinear) convective acceleration terms and are essential to energy transfer across the oceanic tidal spectrum (Hibiya et al 2002; Gerkama et al, 2006), including shoaling surface gravity waves in shallow water (Frelich and Guza, 1984), and are involved in parametric subharmonic instabilities (PSI) at or near critical latitudes (McKinnon and Winters, 2005). modes. The three (or more) complex plane waves involved in a triad have the form:

$$
\begin{aligned}
& Z_{j}(t)=A_{j}(t) \exp \left[i \theta_{j}(t)\right] \\
& \text { with }: \theta_{j}=\left(\mathbf{k}_{\mathbf{j}} \cdot \mathbf{x}-\omega_{j} t\right)=\left(k_{j} x+l_{j} y+m_{j} z-\omega_{j} t\right)
\end{aligned}
$$

146 The $\omega_{\mathrm{j}}$ 's are the frequencies of each wave; $\mathbf{k}_{\mathrm{j}}=\left(k_{j}, l_{j}, m_{j}\right)$ are the wavevectors of each wave, and each wave has a 147 dispersion relation given by $\omega_{\mathbf{j}}\left(\mathbf{k}_{\mathbf{j}}\right)$. For three interacting waves, the main resonance conditions are (Craik, 1985; 148 Simmons, 1969) that the waves are phase locked (i.e., the sum of the phases is a constant), and that the frequencies 149 and wavenumbers are also matched via a summation. Thus:

$$
\theta_{1}+\theta_{2}+\theta_{3}=C,
$$

$$
\begin{aligned}
& \omega_{1} \pm \omega_{2} \pm \omega_{3}=\Delta \omega \\
& \mathbf{k}_{\mathbf{1}} \pm \mathbf{k}_{\mathbf{2}} \pm \mathbf{k}_{\mathbf{3}}=\Delta \mathbf{k}[\text { for }: \mathbf{k}=(k, l, m)]
\end{aligned}
$$


Small frequency and wavenumber mismatches ( $\Delta \omega$ and $\Delta \mathbf{k}$ ) allow for the possibility of near-resonant triads (Craik, 1985); exact triads have $\Delta \omega=0$ and $\Delta \mathbf{k}=0$. Near-resonant triads are possible in the ocean for internal tide generation at or near topographic features (Lamb, 2007). These relationships hold for a single triad of three waves, but are applicable to multiple triads of three waves, or even groups of four waves (tetrads). While Eq. (2b) is satisfied exactly $(\Delta \omega=0)$ by a number of tidal constituent combinations, Eq. (2c) is geometry-dependent. The dispersion relationship, $\omega_{\mathbf{i}}\left(\mathbf{k}_{\mathbf{i}}\right)$, for planar and linear internal waves in the ocean is given by (Gill, 1982):

$$
\omega_{j}\left(\mathbf{k}_{j}\right)^{2}=\frac{N^{2}\left(k_{j}^{2}+l_{j}^{2}\right)+f^{2} m_{j}^{2}}{k_{j}^{2}+l_{j}^{2}+m_{j}^{2}}
$$

Where $N$ indicates the buoyancy frequency, and $f$ is the Coriolis frequency; $f$ is a constant for each gauge, while $N$ is dependent on the local depth profile of temperature and salinity, and may vary seasonally.

There are more than 450 tidal frequencies in the ocean (Cartwright and Tayler, 1971); many of these frequencies could in theory form triads that satisfy Eq. (2b), but most such triads are based on minor tidal constituents and are unlikely to be energetic enough to be measurable. The triad most likely to be detected consists of $\mathrm{K}_{1}, \mathrm{O}_{1}$ and $M_{2}$. The $K_{1}$ and $O_{1}$ tidal frequencies are close to each other, being equidistant (plus or minus $\sim 2 \%$ ) from half the $M_{2}$ frequency; in terms of $\mathrm{M}_{2}$, they are:

$$
\begin{aligned}
& \omega_{m 2}=\omega_{k 1}+\omega_{o 1} \\
& \left(\omega_{\mathrm{k} 1}=0.52 \omega_{\mathrm{m} 2}\right) ;\left(\omega_{\mathrm{o} 1}=0.48 \omega_{\mathrm{m} 2}\right)
\end{aligned}
$$

We note that shallow water (frictional) overtides satisfy Eqs. (2a) and (2b), and may satisfy Eq. (2c).

Ball (1964) details how triad interactions can occur at the interface of a two-layer fluid, e.g., at the thermocline. The strength of the interactions is dependent on the depths of the layers as well as the stratification and the angles of incidence of each wave relative to the thermocline interface. Recent upper-layer warming in the Western Pacific (Domingues et al, 2008) may be leading to a deepening thermocline and stronger stratification (Müller, 2012), which makes the ocean effectively two-layered, and enhanced triad interactions may occur at the interface. MSL rise may also cause an extension in a basin's areal extent, as new areas are inundated. The close frequencies of $\mathrm{K}_{1}$ and $\mathrm{O}_{1}$ will yield similar wavenumber vectors for any given mode. In addition, because they are both nearly half the $\mathrm{M}_{2}$ frequency, internal modes of $\mathrm{K}_{1}$ and $\mathrm{O}_{1}$ may energy exchange via $\mathrm{M}_{2}$. Alternatively, remote changes in barotropic $\mathrm{M}_{2}$ may alter low-mode diurnal internal tides via parametric subharmonic instability (MacKinnon and Winters, 2005). Both possibilities are explored below.

\section{$\underline{\text { 3. Methods }}$}

\subsection{Station Selection and Data}


Twenty-two of the 26 tidal records used in this study were selected from the University of Hawaii Sea Level Center (UHSLC) archives. The Australian stations of Cairns, Gladstone, and Williamstown were provided by the Australian National Tidal Center and Auckland, New Zealand was provided by Land Information New Zealand (LINZ). The factors that guided our station selection were:

1) Location: all stations are in or near the area of anomalous MSL rise.

2) Temporal coverage: all stations used have an LOR (length of record) greater than one nodal cycle (18.6yrs); LOR ranged from 19 to $107 \mathrm{yrs}$.

3) Completeness: the data were more than $80 \%$ complete over the record.

\subsection{Harmonic Analysis and Tidal Admittance}

To account for nodal cycle variability, we investigate tidal trends through the use of a tidal admittance. Admittance is a unitless, complex ratio of an observed tidal constituent $(\mathrm{m})$ to its corresponding astronomical equilibrium amplitude, $\mathrm{V} / \mathrm{g}(\mathrm{m})$; tidal potential $\mathrm{V}$ is in $\mathrm{m}^{2} \mathrm{~s}^{-2}$ and $g$ is the acceleration due to gravity, in $\mathrm{ms}^{-2}$ ). Because nodal and other low-frequency astronomical variability is present with similar (relative) strength in both the observed tidal record and in $\mathrm{V} / g$, it is largely absent in admittance time series. 
For all relevant stations, overlapping yearly tidal harmonic analyses (at monthly time steps) were carried out on hourly records and hourly V/g, using the tidal harmonic analysis package in MATLAB developed by Pawlowicz (2002), and modified to include robust fitting by Leffler and Jay (2009). The tidal potential is determined using a program provided by Richard Ray (National Atmospheric and Space Administration, personal communication) that is based on the methods of Cartwright and Tayler (1971), and Cartwright and Edden (1973). Results from a single harmonic analysis determine an amplitude, $A$, and phase, $\theta$, at the central time of the analysis window for each tidal constituent with error estimates for both. Use of a moving analysis window produces time-series of amplitude and phase; both monthly (767hr) and annual analyses were used. From amplitude $A(t)$ and phase $\theta(t)$ time series one can construct complex amplitudes $\mathbf{Z}(\mathbf{t})$,

$$
\mathbf{Z}(t)=A(t) e^{-i \theta(t)}
$$

We form time-series of tidal admittance ratio (AR) and phase difference (PD) for any constituent using Eqs. (6) and (7),

$$
\mathbf{A R}(t)=\frac{A_{o b s}(t)}{A_{p o t}(t)}
$$

$$
\mathbf{P D}(t)=\theta_{o b s}(t)-\theta_{p o t}(t)
$$

Where the subscripts 'obs' or 'pot' denote the the observed data or the equilibrium amplitude, respectively. Both the admittance ratio in Eq. (6) and the phase difference in Eq. (7) largely remove the nodal-cycle variability, allowing easier examination of the non-tidal signals.

\subsection{Mean Sea Level and Anomaly Trends}

The 26 gauges used have a variable time coverage; some have less than 40 years of data, others have 100 years or more. While the long-term trends are an important concern that must still be considered in the overall picture of the ocean, our primary focus here is the interannual variations of MSL and the tides. MSL time-series are generated by taking overlapping yearly averages of the original hourly water level data at monthly intervals, without corrections for local ground motion or inverted barometer effects. AR and PD time series are generated by overlapping yearly harmonic analyses. We remove trends from the yearly AR, PD, and MSL time-series for each location and constituent over the entire record. The removed residual trends are fit by linear regression, reported in Table 1a (MSL) and $1 \mathrm{~b}$ (ARs and PDs).

The removal of the long-term trends leaves us with time-series of residual variations in AR, PD, and MSL, which are compared with one another (and with other ancillary time-series like thermocline depth), using scatter plots, cross-correlations, and regression to determine a tidal anomaly trend (TAT) and related statistics (Huber, 1981). The mean value of the tidal potential at each location is used as a scale factor to convert the non-dimensional TAT into a 
dimensional amplitude trend (A-TAT, expressed as millimeter change per meter sea level rise $\left(\mathrm{mmm}^{-1}\right)$. The same approach is used with the phase difference time-series to provide phase anomaly trends relative to the potential ( $\mathrm{P}$ TAT), with the trends expressed as degree change per meter sea level rise $\left(\mathrm{degm}^{-1}\right)$.

Sample results (Figure 3) show the A-TATs (top 4 panes, (a) - (d)) and P-TATs (bottom 4 panes, (e) - (h)) for the diurnal $\left(\mathrm{K}_{1}\right.$ and $\left.\mathrm{O}_{1}\right)$ and semidiurnal $\left(\mathrm{M}_{2}\right.$ and $\left.\mathrm{S}_{2}\right)$ tides vs. MSL at Honiara, Solomon Islands $(9.4167 \mathrm{~S}, 159.950$ E). The scatter plots at Honiara exhibit some of the most coherent trends in our data set, for $\mathrm{M}_{2}$, with $\mathrm{r}^{2}>0.9$. While the $\mathrm{M}_{2}$ tide amplitude is relatively small at this location $(\sim 50 \mathrm{~mm})$, the anomaly trend is large, $+65.6 \pm 3.3 \mathrm{~m} \mathrm{~mm}^{-1}$ (132\% of the local $\mathrm{M}_{2}$ amplitude per meter of MSL rise). The $\mathrm{S}_{2}$ trend in amplitude is not as coherent, but is still significant, as are the $\mathrm{K}_{1}$ and $\mathrm{O}_{1}$ A-TATs (Table 2; plots in supplementary materials). Trends in $\mathrm{M}_{2}$ and $\mathrm{S}_{2}$ phase are smaller but still significant (Table 3). The diurnal P-TATs are not significant. A-TAT and P-TAT plots for semidiurnal and diurnal tides at all 26 stations are provided in supplementary materials (Figures S1-1, through S1-26; Online Resource 1).

\subsection{Friction and Overtides}

Overtide generation is superficially similar to a resonant triad interaction, since both may satisfy a similar frequency condition to Eq. $(2 b)$, (i.e., $\left.\omega_{1}+\omega_{2}=\omega_{3}\right)$. Overtides can be linked to bottom topography, but may also results from internal waves of large amplitude (Legg and Klymak, 2008), or from strong flow curvature (Parker, 1991). The largest overtide at most locations is $\mathrm{M}_{4}$, twice the frequency of $\mathrm{M}_{2} ; \mathrm{M}_{4}\left(\omega_{3}\right)$ results from the non-linear interaction of $\mathrm{M}_{2}$ tidal currents with itself $\left(\omega_{1}+\omega_{2}\right)$. However, the wavenumber condition Eq. (2c) will only be satisfied in certain cases (Kukulka and Jay, 2003), and is not a requirement. In addition, the driving non-linearity (quadratic bed friction) is not the same as that for resonant triads (convective accelerations). Still, a frictional triad may interact with a resonant triad, as can a mean flow or an eddy field (Lelong and Kunze, 2013). It is, therefore, reasonable to suppose constituent interactions to be part frictional and part resonant. If overtides change substantially over time, it may indicate changes in non-linear frictional interaction (Parker, 1991). Because $\mathrm{M}_{4}$ is not represented in the astronomical potential, it is normalized by an appropriate overtide ratio (OR) to its forcing constituent, $\mathrm{M}_{2}$,

$$
O R_{m 4}(t)=\frac{A_{m 4}(t)}{\left[A_{m 2}(t)\right]^{2}}
$$

Here, $\mathrm{OR}_{\mathrm{m} 4}$ indicates the overtide ratio of $\mathrm{M}_{4}$. This ratio is analogous to an admittance calculation and will remove known long-period variations such as the nodal cycle. Additional overtides investigated are: $\mathrm{S}_{4}$ (interaction of $\mathrm{S}_{2}$ with itself), $\mathrm{MK}_{3}$ (interaction of $\mathrm{M}_{2}$ and $\mathrm{K}_{1}$ ), $\mathrm{M}_{6}$ (third harmonic of $\mathrm{M}_{2}$ ), $\mathrm{MS}_{4}$ (interaction of $\mathrm{M}_{2}$ and $\mathrm{S}_{2}$ ), and $\mathrm{MO}_{3}$ (interaction of $\mathrm{O}_{1}$ and $\mathrm{M}_{2}$ ). In each case, the overtide "ratio" is that between the overtide amplitude and the product of the amplitudes of the forcing waves. Overtides are small and may not be resolvable against background noise; we consider only overtides with a signal-to-noise ratio greater than 2.0. Temporal trends are normalized as the percentage change (per year) from local means of the overtide ratios (ORs). Additionally, we compare time-series of $\mathrm{M}_{4}$ and $\mathrm{M}_{6}$ 
273 overtide ratios at Honiara and Rabaul, two stations where the local overtides are anomalously large, to local MSL

274 variations, and to the El Nino Southern Oscillation (ENSO) through the use of the Multivariate El Nino Index (MEI),

275 as defined by the National Oceanic and Atmospheric Administration (NOAA) climate data center:

276 http://www.ncdc.noaa.gov. Note that the Rabaul station was decommissioned in 1997.

\subsection{Thermocline Depth and EEMD Analysis}

Observed tidal properties are compared to estimated thermocline depths to diagnose the possible role of internal processes in tidal anomaly trends. Thermocline depths have been synthesized from the NOAA Tropical Atmosphere Ocean project (TAO) buoys: (http://www.pmel.noaa.gov/tao/). The TAO array, established in the early $1990 \mathrm{~s}$, is a gridded network of 70 buoys extending from $8^{\circ} \mathrm{N}$ to $8^{\circ} \mathrm{S}$ and from $137^{\circ} \mathrm{E}$ to $95^{\circ} \mathrm{W}$. These buoys record sea surface temperature (SST), wind speed, and air pressure plus water temperature at increments of $25 \mathrm{~m}$ down to $250 \mathrm{~m}$, and also at $300 \mathrm{~m}$ and $500 \mathrm{~m}$. From this profile, the depth of the $20^{\circ} \mathrm{C}$ isotherm, $\mathrm{D}_{20}$, is estimated and used as a proxy for thermocline depth. $\mathrm{D}_{20}$ time-series are compared to tidal property (AR and PD) time-series for gauges at Honiara, Pago Pago, and Kapingamarangi, where some of the largest TATs (relative to local mean tides) are seen for the semidiurnal tides $\left(\mathrm{M}_{2}\right.$ and $\left.\mathrm{S}_{2}\right)$. Monthly averaged $\mathrm{D}_{20}$ data are compared to monthly $\mathrm{M}_{2}$ and $\mathrm{S}_{2}$ admittance data, calculated using 767 hour analysis windows in $R_{-} T \_$Tide, allowing examination of seasonal, as well as interannual, variations.

The $\mathrm{D}_{20}$ and monthly A-TAT time-series are separated into quasi-orthogonal scales using an EEMD (Ensemble Empirical Mode Decomposition) analysis (Huang, et al., 1998; Huang and Wu, 2008). EEMD uses a sifting process to split signals into approximately dyadic modes — a signal of length $2^{\mathrm{n}}$ yields $\sim \mathrm{n}$ modes. We selectively recombine modes to preserve the desired scales of variation (from about annual to decadal scale), while removing higher frequency variability and the long-term trend. In the language of EEMD, the decomposition of the variables are expressed as intrinsic mode frequencies, or IMFs. For all variables considered, we will use a decomposition of 10 IMFs, with IMF \#10 being the extracted long-term trend of the time series.

\subsection{Analysis of Resonant Triads}

Resonant triad interactions are nonlinear and occur through the convective accelerations. They are described 298 by coupled evolution equations for the "envelopes" of the three interacting waves, assumed to vary on a "slow" 299 timescale, much longer than the actual wave periods. These non-dimensional evolution equations relate the rate of 300 change of the complex amplitude of one wave to the product of the other two waves' complex amplitudes (Craik, 301 1985),

$$
\begin{aligned}
& \left(\partial_{t}+\mathbf{c}_{j} \cdot \nabla\right) \mathbf{Z}_{j}=i \delta_{j}\left(\mathbf{Z}_{k}{ }^{*} \mathbf{Z}_{l}{ }^{*}\right) \\
& l \neq j \neq i
\end{aligned}
$$


Where $\mathbf{c}_{\mathbf{i}}$ is the group velocity, $\mathbf{Z}$ is the complex amplitude, $\mathbf{Z}^{*}$ is the complex conjugate of $\mathbf{Z}$, and $\delta_{\mathrm{j}}$ the interaction coefficient of the $j^{\text {th }}$ mode. The $\delta_{\mathrm{j}}$ describe the strength of the wave interactions; each is the sum of a number of bilinear correlations between waves. We neglect the spatial gradient terms (a "local" assumption), assume that amplitudes and phases will be slowly-varying, and also assume that only one triad — the one linking the $\mathrm{M}_{2}, \mathrm{~K}_{1}$ and $\mathrm{O}_{1}$ tides — is active. Note that the triad relationships involve the slow timescale (interannual or decadal) modulations of the tidal harmonics, not the fast timescale of the tidal frequencies themselves (approximately once and twice daily), and our yearly admittance ratios and phase difference have already removed the fast-scale variations of the tides. Thus, our timeseries for AR and PD can be used to represent slow-scale variation time series of amplitudes and phases, respectively. We rewrite Eq. (1) to show the form of the slowly varying complex triad modes,

$$
Z_{j}(\tau)=A R_{j}(\tau) \exp \left[-i\left(\omega_{j} \tau+P D_{j}(\tau)\right)\right]
$$

Both the AR's and the PD's are time-dependent, and the AR's are real. Thus, taking the time derivative of the LHS under the local assumption of Eq. (9) yields three terms,

$$
\frac{d}{d \tau}\left(Z_{j}(\tau)\right)=\left[\frac{d Z_{j}(\tau)}{d \tau}\right] Z_{j}(\tau)=\left[\frac{1}{A R_{j}(\tau)} \frac{d}{d \tau} A R_{j}(\tau)-i \omega_{j}-i \frac{d}{d \tau} P D_{j}(\tau)\right] Z_{j}(\tau)
$$

Equating this expression to the RHS, combining complex exponential terms, and separating the real and imaginary terms (via the Euler formula) into two equations leads to,

$$
\begin{aligned}
& {\left[\frac{1}{A R_{j}(\tau)} \frac{d}{d \tau} A R_{j}(\tau)\right] A R_{j}(\tau)=\delta_{j}\left(A R_{k}(\tau) A R_{l}(\tau)\right) \sin (\Phi(\tau)+\Delta \omega \tau)} \\
& {\left[\omega+\frac{d}{d \tau} P D_{j}(\tau)\right] A R_{j}(\tau)=\delta_{j}\left(A R_{k}(\tau) A R_{l}(\tau)\right) \cos (\Phi(\tau)+\Delta \omega \tau) .}
\end{aligned}
$$

Here, the $\Delta \omega$ term is the sum of the frequencies as in Eq. (2b): $\Delta \omega=\omega_{1}+\omega_{2}+\omega_{3}$; for the $\mathrm{M}_{2}+\mathrm{K}_{1}+\mathrm{O}_{1}$ triad, $\Delta \omega=0$. The $\Phi(\tau)$ term is the sum of the three phase differences: $\Phi(\tau)=\mathrm{PD}_{1}(\tau)+\mathrm{PD}_{2}(\tau)+\mathrm{PD}_{3}(\tau)$.

Sets of equations like Eq. (11a; b) can, in principle, be solved using inverse scattering methods (Zakharov and Manakov, 1973; Kaup, 1980), but sufficient environmental information to do so is rarely present in an oceanographic context. We manipulate Eq. (11a; b), therefore, to obtain a tool for diagnosis of triad interactions; Eq. (11a) and Eq. (11b) can be rewritten in terms of $\mathrm{M}_{2}, \mathrm{~K}_{1}$, and $\mathrm{O}_{1}$ as:

$$
\begin{aligned}
& C_{\mathrm{Re}}\left[\operatorname{Re}\left\{A R_{M 2}(\tau)\right\}\right]=\Gamma_{\mathrm{Re}}\left[\operatorname{Re}\left\{A R_{K 1}(\tau) A R_{O 1}(\tau)\right\}\right] \sin (\Phi(\tau)) \\
& C_{\mathrm{Im}}\left[\operatorname{Im}\left\{A R_{M 2}(\tau)\right\}\right]=\Gamma_{\mathrm{Im}}\left[\operatorname{Im}\left\{A R_{K 1}(\tau) A R_{O 1}(\tau)\right\}\right] \cos (\Phi(\tau))
\end{aligned}
$$



related to the phase speeds and dispersion relations of the interaction. Finally, we can examine the absolute variation by combing both expressions of Eqs. (11a) and (11b) or (12a) and (12b) into a single equation,

$$
A R_{M 2}(\tau)=\frac{\Gamma_{A b s}}{C_{A b s}} A R_{K 1}(\tau) A R_{O 1}(\tau)
$$

The salient features of Eq. (13) are that: a) $\mathrm{AR}_{\mathrm{M} 2}$ is proportional to the product on the RHS, and b) $\Gamma_{\mathrm{Abs}} / \mathrm{C}_{\mathrm{abs}}=\beta<0$, so that energy lost from $\mathrm{M}_{2}$ is taken up by the two diurnals (at least if the the two diurnals behave in a similar manner). A complete triad problem requires two more equations similar to Eq. (13), but we shall only focus on the one that uses $\mathrm{M}_{2}$ as the primary. Here, we use Eq. (13) as a diagnostic tool to identify and describe qualitatively the $\mathrm{M}_{2}-\mathrm{K}_{1}-\mathrm{O}_{1}$ triad. Eq (2) does not use phase information. But from Eq. (2a) we have a "phase-lock" constraint,

$$
\Phi(\tau)=P D_{1}(\tau)+P D_{2}(\tau)+P D_{3}(\tau)=\text { const }
$$

For the PD variations, we convert variations from degrees to minutes. Also, $\beta$ in Eq. (13) can be estimated by regressing $\mathrm{AR}_{\mathrm{M} 2}$ against $\mathrm{AR}_{\mathrm{K} 1} \times \mathrm{AR}_{\mathrm{O} 1}$. Finally, triad interactions occur on slow, and possibly multiple, timescales. Thus, it is logical to compare variations on multiple scales, separated via EEMD. Trends were extracted, and modes of variability separated via EEMD, as with the thermocline data. Applying this approach, we compare the two sides of Eq. (13) using IMFs 4-10 of all quantities. To illustrate the possible importance of triad interactions, we examine below the coupled variations of $\mathrm{M}_{2}, \mathrm{~K}_{1}$, and $\mathrm{O}_{1}$ at Honiara and Rabaul, stations at which constituent variations are particularly strong and coherent with MSL.

Because the data we analyze are surface water levels and not internal wave amplitudes at the thermocline level, we cannot use Eqs. (11ab, to 13) without additional assumptions. We assume that, for nearly linear internal waves, the induced surface displacement is governed by the depth of the interface and the ratio of the restoring forces between surface and internal waves. If the changes in interfacial depth and stratification are small, then the surface displacements measured at tide gauges will be proportional to the interfacial amplitudes (and their variations) described by Eqs. (12-13). This approach allows us to analyze interactions between baroclinic and surface tides, because the surface displacements of both involve similar potential energies. The method outlined here also assumes that the wavenumber vectors for each wave are constant, with amplitudes and phases that evolve slowly. Rising MSL renders a constant wavenumber assumption questionable, especially for the vertical wavenumbers $\left(m_{\mathrm{i}}\right)$. Still, it is of interest to identify wavenumbers for which triads are possible, assuming stationary wavenumbers. For the triad of interest ( $\mathrm{K}_{1}, \mathrm{O}_{1}$, and $\mathrm{M}_{2}$ ), Eq. (2b) is exact, but Eqs. (2a), (2c) and (3) must still be satisfied. To simplify finding wavenumber vectors that satisfy the triad restraints, the dispersion relation, Eq. (3), can be recast as an aspect ratio or slope factor (Gill, 1982), 


$$
\sqrt{\frac{\left(\omega_{i}^{2}-N^{2}\right)}{\left(f^{2}-\omega_{i}^{2}\right)}}=\frac{m_{i}}{\kappa_{i}}
$$

using a general horizontal wavenumber $\kappa_{i}^{2}=\left(k_{i}{ }^{2}+l_{i}{ }^{2}\right)$. The Coriolis frequency, $f$, will be dependent only on latitude, but $N^{2}$ will depend on temporally variable temperature and salinity profiles. However, because all three triad waves are present at the same place, all three will have the same $N$ at any time. Choosing one vertical wavenumber, $\left(m_{l}\right), \kappa_{l}$ is determined from Eq. (15). We then select $\left(m_{2}, \kappa_{2}, m_{3}\right.$, and $\kappa_{3}$, ) combinations that are consistent with Eq. (15) and then test their consistency with Eq. (2). Because higher modes can be involved in a resonant triad, there could be several wavenumber solutions that satisfy Eqs. (2a, c) and (3); however, higher modes are usually less energetic. We therefore only consider (vertical) modes 1 to 3 , along with the zero-mode (barotropic) waves.

We use the Honiara and Rabaul records to illustrate the role of triad interactions in tidal evolution, because both stations show strong fluctuations in $\mathrm{M}_{2}, \mathrm{~K}_{1}$ and $\mathrm{O}_{1}$ that are relatively coherent with MSL variations. Application of Eqs. (12-15) then requires determination of a locally appropriate density profile. $N^{2}$ profiles are estimated from temperature-salinity (T-S) profiles obtained from the World Ocean Atlas 2009: (Locarnini, et al., 2010), using the TEOS-10 (Thermodynamics Equations of Seawater) standard (Millero, et al., 2008). For convenience, we express all frequencies non-dimensionally, relative to the $\mathrm{M}_{2}$ forcing frequency. Thus, the $\mathrm{M}_{2}$ frequency $=1 ; \mathrm{K}_{1}=0.52 ; \mathrm{O}_{1}=$ 0.48. The Coriolis frequency, $f$, at Honiara $\left(9.5^{\circ} \mathrm{S}\right)$, is $\sim 0.17$; that at Rabaul is $\sim 0.07$. For both stations, nondimensional $N$ in the thermocline ranges from about 10 to 100 . With these values of $N$, Eq. (15) can be simplified, for conceptual purposes, to:

$$
\frac{N}{\omega_{i}} \cong \frac{m_{i}}{\kappa_{i}}
$$

This form emphasizes the fact that $\mathrm{K}_{1}$ and $\mathrm{O}_{1}$ will have similar wavenumbers for any given internal wave mode.

Because we consider only the barotropic waves and the first three internal modes; there are only four choices for each $m_{i} ; m=0,1,2,3$, when non-dimensionalized by depth. Inserting these values of $m_{i}$ into $m_{i} / \kappa_{i}$ ratio (Eqs. 15; 16) gives values for the $\kappa_{\mathrm{i}}$, which may examined for conformity with wavenumber resonance condition Eq. (2c) for each mode. The vertical to horizontal aspect ratio of the ocean is small, so the $m_{i} \gg \kappa_{\mathrm{i}}$. Because $\left|\mathbf{M}_{2}\right|$ is quite small in the Solomon Sea relative to the diurnal constituents, it seems likely that the most easily detected triad is the barotropic $\mathrm{M}_{2}$ wave interacting with a first-mode internal $\mathrm{K}_{1}$, and an oppositely propagating first-mode internal $\mathrm{O}_{1}$. This a form of parametric sub-harmonic instability that has been analyzed in the context of a resonant triad (but not specifically the $\mathrm{M}_{2}-\mathrm{K}_{1}-\mathrm{O}_{1}$ triad) in the South China Sea (Xie, 2008) and also near the Hawaiian Ridge (Carter and Gregg, 2006).

\section{Results}


The spatial distribution of anomaly trends (A-TATs and P-TATs) may help identify connections between MSL rise and tidal evolution on a basin-wide, or amphidromic scale. Figures 4 to 7 show the A-TATs for each constituent. P-TATs are not shown on the plots, but are discussed below in the context of possible amphidromic migration. Exact values and error bands are reported in Tables 2 (A-TATs) and 3 (P-TATs). The magnitude of the A-TATs is shown by the color intensity of the dots, with the color indicating positive (red) or negative (blue). For a gauge with an insignificant A-TAT, the dot is white.

These plots provide a picture of the tidal response to a $1 \mathrm{~m}$ MSL rise and an indication of the spatial coherence of tidal evolution. For a gauge influenced by only one amphidrome, a positive (negative) A-TAT and a zero P-TAT indicates that the amphidrome is moving away (towards) the gauge. Gauges that show significant P-TATs suggest a rotational component to the movement of the amphidrome. If changes in tides (as represented by A-TATs and PTATs) are coherent on an amphidromic scale, they should suggest consistent amphidromidc movement or rotation. If statistically significant TATs do not suggest consistent amphidromic change, then local or regional process are likely more important.

\subsubsection{Diurnal Constituents}

$\mathrm{K}_{1}$ has its largest amplitudes along the western Pacific equator, with much lower amplitudes eastward in the open-ocean (Figure 4). Based on the tidal potential, diurnal tides are expected to be small near the equator, and the 404 large amplitudes seen (4-5 times that predicted by astronomical forcing) around Indonesia and Papua New Guinea may represent a resonance. Diurnal tides are larger within the Coral Sea, but are very small around New Zealand, where semidiurnal tides prevail.

There are statistically significant ( $\mathrm{SNR}>2.0$ ) positive $\mathrm{K}_{1}$ amplitude and phase tidal anomaly trends at 18 of 26 gauges. Large positive A-TATs are seen at both island and shelf stations, while significant negative A-TATs are only seen at island gauges. There is a concentration of positive A-TATs at Australian gauges. All negative A-TATs are north of $\sim 10^{\circ} \mathrm{S}$. For the $\mathrm{K}_{1}$ P-TATs, 18 of 26 stations are significant (though not the same 18 as the A-TATs). The strongest positive P-TAT is seen at Guam, and strong negative trends in phase are seen at the islands near the center of the map.

The amplitude and phase distributions and amphidromic patterns for $\mathrm{O}_{1}$ are similar to those for $\mathrm{K}_{1}$, though 415 archipelago. Amphidromic points are again marked by "A" and "B". Significant positive A-TATs are also found at 416 most Australian shelf stations. In total, there are 14 significant A-TATs, and 20 significant P-TATs.

\section{$417 \quad$ 4.1.2 Semidiurnal constituents}


$\mathrm{M}_{2}$ amplitudes are generally larger than diurnal amplitudes in the study area, with the largest amplitudes occurring around New Zealand and the northern coast of Australia (Figure 6). An amphidromic point is located just to the east of Pago Pago (marked by "B"), with an anti-node (high amplitudes) along the equator west of the date line. Very low $\mathrm{M}_{2}$ amplitudes are seen in and around the Solomon Sea.

There are significant $\mathrm{M}_{2}$ A-TATs at 17 of 26 stations and significant $\mathrm{M}_{2}$ P-TATs at 19 of 26 stations. Positive and negative A-TATs are observed at both island gauges and shelf gauges. Honiara and Rabaul, which are near the

$424 \mathrm{M}_{2}$ amphidrome in the Solomon Sea, have small mean $\mathrm{M}_{2}$ amplitudes ( $\left.\sim 50 \mathrm{~mm}\right)$, but display large relative trends; ( $425+132 \%$ for Honiara and $+240 \%$ for Rabaul), though the strong phase trends at these two gauges have opposite magnitudes. With the exception of Auckland, all significant positive A-TATs are south of the equator, and all negative

427 A-TATs are north of the equator.

$\mathrm{S}_{2}$ is much smaller than $\mathrm{M}_{2}$ at most locations, but with a similar (large) amplification on the northwest coast of Australia (Figure 7). Also similar is the location of the amphidromic points, with "A" indicating another line-shaped amphidrome (which more closely follows the Mariana trench), and an amphidromic point at "B" very near Pago Pago.

\subsubsection{Combined Tidal Trends}

We show the combined A-TATs in Figure 8; values and confidence limits are tabulated in Table 2. The constituent TATs were combined as complex numbers (using A-TAT and P-TAT determinations for each of the four constituents examined), and the real part of the result is plotted. Conceptually, a large and positive combined A-TAT describes locations in which the tidal range increases strongly during periods with a positive sea-level anomaly, whereas a negative combined A-TAT implies decreased tidal range for a positive MSL anomaly. Therefore, shelflocations such as Brisbane, or island stations such as Pago Pago or Noumea could see large tidal range increases for a positive sea-level anomaly. By contrast, stations such as Legaspi, Guam, and Johnston could see decreased tidal range for a positive sea-level anomaly. Large positive tidal-range responses are all south of $9^{\circ} \mathrm{N}$, while all but one of the large negative changes are north of the latitude.

\subsection{Overtides}

Figure 9(a-d) summarizes the spatial distribution of overtide ratios (ORs) for: $\mathrm{M}_{4}, \mathrm{M}_{6}, \mathrm{~S}_{4}$, and $\mathrm{MK}_{3}$; significant long-term trends are shown as colored dots. $\mathrm{MS}_{4}$ and $\mathrm{MO}_{3}$ plots are shown in Figures $\mathrm{S} 2$ and $\mathrm{S} 3$ (Online Resource 1). Significant changes over time for these four ORs are mainly seen at coastal shelf stations, with a few islands showing some moderate change over time. The largest $\mathrm{M}_{4}$ and $\mathrm{M}_{6}$ ratio means are in the Solomon and Coral Seas, and in general, regions of high $\mathrm{M}_{4}$ and $\mathrm{M}_{6}$ ratios correspond to areas where lower $\mathrm{M}_{2}$ amplitude are found (Figure that do are decreasing. Again, the $S_{4}$ ratio is large in areas where $S_{2}$ amplitudes are small (Figure 7). $M_{3}$ is also generally smaller than other overtides, but shows larger relative changes at many stations. Examination of the numerators and denominators of the ORs shows that in almost all cases the trend is driven by changes in the observed 
overtides (numerator), not by changes in the forcing (denominator). This suggests a mechanism of changing ORs in the area being driven by frictional processes rather than by secular increases or spatial shifts of the gravitationally forced tides.

We next consider the fluctuations in ORs at Honiara and Rabaul (which show some of the largest OR values), as well as the simultaneous changes in forcing tides, in MSL, and in the Multivariate El Nino Index (MEI). Figure 10 shows the time-series of the ORs for $\mathrm{M}_{4}$ and, $\mathrm{M}_{6}$; $\mathrm{AR}$ amplitudes for $\mathrm{M}_{2}, \mathrm{~K}_{1}$ and $\mathrm{O}_{1}$; MSL; and the MEI. These two gauges show the largest ORs in the region, and very large fluctuations are associated with high values of MEI (El Niño events). $\mathrm{M}_{2}$ amplitudes are much smaller than predicted by astronomy at these gauges ( $2 \%$ of gravitational potential prediction), suggesting the possibility of increased relative error. However, the coherence between the two records at several frequencies suggests that this is unlikely $-\mathrm{M}_{2}$ at these two gauges show an $\mathrm{r}^{2}=0.8$ correlation to each other, $\mathrm{M}_{4}$ overtide ratios at Honiara and Rabaul show an $\mathrm{r}^{2}=0.4$ correlation to each other, and $\mathrm{M}_{6}$ ratios have a very strong $\mathrm{r}^{2}=0.85$ correlation. MSL signals at the two gauges are also well correlated $\left(\mathrm{r}^{2}=0.80\right) . \mathrm{M}_{4}$ ratios are fairly well correlated to the MEI ( $r^{2}=0.4$ for Honiara and $r^{2}=0.64$ for Rabaul). $\mathrm{M}_{6}$ at Honiara shows an $\mathrm{r}^{2}=0.7$ correlation to MEI, while Rabaul shows a correlation of $\mathrm{r}^{2}=0.65$ for $\mathrm{M}_{6}$ to MEI. Both gauges show very strong correlations $\left(r^{2}=0.85\right.$ for Honiara; $\mathrm{r}^{2}=0.75$ for Rabaul) of local MSL to the MEI.

Figure 9 suggests that there is a threshold relationship between the occurrence of large ORs, local MSL, and the MEI. As shown by the yellow boxes, significant increases in ORs by a factor of $3 \times$ to $10 \times$ occur when the MEI is high and MSL is low, under El Niño conditions. Increased OR values during El Niño periods of low MSL could result from several factors, including increased friction over reefs and in shallow lagoonal areas. Most of Indonesia and Australia receive less rain during El Niño events (Roplewski and Halpert, 1987, Figure 21). Honiara and Rabaul are on the edge of this ENSO-induced drought region, and MSL rapidly decreases at both these gauges during El Nino events. $M_{4}$ and $M_{6}$ ORs have started to decrease in recent years at Honiara, while $M_{2}$ has shown a strong increase. This is likely due to the fact that sea level has risen rapidly in recent years, reducing bed friction.

\section{$\underline{4.3 \text { Thermocline depth and tidal variations }}$}

Thermocline depth, MSL and tidal properties are closely linked at some, but not all, stations. Figure 11 shows EEMD decomposed time-series (seasonal scales and longer) of $\mathrm{D}_{20}$ from the TAO buoys (as detailed in section 3.5), along with the $\mathrm{M}_{2}$ and $\mathrm{S}_{2}$ tidal amplitude variations (determined from monthly admittance amplitudes); for all relevant time series, we only use IMFs \#4-9 so the long-term trends are not included. This analysis is performed at Honiara, Kapingamarangi, and Pago Pago; buoys and gauge locations are shown in Figure 11a. The $\mathrm{D}_{20}$ variations at the three TAO buoys nearest Honiara are mutually coherent; we take, therefore, a mean of these three equidistant buoys (Figure 11b). For the other two gauges, only one TAO buoy is used to compare thermocline depths. Figure 11c and 11d show this $\mathrm{D}_{20}$ time-series with $\mathrm{M}_{2}$ and $\mathrm{S}_{2}$ variations at Honiara and Kapingamarangi; both gauges show positive correlations of thermocline depth fluctuations to $\mathrm{M}_{2}$ and $\mathrm{S}_{2}$ fluctuations, with $\mathrm{r}^{2}$ being between +0.69 and +0.89 in all cases. For Pago Pago, the coherence between the time-series is insignificant $\left(\mathrm{r}^{2}<0.1\right)$. It is unclear whether this is the result of 
the distance between buoy 5 and Pago Pago, or whether different processes are at work at this station. The thermocline, as represented by $\mathrm{D}_{20}$, shoaled during the 1997-1998 ENSO event. At the same time, there was drop in tidal admittance for $\mathrm{M}_{2}$ and $\mathrm{S}_{2}$ at Honiara, Kapingamarangi, and Pago Pago, but available data do not provide any apparent connection of the tides to changes in thermocline depth at Pago Pago.

\subsection{Spatial Summary}

The long-term trends of the $\mathrm{M}_{2}$ tide are mainly positive, while diurnals are mixed, but generally negative, in Australian and New Zealand waters. For the A-TATs, $\mathrm{M}_{2}$ is mainly negative, while the diurnal A-TATs are all positive. Overtides, even $\mathrm{M}_{4}$, are generally growing, despite extensive harbor development at some locations. These changes suggest regionally driven tidal evolution involving a combination of frictional and triad interaction, perhaps tied to the reef systems in the Coral Sea. The waters around the Solomon Islands show $\mathrm{M}_{2}$ A-TAT to be increasing, while $\mathrm{K}_{1}, \mathrm{O}_{1}$ and the main overtide ratios are decreasing, with all variations coherent with, and likely driven by, variations in the depth of the thermocline.

\section{$\underline{4.5 \text { Anomaly Trends Over Time }}$}

The majority of the Western Pacific stations used in this study show larger yearly MSL rise rates after 1993 than before (Table 1a; Figure 2). This rather abrupt increase in MSL rise in the southwest Pacific after 1993 provides an opportunity to test the relationship between MSL rise and tidal evolution. Thus, if TATs are sensitive to absolute MSL or rate of change of MSL, we might expect to see differences in TATs between these two epochs at gauges that show MSL acceleration. If TATs are the same in both time periods for such gauges, then they are likely independent of MSL. Thus, analyses were performed to evaluate differences in TATs before and after 1993 . Twenty out of 26 stations have enough data both before and after 1993 to cover a nodal period and allow meaningful comparison. Results of the "before and after" 1993 analyses for these 20 gauges are summarized in Tables S1 $\left(\mathrm{K}_{1}\right)$ and S2 $\left(\mathrm{M}_{2}\right)$ (Online Resource 1). To illustrate spatial trends in these shifts, figures are provided for $\mathrm{K}_{1}$ (Figure 12) and $\mathrm{M}_{2}$ (Figure 13), analogous to Figure 4 through 7, but now the color intensity of the dots represent the difference in A-TATs between the two time eras.

There are strong positive $\mathrm{K}_{1}$ A-TAT temporal shifts at three shelf gauges, and at two islands; there is a negative shifts at only one shelf gauge. $\mathrm{M}_{2}$ A-TAT shifts tend to be generally larger than $\mathrm{K}_{1}$. Most shelf gauges show significant $\mathrm{M}_{2}$ shifts, positive at four, and negative at two stations. Two island gauges show positive shifts, with only one negative result. In general, shelf gauges show larger magnitude shifts than island gauges, where it is harder to distinguish the two periods (pre and post-1993). Similar plots and tables are provided for O 1 (Figure S4, Table S1,

Online Resource 1) and $\mathrm{S}_{2}$ (Figure S5, Table S2, Online Resource 1). $\mathrm{O}_{1}$ A-TATs shifts are also mainly positive after 1993, but $\mathrm{S}_{2}$ A-TATs and P-TATs have shifted only slightly.

\section{$\underline{\text { 4.6 Triad Results }}$}


The Honiara and Rabaul tidal records show striking examples of what appears to be $\mathrm{M}_{2}-\mathrm{K}_{1}-\mathrm{O}_{1}$ triad interactions (Figures 14 and 15). Figure 14 (a) shows $\mathrm{K}_{1} \mathrm{O}_{1}$ vs. $\mathrm{M}_{2}$ at Honiara; Figure 14(b) shows Rabaul. $\mathrm{M}_{2}$ amplitudes are small, $51 \mathrm{~mm}$ at Honiara and $40 \mathrm{~mm}$ at Rabaul, and their temporal variability is high (Figures 10 and 11). Diurnal tides are larger; $K_{1}$ amplitudes are $229 \mathrm{~mm}$ and $240 \mathrm{~mm}$ at Honiara and Rabaul, while $O_{1}$ amplitudes are $112 \mathrm{~mm}$ and $126 \mathrm{~mm}$, respectively. Since we further multiply the $\mathrm{K}_{1}$ and $\mathrm{O}_{1} \mathrm{ARs}$ together, the magnitude of the RHS of Eq. (13) will be much larger than the $\mathrm{M}_{2}$ AR appearing on the LHS, meaning that the interaction coefficients, $\beta$, must be small as well as negative (Figure 14). As noted above, $\beta$ can be estimated by regression, using Eq. (13); see Figure 15. If triad resonance is occurring, the variations of the summed variables (LHS and RHS sides of Eq. (13)) should be less than the variations in the LHS and RHS individually, a condition that is generally fulfilled for both stations in Figure 14, though some deviations are seen during El Niño. Also, the $\mathrm{r}^{2}$ values of 0.59 (Honiara) and 0.72 (Rabaul) in Figure 15 suggest that resonant triad dynamics explain a substantial fraction, though not all, of the variations in the major constituents at these stations. A fraction of this energy may be lost to overtide generation during El Niño events, but direct comparison of $\mathrm{M}_{4}$ and $\mathrm{M}_{2}{ }^{2}$ fluctuations does not show a significant correlation. Finally, the variations in $\mathrm{AR}_{\mathrm{M} 2}$ are impressive: $\pm 30+\%$. Thus for a small constituent like $\mathrm{M}_{2}$, triad interactions can lead to very large time variations, in relative terms.

Also, it is evident from Figure 16 and Table 4 that the phase-lock condition Eq. (2a) is generally approximately met for IMF\#s 4-10. While $\Phi(\tau)$ is not constant, particularly during the ENSO events, it is less variable than the individual phases. For most of the record, the $\mathrm{O}_{1}$ and $\mathrm{K}_{1}$ PDs are negatively correlated, with $\mathrm{M}_{2}$ making up the difference between the two. During El Niño events, in contrast, there are large $\mathrm{M}_{2}$ phase excursions that perturb the phase lock. The sum of the variances is $2-13 \times$ as large as the variance $\Phi$, and the phase lock is more closely met after 1993 than before, despite very large fluctuations in the $\mathrm{O}_{1}$ PD. Interestingly, the 1998 El Niño does not cause large excursions in the $\mathrm{M}_{2} \mathrm{PD}$, even though large $\mathrm{M}_{4}$ amplitudes are seen at Honiara.

To confirm that the variations shown in Figures 14-16 indeed represent a triad interaction, we should verify that the resonance conditions of Eq. (2) and Eq. (3) are satisfied. For $\mathrm{M}_{2}, \mathrm{~K}_{1}$, and $\mathrm{O}_{1}$, the frequency condition, Eq. (2b), is satisfied by definition, and the phase-lock condition, Eq. (2a), is shown in Figure 15. There are, however, only a few wave combinations that will satisfy the resonance condition, Eq. (2c), that $\Sigma \boldsymbol{k}_{i}=0$. For simplicity, we consider only cases in which Eq. (2c) can be satisfied in two dimensions (2D). We exclude 3D solutions on the grounds that they would require a rather special geometry and that the matching conditions would likely be transient -- small changes in thermocline depth could cause large changes in the angles between the matching wavenumber vectors. Given fixed geometry, it seems unlikely that the resonance would endure. There are only two possible 2D interactions between waves of zero or low vertical wavenumber. The most likely situation is a parametric sub-harmonic instability (PSI): a barotropic $\mathrm{M}_{2}$ wave interacting with first-mode $\mathrm{K}_{1}$ and $\mathrm{O}_{1}$ internal waves. The other possibility is a second mode $\mathrm{M}_{2}$ wave interacting with first and third mode diurnal waves, the case examined numerically by Lamb (2007).

For the PSI case, the vertical wavenumber for $\mathrm{M}_{2}$ is $m_{\mathrm{M} 2}=0$; and $\kappa_{\mathrm{M} 2}$ will be small relative to the $\kappa_{\mathrm{i}}$ for the diurnals, because barotropic tidal wavelengths are much longer than internal wavelengths. As detailed above, we find 
values of the $\mathrm{m}_{\mathrm{i}} / \mathrm{\kappa}_{\mathrm{i}}$ ratio for the internal waves from Eq. (11). Table 5a shows these ratios for a range of values of $\mathrm{N}$ of 10-100. The $m_{i}$ for $\mathrm{K}_{1}$ and $\mathrm{O}_{1}$ will be equal and of opposite sign, while their $\kappa_{i}$ will differ by $\sim 8 \%$. An exact triad would occur when the small difference between the two diurnal $\kappa_{i}$ matches the $\kappa_{\mathrm{M} 2}$. For the barotropic forcing wave, $\mathrm{M}_{2}$, we find $\kappa$ from the shallow-water relation: $\kappa=\omega / \mathrm{sqrt}(\mathrm{gH})$, where $g$ is the gravitational acceleration, $\omega$ is the frequency of $\mathrm{M}_{2}$, and $H$ is the bottom depth, taken to be $\sim 500 \mathrm{~m}$ based on the average depth near Honiara. These values yield a $\kappa=2.0 \times 10^{-6} \mathrm{~m}^{-1}$. However, the depth is this area is highly variable and water depths of up to $5 \mathrm{~km}$ are found within a wavelength of Honiara. If, on the other hand, the triad interaction is localized near the gauge, the relevant depth could be as little as $100-200 \mathrm{~m}$. Thus, a plausible range of $\kappa$ values for barotropic $\mathrm{M}_{2}$ is $\sim 0.7$ to $4 \times 10^{-6} \mathrm{~m}^{-1}$. For the $\mathrm{K}_{1}$ and $\mathrm{O}_{1}$ first-mode internal waves, the internal wave relation gives $\kappa=\omega / \mathrm{c}_{\mathrm{ph}}$, where $\mathrm{c}_{\mathrm{ph}}$ is the phase speed of each wave. We use the $\mathrm{N}$ profile near Honiara (with $10<N<100$ ) to find a typical first-mode diurnal $\mathrm{c}_{\mathrm{ph}} \sim 2.7 \pm 0.1 \mathrm{~ms}^{-}$ ${ }^{1}$ for both $\mathrm{K}_{1}$ and $\mathrm{O}_{1}$ (Rainville and Pinkel, 2006). The resulting first-mode wavenumbers are: $\kappa \sim 2.7$ and $2.5 \times 10^{-5} \mathrm{~m}^{-1}$ for $\mathrm{K}_{1}$ and $\mathrm{O}_{1}$, respectively. The difference between these two $\kappa$ values, $\sim 2 \times 10^{-6} \mathrm{~m}^{-1}$, gives an exact resonant triad $(\Delta \kappa$ $=0$ ) for a barotropic $\mathrm{M}_{2}$ wave corresponding to depth of $500 \mathrm{~m}$, as well as near-resonant triads for depths ranging from 5000 to $100 \mathrm{~m}$ (Table 5b). Given the uncertainty in and temporal variability of $\mathrm{N}$, an exact resonant triad is likely present only on a transient basis, and a near-resonant triad is probably the usual situation. It is encouraging, however, that such a simple configuration is possible in $2 \mathrm{D}$, and Table $5 \mathrm{~b}$ indicates that $\Delta \kappa$ remains small for a range of possible values of $\mathrm{N}$.

There is only one $2 \mathrm{D}$, low-mode $\mathrm{M}_{2}-\mathrm{K}_{1}-\mathrm{O}_{1}$ triad that does not involve a barotropic wave: $1^{\text {st }}(m= \pm 1)$ and $2^{\text {nd }}$ mode $(m= \pm 2)$ waves of the same sign, coupled with a $3^{\text {rd }}$ mode wave $(m=\mp 3)$ of opposite sign. To satisfy the wavenumber condition Eq. (2c), the second mode wave must be $\mathrm{M}_{2}$, the case studied by Lamb (2007). There are two "flavors" of this triad, because there are two diurnals $\left(\mathrm{K}_{1}\right.$ and $\left.\mathrm{O}_{1}\right)$, one third mode and one first mode. Which diurnal should be chosen as the first mode depends on the fit to Eq. (2c) -- the correct choice will minimize $\Delta \kappa$. Table 5c lists the $\kappa_{\mathrm{i}}$ and $\Delta \kappa$ for these two possibilities. $\Delta \kappa$ is minimized by factor of 5 for a $\mathrm{K}_{1}$ mode 3 and an $\mathrm{O}_{1}$ mode 1 over the reverse situation, but both show a very small $\Delta \kappa$. While both the Lamb analysis and Table $5 \mathrm{c}$ suggest that this triad is possible, measurable surface deflections seem unlikely for an $\mathrm{M}_{2}$ wave with $m= \pm 2$, given the small barotropic $\mathrm{M}_{2}$ in the Solomon Sea Thus, it seems a less likely candidate to account for the triad features seen in Figures 14-16.

\section{Discussion}

We observed above that fluctuations in observed tidal properties are associated with sea-level anomalies. At three stations (Honiara, Kapingamarangi, and Rabaul), semidiurnal tidal properties (influenced by both local and amphidromic scale processes) and overtide generation (a local, frictional process) are strongly correlated with anomalies in sea level and stratification. These observations leave open, however, the question of whether constituent variability is primarily related to local processes, to basin-scale phenomena, or to some combination thereof. Furthermore, it is yet to be determined if the observed tidal variability is influenced only at the at the interannual time 
scale, or if there is also a combination of dynamics across multiple frequency bands, including the long-term trends of MSL. In the following discussion we attempt to identify the mechanisms behind the observed TATs.

\subsection{Spatial Patterns}

Here we summarize and interpret spatial patterns in selected areas, focusing on two regions that exhibit reasonably coherent changes; a) the eastern coast of Australia and the Great Barrier Reef; and b) the Solomon Sea. We will also consider not just the anomaly trends (TATs), but also the long term trends (LTTs) in tidal constituents.

\subsubsection{Australian Shelf and the Great Barrier Reef}

Anomaly trends for the Australian stations are relatively coherent. There is a positive trend in the A-TATs for $\mathrm{K}_{1}$ and $\mathrm{O}_{1}$ along the eastern Australian coast, and (with the exception of Brisbane) a negative trend to $\mathrm{M}_{2}$ A-TATs. Stations north of Brisbane lie on the semi-enclosed Coral Sea behind the Great Barrier Reef (GBF); the regional bathymetry is highly variable, from deep $(>4000 \mathrm{~m})$ to inter-tidal. The pattern of TATs suggests larger diurnal and smaller semidiurnal tides in this region as MSL rises. The large trends in A-TATs at Auckland show a heightened sensitivity of tidal dynamics to water level, though New Zealand has its own $\mathrm{M}_{2}$ amphidrome, the dynamics are still likely connected to the Australian waters across the Coral Sea. Auckland shows a negative $\mathrm{M}_{2}$ A-TAT and a negative LTT in $\mathrm{M}_{2}$, but for diurnals the A-TAT is positive and the LTT negative.

Overtide ratios (Figure 9) for $\mathrm{M}_{4}$ and $\mathrm{MK}_{3}$ are increasing for most Australian stations north of Brisbane, with some of the largest increases seen at Cairns $\left(+3 \% \mathrm{yr}^{-1}\right.$ for $\mathrm{M}_{4}$, and $+4 \% \mathrm{yr}^{-1}$ for $\left.\mathrm{MK}_{3}\right)$. Decreases are seen only at Townsville for $\mathrm{S}_{4}$ and $\mathrm{MK}_{3}\left(-2 \% \mathrm{yr}^{-1}\right)$ and at Bundaberg and Gladstone for $\mathrm{M}_{4}\left(-2 \% \mathrm{yr}^{-1}\right)$. Overtides are typically driven by frictional interactions, and friction at harbor stations is usually reduced, not increased, by navigational development (e.g., Jay et al., 2011), which may help explain the decreasing trends at Townsville, Bundaberg, and Gladstone. These harbors are amongst the busiest in Australia, and have had an extensive history of development over the last 50 years. This would not, however, explain the overtide increases seen at other nearby Australian gauges. It is likely that the regional overtide changes are related to larger scale processes, perhaps a coupling of resonant triads and overtides. Tidal evolution at the Australian gauges on the Coral Sea may be a response in part to MSL rise over the complex topography of the Great Barrier and other reef systems (Hughes, et al, 2010; Hughes et al, 2003; Wolanski, 1994).

\subsubsection{Solomon Islands: Overtide Ratios and Thermocline Depth Variations}

The Honiara and Rabaul tide gauges are located in an area of water shallower $(\sim 300-700 \mathrm{~m})$ than at nearby island stations. To the direct west of the island chain is the deep Solomon Sea basin, which is connected to the waters of Honiara and Rabaul via a semi-enclosed basin directly east of Papua New Guinea known as "The Slot". Much deeper water lies both north and south of Honiara and Rabaul, but the only open-water connection to the north is a through a narrow deep channel east of the Honiara gauge. The connecting waters south of Honiara and Rabaul have very strong currents due to the motion of the South Equatorial Current (SEC) that runs through the area, both on the surface, and in the deeper thermocline layer. The local bathymetry (Figure 1) is irregular and steep, with relatively 
narrow deep-water connections between neighboring deep-water basins. This region also has some of the strongest ORs for $\mathrm{M}_{4}$, and $\mathrm{M}_{6}$, an order of magnitude greater than neighboring stations. The connections detailed above between the temporal fluctuations in the ORs, MSL and the El Niño (Figure 10) highlight the heightened sensitivity of tides to water level in this area. Thus, changes in friction, related to changes in lagoonal inundation or "sill depth" that connect the deep and interconnecting basins in the complex bathymetric region may be tied to changing ORs, since the large MSL fluctuations due to ENSO represent a larger relative change in water level. The $\mathrm{M}_{2}$ A-TAT is positive at Honiara and Rabaul, while the both the diurnals show negative A-TATs. Long-term trends are negative at Honiara for $\mathrm{M}_{2}, \mathrm{~K}_{1}$, and $\mathrm{O}_{1}$. At Rabaul, the long-term trends are negative in $\mathrm{M}_{2}$ and positive for the diurnals, but this trend is only estimated up to 1997 when the Rabaul gauge was de-commissioned so a direct comparisons of LTTs will not be accurate.

The similarity of behavior between TATs and $\mathrm{D}_{20}$ variations (Figure 11) suggests that the semidiurnal tidal properties in this region may be dependent on local thermocline depth. These results are (at least partially) consistent with the processes inferred for Hawaii; i.e., that increased $\mathrm{M}_{2}$ amplitude is correlated with times of deeper thermocline, due to changing internal wave phases (Mitchum and Chiswell, 2000; Colosi and Munk, 2006). In principle, changing thermocline depth could change ORs by altering internal tidal wave steepness. However, the observation (above) that

632 changes in ORs are driven by changes in the overtides (not the parent constituents) suggests a frictional mechanism.

633 That is, it seems unlikely that the $\mathrm{M}_{2}$ wave would become significantly steeper at several stations without modifying

$634 \mathrm{M}_{2}$ amplitudes at any of them. Moreover, the deeper thermocline during El Niño does not suggest internal tide steepening. Finally, scaling relationships suggest that changes in friction associated with lowered sea levels are a more

636 likely cause of increased ORs than internal wave steepening. In any event, evidence for a direct relationship between

637 overtides, the thermocline, local MSL and the forcing tides can only so far be provided for the gauges near the Solomon

638 Islands (Rabaul, Honiara, Kapingamarangi), presumably due in part to the variable topography and shallower relative water level amplifying both the overtide and thermocline mechanisms. However, lack of correlation between ORs and

640 thermocline depth may also be attributable to the distance of the TAO buoy datasets from other gauges in the study 641 area, e.g., near Pago Pago.

\section{2}

\subsection{Temporal changes}

Analyses of TATs before and after 1993 show that most stations on the Australian shelf exhibit larger ATATs before than after 1993 for $\mathrm{M}_{2}$, and also for $\mathrm{K}_{1}$ (Figure 12 and 13; Tables S1 and S2; Online Resource 1). No other region in this study showed such spatial coherence in the shifting of TATs. Overall, these results are locally interesting, but do not conclusively show that the rate of MSL during different epochs is directly influencing the response of the tides to MSL variability, since the majority of all gauges analyzed show more or less unchanged TATs before 1993 and after. Gauges that do show a significant shift in TATs are likely due to local dynamical factors mentioned above (overtide and thermocline variability), as well as the fact that the post-1993 period captures the 1997$1998 \mathrm{El}$ Nino event, the strongest such event in the modern record, which produced the largest interannual variability in both MSL and the tidal dynamics, particularly in this region. Therefore, the comparison of the tidal variability 
652 between these two time periods with different MSL rates is either not able to isolate the effect of long-term sea level 653 change, or it is not the mechanism for the observed tidal variability at this time scale.

\section{$\underline{5.3 \text { Amphidromic movements }}$}

655

656

657

658

659

660

661

662

663

664

665

666

667

668

669

670

671

672

673

674

675

676

677

678

679

680

681

682

683

The observed TATs for $\mathrm{K}_{1}$ (Figure 4) are consistent with a westward, slightly northwest-ward movement and counter-clockwise rotation of amphidrome "A", and an eastward movement and clockwise rotation of amphidrome "B" associated with positive MSL fluctuations. These combined motions would also allow an increase in the $\mathrm{K}_{1}$ amplitudes within the Coral Sea, as observed in TATs for the area. Though diurnal A-TATs are decreasing at nearby Honiara and Rabaul, these gauges are within a semi-enclosed basin, and are essentially separated from the Coral Sea and the open Pacific. The $\mathrm{O}_{1}$ tidal field shows a similar movement of amphidromic points as $\mathrm{K}_{1}$ (Figure 5) Unlike $\mathrm{K}_{1}$, there is an additional amphidromic point off the New Zealand coast. A westward movement of this point would explain trends observed at the Australian shelf and Auckland. Thus, we conclude that changes in diurnal tides within amphidromes "A" and "B" are amphidromic scale, though modulated by other local factors at some stations.

For $\mathrm{M}_{2}$, (Figure 6) an eastward movement of amphidrome "B", along with a counterclockwise rotation that expands anti-node " $\mathrm{C}$ " westward and southwest-ward would agree with most of the observed $\mathrm{M}_{2}$ TATs. The long, narrow amphidrome, "A" (more or less aligned with the Mariana Trench) is not changing in an obvious pattern. The $\mathrm{S}_{2}$ patterns (Figure 7) of A-TATs and P-TATs show some similarities to those for $\mathrm{M}_{2}$ (e.g., at Yap, Kapingamarangi, and Noumea), but also many differences (e.g., Legaspi, Rabaul and Pago Pago). Honiara has a similar $\mathrm{M}_{2}$ A-TAT to other regional gauges, but an opposite P-TAT. The overall pattern of change for $\mathrm{S}_{2}$ may echo $\mathrm{M}_{2}$, with an amphidromic point east of Pago Pago moving westward, and a central anti-node rotating counter-clockwise. It is not surprising that the $\mathrm{M}_{2}$ and $\mathrm{S}_{2}$ behavior show some difference, because $\mathrm{S}_{2}$ has a significant radiational component that is absent for $\mathrm{M}_{2}$ (Godin, 1986; Ray, 2001; Arbic, 2005). Still there is a strong suggestion of regional coherence for the semidiurnals, as with the diurnals.

If these suggestions of amphidromic-scale tidal evolution are real, they require an explanation relevant to such a scale. The two most likely candidates are the barotropic "back-effect" mechanism suggested by Arbic and Garrett (2010) and altered stratification (Müller, 2012). The first requires continental shelf areas over which friction or depth are changing, which seems more relevant to amphidrome $\mathrm{B}$, for both the diurnals and the semidiurnals. Altered stratification may have occured over large areas in both amphidromes A and B, and there is a clear connection between stratification and tidal properties at Honiara and Kapingamarangi. At least the latter is affected by amphidrome A for both diurnals and semidiurnals. Thus altered stratification seems the more likely agent of tidal evolution in amphidrome A. We note that amphidromic movements are not a cause of the observed TATs, but are rather symptoms of tidal evolution that represent a re-distribution the tidal fields driven by other factors.

\subsection{Triad Interactions}


Honiara and Rabaul in the Solomon Sea show resonant triad behavior at sub-decadal and longer timescales, with some fluctuations during ENSO events. Estimates of possible wave vectors show there are multiple situations that can satisfy the resonance conditions, Eqs. (2) and (3). Triads that involve higher- mode internal tides are, however, unlikely to be observed at a coastal tide gauge. Thus, the triad interaction that we do see is possibly a parametric subharmonic instability (PSI) interaction of barotropic $\mathrm{M}_{2}$ with first-mode internal $\mathrm{K}_{1}$ and $\mathrm{O}_{1}$.

There are also frictional triad interactions in the Solomon Sea that are correlated with MSL fluctuations, likely due to decreased lagoonal depths during periods of lowered MSL (Figure 10). Thus, frictionally-driven overtides $\mathrm{M}_{4}$ and $\mathrm{M}_{6}$ strongly vary with MSL (and thermocline depth) even though $\mathrm{MO}_{3}$ and $\mathrm{MK}_{3}$ do not. This likely reflects the fact that $\mathrm{M}_{2}$ is decreased and the diurnals $\left(\mathrm{K}_{1}\right.$ and $\left.\mathrm{O}_{1}\right)$ increased by a deeper thermocline. These opposite fluctuations compensate each other in $\mathrm{MO}_{3}$ and $\mathrm{MK}_{3}$, while $\mathrm{M}_{4}$ and $\mathrm{M}_{6}$ variations are proportional to the square and cube (respectively) of $\mathrm{M}_{2}$. Interestingly, the strong ENSO events, which caused large fluctuations in MSL, $\mathrm{O}_{1}, \mathrm{~K}_{1}$, $\mathrm{M}_{2}, \mathrm{M}_{4}$, and $\mathrm{M}_{6}$ individually, do not destroy the triad conservation relation Eq. (14), because of the manner in which the oscillations in individual constituents are coupled.

Resonant triad behavior at Honiara shows a difference in behavior before and after 1993, with larger excursions from stability after 1993. These excursions are caused by decreases in $\mathrm{K}_{1}$ and $\mathrm{O}_{1}$ amplitudes that are not fully compensated by changes in $\mathrm{M}_{2}$. These may be caused by the rising MSL in the area. Also, the ENSO response in 2009 and 2010 was less dramatic than in the four previous El Niños, perhaps because the most recent El Niño was weaker. Determining whether MSL rise has fundamentally altered Solomon Sea triad behavior awaits the next major El Niño.

\section{Conclusions}

Tidal anomalies are related to MSL anomalies via tidal anomaly trends for both amplitude and phase (ATATs and P-TATs) over much of the western Tropical Pacific, at both coastal and open-ocean stations. Comparison of periods before and after 1993 at stations with records >40 yrs long shows considerable temporal variability. . However, complex spatial patterns, differences between constituents and differences between TATs and trends make it difficult to draw conclusions regarding causes of tidal evolution. Observed trends so far suggest the existence of multiple mechanisms with spatial scales from strictly local (e.g., lagoonal depth and harbor modification) to amphidromal, as evidenced in the apparent movement and rotation of both diurnal and semidiurnal amphidromes. Comparison of the long-term trends (LTTs) in MSL and tidal properties with the short-term variability of MSL and tides, as exhibited by the A-TATs and P-TATs, do not show ubiquitous overlap of behavior. At some locations, the LTTs and TATs are correlated, but at others, anti-correlated. This suggests that multiple dynamics are active in different parts of the frequency spectrum, with temporal scales from interannual to decadal, and as of yet, no significant prediction about the future behavior of tidal constituents may be inferred from the analysis of interannual tidal and MSL fluctuations. Thus, the question posed in the title must be answered in the negative, at least for now, though further analysis with longer records from a different part of the world ocean might suggest a different answer. 
Two regions were studied in detail; the Solomon Sea, and the Coral Sea area including the east coast of Australia and New Zealand. Both areas show regionally coherent changes, but with different manifestations. In both cases, there is considerable variability between stations related to local processes. To the extent that the reefs of the Coral Sea are a factor, changes in the Australia-New Zealand area may be unusual - regionally coherent but not likely applicable in other settings.

To summarize the available evidence:

1. Internal tides: The surface manifestation of internal tides, generated across steep topography, can affect major

2. Changing friction: Frictional interactions are most prominent for overtides but affect the main tidal species as tidal constituents over the entire region investigated here, which is between the critical latitudes for both diurnal and semidiurnal tides. There has been a deepening and strengthening of the thermocline in the area (documented for 1993-2003 by Church et al., 2011), which necessarily changes internal tides and may affect surface tides (Müller, 2012). The $\mathrm{M}_{2}$ and $\mathrm{S}_{2}$ constituents are strongly (positively) correlated with nearby thermocline depth in the region surrounding the Solomon Islands as well as MSL, and diurnal tides show a negative (decreasing) response to increasing MSL and deepening thermocline. Thus, changing stratification appears to be the most likely agent of large-scale tidal evolution in the northern part of the study area (amphidrome A for both diurnals and semidiurnal). It may affect amphidrome B in the southern part of the study area, but we have no definite evidence of this. well. A-TATs, and LTTs of the major tides sometimes reinforce each other, but also show opposing behavior at some locations. These two calculations of trends have different time scales, and are likely due to unrelated mechanisms. The similarity in trends between coastal and island stations gives some support to the hypothesis that changes in amphidrome B may be driven by continental shelf processes, which can have a back-effect upon open-ocean trends (Arbic and Garrett, 2010). Comparison of TATs for the pre- and post-1993 periods shows the trends have changed for many Australian shelf stations, including sign reversals. Changes in ORs over time also suggest a frictional component to changing tides in the region of study. Particularly over the Australian shelf, this appears to have a regional rather than local origin.

3. Resonant triad interactions: Triad interactions of the diurnal and semidiurnal tides $\left(\mathrm{K}_{1}, \mathrm{O}_{1}\right.$, and $\left.\mathrm{M}_{2}\right)$, may both be mediated by and enhanced by variations in thermocline properties (Ball, 1964). The strength of these interactions can be modulated by changing water depth (MSL), which changes bottom friction, and also the deepening of the thermocline, which changes both surface-layer depth and stratification. Triads can involve a transfer of tidal energy across multiple frequencies, and is therefore a likely candidate to connect the other variability explored in this work, as illustrated by analysis of the Honiara and Rabual in the Solomon Sea region. Whether triad interactions are relevant on a regional basis, or only locally important, remains unclear.

It is likely the above mechanisms are not altogether independent, and the situation in the Solomon Sea suggests that there is a connection between triad and frictional interactions, with $\mathrm{M}_{2}$ energy feeding both the resonant 
752 and frictional triads. This results in large ( $\pm 30 \%)$ interannual fluctuations in $\mathrm{M}_{2}$ amplitude. Variations in thermocline 753 depth may be tied to changes in shallow water frictional interactions, because a shallower total depth makes 754 fluctuations in the upper-layer thickness larger, in percentage terms, than at deep water stations. The amphidromic 755 movements associated with MSL will likely have secondary regional effects as the basin-wide water levels and tidal 756 admittances adjust to changes in sea level and in thermocline profile. Resonant triads may also help redistribute the

757 amphidromes of each wave involved in the triad. Further work is underway to test the contribution of each of these 758 mechanisms through modeling in coordination with analyses of satellite altimetry data, as well as investigations 759 focusing on sub-annual (seasonal) dynamics based on complete monthly analyses.

761 Acknowledgements: Support for this project was provided by the National Science Foundation (NSF) project: Secular 762 Changes in Pacific Tides, OCE-0929055, and by the National Aeronautics and Space Administration (NASA) project: 763 NNX13AH06G. Thanks to Land Information New Zealand (LINZ) and Glen Rowe who provided data for Auckland 764 after extended personal communication.

765

766 


\section{References:}

Arbic BK, Karsten RH, Garrett C (2009) On tidal resonance in the global ocean and the back-effect of coastal tides upon open-ocean tides, Atmosphere-Ocean 47 (4) , 239-266, DOI:10.3137/OC311.2009

Arbic BK and Garrett C (2010) A coupled oscillator model of shelf and ocean tides Cont. Shelf Res. 30 (6), 564-574, DOI: $10.1016 /$ j.csr.2009.07.008

Arbic BK (2005) Atmospheric forcing of the oceanic semidiurnal tide, Geophys. Res. Lett., 32, L02610, DOI: $10.1029 / 2004 G L 021668$

Armstrong JA, Bloembergen N, Ducuing J, Pershan PS (1962) Interactions between light waves in a nonlinear dielectric, Phys. Rev. 127, 1918-1939, DOI: 10.1103/PhysRev.127.1918

Ball FK (1964) Energy transfer between external and internal gravity waves, J. Fluid. Mech., 20, 465-478, DOI: $10.1017 / \mathrm{S} 0022112064001550$

National Research Council (2012) Sea-Level Rise for the Coasts of California, Oregon, and Washington: Past, Present, and Future. National Academies Press

Bretherton FP (1964) Resonant interactions between waves J. Fluid Mech., 20, 457-479, DOI: $10.1017 /$ S0022112064001355

Bromirski PD, Miller AJ, Flick RE, Auad G (2011) Dynamical suppression of sea level rise along the Pacific coast of North America: Indications for imminent acceleration., Jour. Of GeoPhys. Res. 116, CO7005, DOI: $10.1029 / 2010 J C 006759$

Carter GS, Gregg MC (2006) Persistent near-diurnal internal waves observed above a site of $\mathrm{M}_{2}$ barotropic-tobaroclinic conversion, Jour. of phys. Oceanogr. 36(6), 1136-1147, DOI: 10.1175/JPO2884.1

Cartwright DE, Edden AC (1973) Corrected tables of tidal harmonics Geophys. Res. Lett. 33, 253-264, DOI: 10.1111/j.1365-246X.1973.tb03420.x

Cartwright DE, Tayler RJ (1971) New computations of the tide-generating potential, Geophysical Journal of the Royal Astronomical Society, 23, 45-74, DOI: 10.1111/j.1365-246X.1971.tb01803.x

Cazenave A, Nerem RS (2004) Present-day sea level change: observations and causes, Reviews of Geophysics, 42, RG3001, 1-20, DOI: 10.1029/2003RG000139

Chiswell, SM (1994) Vertical structure of the baroclinic tides in the central North Pacific subtropical gyre, Jour. Of Phys. Oceanogr. 24, 2032-2039, DOI: 10.1175/1520-0485(1994)24[2032:VSOTBT] 2.0.CO;2

Church JA and White NJ (2006) A 20th century acceleration in global sea-level rise, Geophys. Res. Lett., 33, L01602, DOI: 10.1029/2005GL024826 
Church, JA and White, NJ (2011) Sea-Level Rise from the Late 19th to the Early 21st Century. Surv. Geophys., DOI 10.1007/s10712-011-9119-1

Church JA, Roemmich D, Domingues CM, Willis JK, White NJ, Gilson JE, Stammer D, Köhl A, Chambers DP, Landerer FW, Marotzke J, Gregory JM, Tatsuo Suzuki, Cazenave A, Pi.-Y. Le Traon, (2011) Ocean Temperature and Salinity Contributions to Global and Regional Sea-Level Change, in Understanding Sea-Level Rise and Variability, Wiley-Blackwell, Oxford, pp. 143-176, DOI: 10.1029/2007EO040008

Church JA, NJ White, R Coleman, K Layback, JX Mitrovica (2004) Estimates of the regional distribution of sea level rise over the 1950-2000 period, J. Clim., 17, 2609-2625, doi:10.1175/1520-0442(2004)

Colossi JA and Munk W (2006) Tales of the Venerable Honolulu Tide Gauge, J. Phys. Oceanogr., 36, 967-996, DOI: $10.1175 / \mathrm{JPO} 2876.1$

Craik, A. D. D. (1985) Wave Interactions and Fluid Flows, Cambridge Univ. Press, Cambridge, U. K, ISBN: 978 0521368292

Domingues CM, Church JA, White NJ, Glecker PJ, Wijffels SE, Barker PM, Dunn JR (2008) Improved estimates of upper-ocean warming and multi-decadal sea-level rise, Nature, 453, 1090-1094, DOI: :10.1038/nature07080

Dushaw BD, Cornuelle BD, Worcester PF, Howe BM, Luther DS (1995) Barotropic and baroclinic tides in the central North Pacific Ocean determined from long-range reciprocal acoustic transmissions, Jour. Of Phys. Oceangr. 25, 631-647, DOI: 10.1175/1520-0485(1995)025<0631:BABTIT>2.0.CO;2

Egbert GD and Erofeeva SY (2002) Efficient inverse modeling of Barotropic Ocean tides, J. Atm. and Ocean. Tech., 19, 18 (204), DOI: 10.1175/1520-0426(2002)019<0183:EIMOBO>2.0.CO;2

Egbert GD and Erofeeva SY (2010) OTIS (OSU Tidal Inversion Software) TPXO7.2. College of Oceanic and Atmospheric Sciences, Oregon State University, Corvallis, Oregon, http://volkov.oce.orst.edu/tides/otis.html

Flick RE, Murray JF, Ewing LC (2003) Trends in United States Tidal Datum Statistics and Tide Range, J. Waterway, Port, Coastal and Ocean Eng. Amer. Soc. Civil Eng., 129(4): 155-164, DOI: 10.1061/ ASCE10733950X 20031129:4 1551

Gerkema, T., C. Staquet, and P. Bouruet-Aubertot (2006) Decay of semidiurnal internal-tide beams due to subharmonic resonance, Geophys. Res. Lett., 33, L08604, DOI: 10.1029/2005GL025105

Gill, AE (1982) Atmosphere-ocean dynamics (Vol. 30), Academic press, ISBN: 978-0122835223

Haigh I, Nicholls R, Wells N (2010) Assessing changes in extreme sea levels: Applications to the English Channel, 1900-2006, Cont. Sh. Res. 30, 1042-1055, DOI: 10.1016/j.csr.2010.02.002

Hamlington, BD, RR Leben, RS Nerem, W Han, KY Kim (2011) Reconstructing sea level using cyclostationary empirical orthogonal functions, J. Geophys. Res., 116, C12015, doi:10.1029/2011JC007529 
Hibiya, T., M. Nagasawa, and Y. Niwa (2002) Nonlinear energy transfer within the oceanic internal wave spectrum at mid and high latitudes, J. Geophys. Res., 107(C11), 3207, DOI: 10.1029/2001JC001210

Horsburgh KL, Wilson C. (2007) Tide-surge interaction and its role in the distribution of surge residuals in the North Sea, Jour. of Geophys. Res. 112, CO8003, DOI: 10.1029/2006JC004033

Huang NE, Shen Z, Long SR, Wu MC, Shih HH, Zheng Q, Yen NC, Tung CC, Liu HH (1998) The empirical mode decomposition and the Hilbert spectrum for nonlinear and non-stationary time-series analysis Proc. R. Soc. Lond. A. 454, 903-995, DOI: 10.1098/rspa.1998.0193

Huang NE, Wu Z (2008) A review on Hilbert-Huang Transform: Method and its application to geophysical studies, Rev. of GeoPhys. 46, RG2006, 1-23, DOI: 10.1029/2007RG000228

Huber PJ Robust Statistics Hoboken, NJ: John Wiley \& Sons, Inc., 1981 DOI: 10.1137/1.9781611970036.fm

Hughes TP, Baird AH, Bellwood DR, Card M, Connolly, SR, Folke C, Grosberg R, Hoegh-Guldberg O, Jackson JBC, Kleypas J, Lough JM, Marshall P, Nystrom M, Palumbi SR, Pandolfi JM, Rosen B, Roughgarden J (2003) Climate Change, Human Impacts, and the Resilience of Coral Reefs, Science 301, 929, DOI: $10.1126 /$ science.1085046

Hughes TP, Graham NAJ, Jackson JBC, Mumby PJ, Steneck RS (2010) Rising to the challenge of sustaining coral reef resilience, Trends in Ecology and Evolution, 25, 11, DOI: 10.1016/j.tree.2010.07.011

Jay DA (2009) Evolution of tidal amplitudes in the eastern Pacific Ocean, Geophys. Res. Lett., 36, L04603, DOI: $10.1029 / 2008$ GL036185

Jay DA, Leffler K, Degens S, (2011) Long-term evolution of Columbia River tides, ASCE Journal of Waterway, Port, Coastal, and Ocean Engineering, 137: 182-191; DOI: 10.1061/(ASCE)WW.1943- 5460.0000082

Kaup DJ (1980) A method for solving the separable initial value problem of the full three dimensional three-wave interaction, Stud. Appl. Math, 62, 75-83

Kohl A, Stammer D, and Cornuelle B (2007) Interannual to decadal changes in the ECCO Global Synthesis. $J$. Phys.Oceanogr., 37, 313-337, DOI: 10.1175/JPO3014.1

Kukulka, T., and Jay DA, (2003) Impacts of Columbia River discharge on salmonid habitat II. Changes in shallowwater habitat, J. Geophys. Res. 108, 3294 DOI: 10.1029/2003JC001829.

Lamb KG (2007) Tidally generated near-resonant internal wave triads at a shelf break, Geophys. Res. Lett. 34, L18607, DOI: $10.1029 / 2007 \mathrm{GL} 030825$

Leffler KE, Jay DA (2009) Enhancing tidal harmonic analysis: Robust solutions, Cont. Shelf Res., 29.1, 78-88, DOI: 10.1016/j.csr.2008.04.011 
Legg S, J Klymak (2008) internal hydraulic jumps and overturning generated by tidal flow over a tall steep ridge, $J$. Phys. Oceangr., 38, 1949-1964

Lelong MP, Kunze E (2013) Can barotropic tide-eddy interactions excite internal waves? Journal of Fluid Mechanics, 721, 1-27, DOI: 10.1017/jfm.2013.1

Livezey, RE and WY Chen, (1983) Statistical field significance and its determination by Monte Carlo techniques. Mon. Wea. Review, 111, 46-59, DOI: 10.1175/1520-0493(1983)111<0046: SFSAID>2.0.CO;2

Locarnini, R.A., Mishonov, A.V., Antonov, J.I., Boyer, T.P., Garcia, H.E., Baranova, O.K., Zweng, M.M. \& Johnson, D.R. (2010) World Ocean Atlas 2009, S. Levitus, Ed. NOAA Atlas NESDIS 67, U.S. Gov. Printing Office, Wash., D.C., 184 pp

Lombard A, Garric G, Penduff T (2009) Regional patterns of observed sea level change: Insights from a 1/48 global ocean/sea-ice hindcast, Ocean Dyn., 59, 433-449, DOI: 10.1007/s10236-008-0161-6

MacKinnon, J. A., and K. B. Winters (2005) Subtropical catastrophe: Significant loss of low-mode tidal energy at 28.9N, Geophys. Res. Lett., 2, L15605, DOI: 10.1029/2005GL023376

Merrifield MA (2011) A shift in western tropical Pacific sea level trends during the 1990s, Jour. of Climate, 24, 41264138, DOI: 10.1175/2011JCLI3932.1

Millero FJ, F Rainer, DG Wright, TJ McDougall (2008) The composition of standard seawater and the definition of the reference-composition salinity scale, Deep Sea Res. Part 1, 55, 1, 50-72, DOI:10.1016/j.dsr.2007.10.001

Mitchum GT, Chiswell SM (2000) Coherence of internal tide modulations along the Hawaiian ridge J. Geophys. Res., 105(C12), 28653-28661, DOI: 10.1029/2000JC900140

Müller M, Arbic BK, Mitrovica J (2011) Secular trends in ocean tides: observations and model results. J. Geophys. Res., 116, C05 013, DOI: 10.1029/2010JC006387

Müller M (2012) The influence of changing stratification conditions on barotropic tidal transport. Contin. Shelf Res., 47 (15), 107-188, DOI: 10.1016/j.csr.2012.07.003

Nerem RS, Chambers DP, Leuliette EW, Mitchum GT, Giese BS (1999) Variations in global mean sea level associated with the 1997-1998 ENSO event: Implications for measuring long term sea level change, Geophys. Res. Lett. 26(19), 3005-3008, DOI: 10.1029/1999GL002311

Nicholls, RJ, A Cavenaze (2010) Sea level rise and its impacts on coastal zones, Science 18, June 2010: 328, 5985 pp.1517-1520 DOI: 10.1126/science.1185782

Pawlowicz R, B Beardsley, S Lentz (2002) Classical tidal harmonic analysis including error estimates in MATLAB using T_TIDE, Computers and Geosciences, 28, 8, 929-937

Parker, Bruce (1991) Tidal Hydrodynamics, John Wiley and Sons, NY, 1-883, ISBN: 978-0471514985 
Pickering MD ,Wells NC, Horsburgh KJ, Green JAM (2010) The impact of future sea-level rise on the European Shelf tides, Cont. Sh. Res. 35, 1-15, DOI: 10.1016/j.csr.2011.11.011

Pugh DT (1987) Tides, surges and mean sea-level: a handbook for engineers and scientists, Wiley, Chichester, 472pp, ISBN: 978-0471915058

Pugh DT (2004) Changing sea levels. Effects of tides, weather and climate. Cambridge University Press, 280pp, ISBN: 978-0521532181

Ray RD, Mitchum GT (1996) Surface manifestations of internal tides generated near Hawaii. Geophys. Res. Letters 23, 2101-2104, DOI: 10.1029/96GL02050

Ray RD, Mitchum GT (1997) Surface manifestations of internal tides in the deep ocean: observations from altimetry and island gauges, Prog. Oceanography, 40,135-162, DOI:10.1016/S0079-6611(97)00025-6

Ray RD (2001) Comparisons of global analyses and station observations of the $\mathrm{S}_{2}$ barometric tide Geophys. Res. Lett. 28, 21-24, DOI: 10.1016/S1364-6826(01)00018-9

Ray RD (2006) Secular changes of the M2 tide in the Gulf of Maine, Cont. Shelf. Res., 26(3), 422-427, DOI: 10.1016/j.csr.2005.12.005

Ray RD (2009) Secular changes in the solar semidiurnal tide of the western North Atlantic Ocean, Geophysical Research Letters, 36, L19601, DOI: 10.1029/2009GL040217

Rainville L, R Pinkel (2006) Propagation of low-mode internal waves through the ocean, J. Phys. Oceangr., 36, 6, 1220-1236, DOI: 10.1175/JPO2882.1

Ropelewski CF, Halpert MS (1987) Global and regional scale precipitation patterns associated with the El Nino/ Southern Oscillation, Monthly Weather Review, 115, 1606-1626

Timmermann A, McGregor S, Jin FF (2010) Wind effects on past and future regional sea level trends in the southern Indo-Pacific. J. Climate, 23, 4429-4437, DOI: 10.1175/2010JCLI3519.1

Weiland J Wilhelmsson H. (1977) Coherent non-linear interaction of waves in plasmas, Pergamon Press, ISBN: 9780080209647

White WB, Cayan DR, Dettinger MD, Auad G (2001) Sources of global warming in the upper ocean temperature during El Nino, J. Geophys. Res., 106(C3), DOI: 10.1029/1999JC000130

Wolanski, E (1994) Physical oceanographic processes of the Great Barrier Reef, CRC Press, 208pp, ISBN: 0849380472

Woodworth PL (2010) A survey of recent changes in the main components of the ocean tide, Continental Shelf Research, 30(15), 1680-1691, DOI: 10.1016/j.csr.2010.07.002 
919 Wu Z Huang NE (2009) Ensemble empirical mode decomposition: A noise-assisted data-analysis method, Advances in Adaptive Data Analysis, 1(1), 1-41

921 Xie XH, Chen GY, Shang XD, Fang WD (2008) Evolution of the semidiurnal (M2) internal tide on the continental 922 slope of the northern South China Sea, Geophys. Res. Lett., 35, L13604, DOI: 10.1029/2008GL034179

923 Zakharov VE, Manakov SV (1973) Resonant interaction of wave packets in nonlinear media, Soviet Phys. - J.T.E.P. 924 Lett. $18,243-247$

925 Zaron, E, DA Jay (2014) An analysis of secular changes in tides at open-ocean sites in the Pacific. Accepted by Journal 926 of Physical Oceanography.

927

928

929

930

931

932 
Table 1a Station information for tidal records used in this study; locations are shown in Figure $1^{\text {a }}$

\begin{tabular}{|c|c|c|c|c|c|c|c|}
\hline Station & Country & Start Year & End Year & Environment & MSL Rates $^{*}$ & Pre-1993 ${ }^{*}$ & Post-1993 $^{*}$ \\
\hline Pohnpei & Micronesia & 1974 & 2012 & volcanic & $2.22 \pm 0.01$ & $-2.20 \pm 0.28$ & $4.71 \pm 0.27$ \\
\hline Majuro & Marshall Is. & 1974 & 2012 & atoll & $3.91 \pm 0.15$ & $2.66 \pm 0.45$ & $7.02 \pm 0.41$ \\
\hline Malakal & Belau & 1974 & 2012 & mountainous/reef & $2.98 \pm 0.15$ & $-1.56 \pm 0.44$ & $10.36 \pm 0.42$ \\
\hline Yap & Micronesia & 1974 & 2012 & mountainous/reef & $1.99 \pm 0.12$ & $-2.91 \pm 0.34$ & $7.30 \pm 0.34$ \\
\hline Honiara & Solomon Is. & 1975 & 2012 & volcanic & $0.88 \pm 0.08$ & $-5.15 \pm 0.24$ & $8.51 \pm 0.20$ \\
\hline Rabaul & Pap. N. Gui. & 1966 & 1997 & volcanic & $-3.16 \pm 0.09$ & $-5.94 \pm 0.10$ & N/A \\
\hline Kanton & Kiribati & 1949 & 2012 & atoll & $0.89 \pm 0.05$ & $0.12 \pm 0.08$ & $4.69 \pm 0.29$ \\
\hline Noumea & France & 1967 & 2012 & reef & $1.37 \pm 0.09$ & $0.53 \pm 0.20$ & $5.93 \pm 0.34$ \\
\hline Saipan & N. Mar. Is. & 1978 & 2012 & mountainous & $2.27 \pm 0.10$ & N/A & N/A \\
\hline Kapinga & Micronesia & 1978 & 2009 & atoll & $2.82 \pm .12$ & N/A & N/A \\
\hline Lautoka & Fiji & 1992 & 2012 & volcanic & $5.58 \pm 0.10$ & N/A & N/A \\
\hline Midway & USA & 1947 & 2012 & atoll & $0.86 \pm 0.02$ & $-0.25 \pm 0.04$ & $5.40 \pm 0.17$ \\
\hline Wake & USA & 1950 & 2012 & atoll & $1.99 \pm 0.05$ & $1.42 \pm 0.07$ & $1.12 \pm 0.36$ \\
\hline Johnston & USA & 1947 & 2012 & atoll & $0.85 \pm 0.05$ & $0.51 \pm 0.06$ & $3.04 \pm 0.59$ \\
\hline Guam & USA & 1948 & 2012 & mountainous & $1.32 \pm 0.04$ & $-0.89 \pm 0.06$ & $9.32 \pm 0.31$ \\
\hline Kwajalein & Marshall Is. & 1946 & 2012 & atoll & $1.72 \pm 0.07$ & $0.71 \pm 0.10$ & $8.07 \pm 0.50$ \\
\hline Pagopago & USA & 1948 & 2012 & volcanic & $2.13 \pm 0.05$ & $1.45 \pm 0.08$ & $6.44 \pm 0.37$ \\
\hline Brisbane & Australia & 1984 & 2012 & estuary & $2.75 \pm 0.10$ & N/A & N/A \\
\hline Bundaberg & Australia & 1984 & 2012 & estuary & $1.90 \pm 0.08$ & N/A & N/A \\
\hline Ft. Denison & Australia & 1914 & 2012 & estuary/ria & $0.92 \pm 0.12$ & $1.06 \pm 0.22$ & $2.84 \pm 0.56$ \\
\hline Townsville & Australia & 1985 & 2012 & coastal bay & $0.81 \pm 0.16$ & N/A & N/A \\
\hline Legaspi & Philippines & 1984 & 2007 & coastal bay & $8.97 \pm 0.42$ & N/A & N/A \\
\hline Cairns & Australia & 1985 & 2010 & coastal inlet & $2.14 \pm 0.33$ & N/A & N/A \\
\hline Gladstone & Australia & 1978 & 2010 & coastal bay & $2.47 \pm 0.58$ & N/A & N/A \\
\hline Williamstown & Australia & 1966 & 2010 & coastal bay & $1.39 \pm 0.07$ & $0.09 \pm 0.17$ & $2.48 \pm 0.25$ \\
\hline Auckland & New Zealand & 1904 & 2010 & coastal bay & $1.48 \pm 0.09$ & $1.33 \pm 0.07$ & $3.75 \pm 0.18$ \\
\hline
\end{tabular}

$934{ }^{a}$-Expressed in $\mathrm{mm} \mathrm{yr}^{-1}$. N/A indicates there was not a full nodal cycle ( 18.6 years) of data before 1993 available. 
Table 1b Long-term (linear) trends, with $95 \%$ confidence limits, for tidal amplitudes and phases ${ }^{\mathrm{a}}$

\begin{tabular}{|c|c|c|c|c|c|c|c|c|}
\hline $\begin{array}{l}\text { Tidal } \\
\text { Comp: }\end{array}$ & $\begin{array}{c}K_{1} \\
\text { A-LTT }\end{array}$ & $\begin{array}{c}\mathrm{K}_{1} \\
\text { P-LTT }\end{array}$ & $\begin{array}{c}\mathbf{O}_{1} \\
\text { A-LTT }\end{array}$ & $\begin{array}{c}\text { O }_{1} \\
\text { P-LTT }\end{array}$ & $\begin{array}{c}M_{2} \\
\text { A-LTT }\end{array}$ & $\begin{array}{c}M_{2} \\
\text { P-LTT }\end{array}$ & $\begin{array}{c}S_{2} \\
\text { A-LTT }\end{array}$ & $\begin{array}{c}S_{2} \\
\text { P-LTT }\end{array}$ \\
\hline Station & $\left(\mathrm{mmcy}^{-1}\right)$ & $\left(\operatorname{degcy}^{-1}\right)$ & $\left(\right.$ mmcy $\left.^{-1}\right)$ & $\left(\right.$ degcy $\left.^{-1}\right)$ & $\left(\mathrm{mmcy}^{-1}\right)$ & $\left(\operatorname{degcy}^{-1}\right)$ & $\left(\right.$ mmcy $\left.^{-1}\right)$ & $\left(\operatorname{degcy}^{-1}\right)$ \\
\hline Pohnpei & $-7.5 \pm 2.5$ & $-7.5 \pm 1.7$ & $4.4 \pm 1.3$ & $5.7 \pm 1.1$ & $22.0 \pm 6.7$ & $8.0 \pm 1.8$ & $18.2 \pm 4.4$ & $1.8 \pm 2.0$ \\
\hline Majuro & $0.4 \pm 2.6$ & $17.7 \pm 2.7$ & $3.7 \pm 1.5$ & $23.2 \pm 2.4$ & $44.9 \pm 8.3$ & $0.8 \pm 1.2$ & $35.8 \pm 3.8$ & $4.6 \pm 0.9$ \\
\hline Malakal & $15.7 \pm 4.8$ & $2.6 \pm 1.3$ & $-1.0 \pm 3.0$ & $-5.5 \pm 2.8$ & $62.3 \pm 5.8$ & $0.1 \pm 1.2$ & $29.5 \pm 2.3$ & $-0.7 \pm 1.4$ \\
\hline Yap & $14.0 \pm 3.2$ & $4.1 \pm 1.3$ & $21.8 \pm 4.6$ & $16.3 \pm 4.7$ & $41.3 \pm 6.1$ & $10.5 \pm 1.8$ & $16.2 \pm .31$ & $10.6 \pm 2.2$ \\
\hline Honiara & $-2.1 \pm 4.9$ & $15.6 \pm 1.9$ & $-4.8 \pm 4.5$ & $22.5 \pm 9.8$ & $-6.2 \pm 5.4$ & $17.8 \pm 2.8$ & $4.0 \pm 2.7$ & $6.8 \pm 1.7$ \\
\hline Rabaul & $23.6 \pm 3.9$ & $1.0 \pm 1.3$ & $5.4 \pm 3.1$ & $0.0 \pm 1.4$ & $-13.1 \pm 13.1$ & $-0.8 \pm 12.8$ & $14.4 \pm 5.6$ & $0.8 \pm 2.5$ \\
\hline Kanton & $3.0 \pm 1.0$ & $-2.4 \pm 2.6$ & $4.0 \pm 0.9$ & $6.4 \pm 2.4$ & $27.8 \pm 4.8$ & $-5.0 \pm 0.8$ & $15.3 \pm 1.3$ & $-1.5 \pm 0.6$ \\
\hline Noumea & $6.9 \pm 1.2$ & $0.6 \pm 0.5$ & $0.3 \pm 0.9$ & $0.9 \pm 1.2$ & $25.3 \pm 6.1$ & $-2.5 \pm 0.7$ & $19.3 \pm 2.5$ & $-4.6 \pm 0.8$ \\
\hline Saipan & $-11.2 \pm 4.9$ & $0.7 \pm 1.7$ & $1.3 \pm 2.3$ & $-0.2 \pm 2.0$ & $33.2 \pm 6.7$ & $7.6 \pm 2.6$ & $-15.8 \pm 3.9$ & $-13.4 \pm 5.2$ \\
\hline Kapinga & $19.8 \pm 6.3$ & $1.7 \pm 3.1$ & $-1.5 \pm 12.5$ & $7.2 \pm 5.9$ & $49.7 \pm 9.7$ & $7.9 \pm 5.7$ & $35.1 \pm 6.6$ & $10.3 \pm 5.7$ \\
\hline Lautoka & $1.8 \pm 2.2$ & $-3.5 \pm 15.1$ & $2.8 \pm 2.3$ & $-8.1 \pm 8.4$ & $36.7 \pm 7.1$ & $-5.2 \pm 0.9$ & $12.4 \pm 6.0$ & $14.1 \pm 5.2$ \\
\hline Midway & $1.5 \pm 0.7$ & $0.2 \pm 0.4$ & $1.6 \pm 0.5$ & $-2.3 \pm 0.5$ & $7.4 \pm 1.2$ & $-5.5 \pm 0.7$ & $-0.3 \pm 0.5$ & $-17.2 \pm 1.7$ \\
\hline Wake & $-3.4 \pm 0.6$ & $-0.7 \pm 0.6$ & $0.9 \pm 0.6$ & $2.0 \pm 0.7$ & $-11.9 \pm 2.7$ & $2.4 \pm 0.5$ & $5.7 \pm 1.1$ & $2.1 \pm 0.5$ \\
\hline Johnston & $-3.9 \pm 0.8$ & $-7.0 \pm 0.5$ & $-2.0 \pm 0.4$ & $1.8 \pm 0.6$ & $2.6 \pm 1.7$ & $-4.1 \pm 0.7$ & $8.1 \pm 1.4$ & $-11.3 \pm 0.7$ \\
\hline Guam & $4.7 \pm 1.9$ & $4.3 \pm 0.9$ & $-3.4 \pm 1.6$ & $3.5 \pm 0.7$ & $-0.5 \pm 2.4$ & $1.6 \pm 0.6$ & $0.1 \pm 0.9$ & $7.7 \pm 1.2$ \\
\hline Kwajalein & $1.6 \pm 0.6$ & $0.4 \pm 0.5$ & $-1.0 \pm 0.5$ & $0.2 \pm 0.4$ & $-7.3 \pm 1.7$ & $0.4 \pm 0.2$ & $-0.1 \pm 1.4$ & $-1.8 \pm 0.2$ \\
\hline Pagopago & $2.2 \pm 0.9$ & $0.3 \pm 0.7$ & $2.2 \pm 0.9$ & $3.8 \pm 0.9$ & $10.1 \pm 2.5$ & $-0.2 \pm 0.5$ & $1.0 \pm 0.8$ & $-1.8 \pm 0.2$ \\
\hline Brisbane & $-12.9 \pm 3.7$ & $2.5 \pm 1.1$ & $-4.9 \pm 3.3$ & $6.2 \pm 1.5$ & $15.6 \pm 13.6$ & $13.9 \pm 1.1$ & $12.3 \pm 7.2$ & $9.1 \pm 1.5$ \\
\hline Bundaberg & $-8.7 \pm 3.1$ & $0.3 \pm 1.1$ & $-8.3 \pm 2.4$ & $0.5 \pm 1.1$ & $2.3 \pm 5.6$ & $1.9 \pm 1.2$ & $7.9 \pm 4.4$ & $2.5 \pm 1.4$ \\
\hline Ft Denison & $-1.1 \pm 0.4$ & $-0.4 \pm 0.2$ & $-0.2 \pm 0.4$ & $-0.9 \pm 0.2$ & $-27.8 \pm 10.0$ & $-2.0 \pm 0.2$ & $-5.1 \pm 0.4$ & $-3.5 \pm 0.2$ \\
\hline Townsville & $3.3 \pm 1.7$ & $-1.6 \pm 0.3$ & $2.6 \pm 1.2$ & $1.1 \pm 0.5$ & $66.8 \pm 3.2$ & $-3.0 \pm 0.4$ & $9.9 \pm 2.0$ & $1.9 \pm 0.4$ \\
\hline Legaspi & $-14.8 \pm 6.9$ & $0.1 \pm 2.7$ & $-28.7 \pm 7.2$ & $9.4 \pm 3.8$ & $-69.3 \pm 27.6$ & $-4.1 \pm 4.1$ & $-13.1 \pm 15.1$ & $-0.1 \pm 3.4$ \\
\hline Cairns & $8.8 \pm 5.7$ & $-0.1 \pm 0.8$ & $10.2 \pm 3.1$ & $0.4 \pm 0.9$ & $49.5 \pm 12.5$ & $-1.4 \pm 1.4$ & $15.4 \pm 6.0$ & $-3.1 \pm 1.7$ \\
\hline Gladstone & $-2.2 \pm 3.3$ & $0.1 \pm 0.7$ & $-8.9 \pm 2.3$ & $1.7 \pm 1.1$ & $14.1 \pm 8.2$ & $1.6 \pm 0.7$ & $57.3 \pm 6.7$ & $2.3 \pm 0.8$ \\
\hline Wllmstwn & $18.2 \pm 1.6$ & $5.1 \pm 1.3$ & $7.8 \pm 1.6$ & $9.6 \pm 1.7$ & $34.8 \pm 2.1$ & $11.7 \pm 1.2$ & $6.6 \pm 1.5$ & $18.9 \pm 1.8$ \\
\hline Auckland & $-1.4 \pm 0.4$ & $1.2 \pm 0.3$ & $-0.8 \pm 0.3$ & $19.5 \pm 1.3$ & $-31.7 \pm 2.0$ & $0.6 \pm 0.2$ & $-3.6 \pm 0.7$ & $1.6 \pm 1.5$ \\
\hline
\end{tabular}

$938{ }^{a}$-Expressed as mm century ${ }^{-1}\left(\right.$ mmcy $\left.^{-1}\right)$ for amplitudes, or degrees century ${ }^{-1}\left(\right.$ degcy $\left.^{-1}\right)$ for phases. Significant values 939 are shaded grey; significant values have SNR $>2$, and an absolute magnitude of $>10$ mmcy $^{-1}$ or degcy ${ }^{-1}$ 
Table 2 Amplitude tidal anomaly trends (A-TATs) with 95\% confidence limits and combined A-TATs for major diurnal and semidiurnal constituents ${ }^{\mathrm{a}}$.

\begin{tabular}{|c|c|c|c|c|c|}
\hline $\begin{array}{l}\text { Tidal Comp: } \\
\text { ( } \pm 95 \% \text { CI })\end{array}$ & $\begin{array}{c}\mathbf{K}_{1} \\
\text { A-TAT }\end{array}$ & $\begin{array}{c}\text { O }_{1} \\
\text { A-TAT }\end{array}$ & $\begin{array}{c}\text { M }_{2} \\
\text { A-TAT }\end{array}$ & $\begin{array}{c}\text { S }_{2} \\
\text { A-TAT }\end{array}$ & $\begin{array}{c}\text { Comb. } \\
\text { A-TATs }\end{array}$ \\
\hline Station & $\left(\mathrm{mmm}^{-1}\right)$ & $\left(\mathrm{mmm}^{-1}\right)$ & $\left(\mathrm{mmm}^{-1}\right)$ & $\left(\mathrm{mmm}^{-1}\right)$ & $\left(\mathbf{m m m}^{-1}\right)$ \\
\hline Pohnpei & $22.9 \pm 3.6$ & $0.2 \pm 2.3$ & $-4.1 \pm 12.2$ & $-5.6 \pm 3.2$ & $13.5 \pm 13.3$ \\
\hline Majuro & $7.6 \pm 6.8$ & $-17.7 \pm 4.2$ & $-21.6 \pm 23.3$ & $-0.9 \pm 5.0$ & $-32.6 \pm 25.2$ \\
\hline Malakal & $46.4 \pm 3.8$ & $6.3 \pm 3.4$ & $-28.5 \pm 7.2$ & $-2.2 \pm 1.5$ & $21.9 \pm 9.0$ \\
\hline Yap & $19.6 \pm 4.0$ & $3.6 \pm 5.8$ & $-39.6 \pm 7.9$ & $-9.7 \pm 1.5$ & $-26.1 \pm 10.7$ \\
\hline Honiara & $-21.2 \pm 6.3$ & $-27.6 \pm 4.5$ & $65.6 \pm 3.3$ & $15.9 \pm 0.8$ & $32.7 \pm 8.4$ \\
\hline Rabaul & $-24.3 \pm 3.1$ & $-8.4 \pm 2.9$ & $91.1 \pm 7.5$ & $-11.7 \pm 1.8$ & $46.7 \pm 8.8$ \\
\hline Kanton & $-14.0 \pm 3.6$ & $-2.4 \pm 3.7$ & $33.0 \pm 18.3$ & $8.7 \pm 2.2$ & $25.3 \pm 19.1$ \\
\hline Noumea & $23.6 \pm 4.2$ & $2.9 \pm 3.3$ & $70.9 \pm 19.0$ & $12.9 \pm 3.3$ & $110.4 \pm 20.0$ \\
\hline Saipan & $-10.6 \pm 8.2$ & $8.9 \pm 3.8$ & $17.0 \pm 11.1$ & $-8.1 \pm 2.6$ & $7.2 \pm 14.6$ \\
\hline Kapinga & $-18.3 \pm 5.8$ & $-20.7 \pm 12.5$ & $47.6 \pm 7.7$ & $17.4 \pm 1.6$ & $26.1 \pm 15.8$ \\
\hline Lautoka & $5.4 \pm 3.3$ & $12.3 \pm 2.9$ & $21.9 \pm 10.6$ & $6.4 \pm 3.8$ & $46.0 \pm 12.1$ \\
\hline Midway & $7.4 \pm 3.1$ & $-7.7 \pm 2.4$ & $6.6 \pm 6.0$ & $2.9 \pm 1.1$ & $9.1 \pm 7.2$ \\
\hline Wake & $-9.0 \pm 2.6$ & $4.1 \pm 2.6$ & $-43.6 \pm 11.8$ & $-2.4 \pm 2.1$ & $-50.9 \pm 12.6$ \\
\hline Johnston & $-26.1 \pm 3.4$ & $2.1 \pm 2.1$ & $-38.4 \pm 8.9$ & $-21.9 \pm 2.6$ & $-84.3 \pm 10.1$ \\
\hline Guam & $-29.0 \pm 4.2$ & $-35.9 \pm 2.9$ & $-23.3 \pm 5.8$ & $1.3 \pm 0.9$ & $-86.9 \pm 7.7$ \\
\hline Kwajalein & $-1.1 \pm 2.6$ & $8.2 \pm 2.0$ & $-2.7 \pm 6.6$ & $9.1 \pm 2.0$ & $13.4 \pm 7.6$ \\
\hline Pagopago & $20.3 \pm 3.1$ & $2.7 \pm 1.5$ & $82.7 \pm 7.7$ & $-9.9 \pm 1.1$ & $95.8 \pm 8.5$ \\
\hline Brisbane & $19.4 \pm 10.2$ & $30.3 \pm 8.4$ & $177.6 \pm 28.8$ & $15.2 \pm 8.4$ & $242.4 \pm 32.8$ \\
\hline Bundaberg & $50.8 \pm 10.6$ & $1.9 \pm 6.8$ & $-32.2 \pm 15.4$ & $-9.3 \pm 4.9$ & $11.2 \pm 20.5$ \\
\hline Ft. Denison & $18.1 \pm 4.8$ & $10.2 \pm 4.1$ & $-47.9 \pm 11.0$ & $-0.5 \pm 1.8$ & $-20.1 \pm 12.8$ \\
\hline Townsville & $10.4 \pm 11.6$ & $1.0 \pm 7.2$ & $-4.7 \pm 19.6$ & $-6.0 \pm 4.4$ & $0.7 \pm 24.3$ \\
\hline Legaspi & $-11.2 \pm 7.1$ & $-29.1 \pm 6.2$ & $-152.0 \pm 21.2$ & $26.0 \pm 4.5$ & $-166.2 \pm 23.6$ \\
\hline Cairns & $15.8 \pm 16.4$ & $27.1 \pm 8.0$ & $35.5 \pm 36.0$ & $1.7 \pm 6.9$ & $80.1 \pm 40.9$ \\
\hline Gladstone & $38.3 \pm 10.5$ & $6.8 \pm 7.7$ & $-34.1 \pm 26.8$ & $-23.1 \pm 8.5$ & $-12.1 \pm 31.0$ \\
\hline Wllmstown & $1.0 \pm 6.3$ & $-0.1 \pm 6.2$ & $9.2 \pm 8.2$ & $9.2 \pm 2.2$ & $19.3 \pm 12.3$ \\
\hline Auckland & $6.0 \pm 3.0$ & $-0.8 \pm 2.3$ & $-58.2 \pm 17.2$ & $3.4 \pm 2.5$ & $-49.5 \pm 17.8$ \\
\hline
\end{tabular}

$946{ }^{a}$-All values are expressed as millimeter change in tide per meter rise in MSL $\left(\mathrm{mm} \mathrm{m}^{-1}\right)$. Significant values are shaded 947 grey, based on a SNR > 2, and an absolute magnitude of $>10 \mathrm{~mm} \mathrm{~m}^{-1}$ 
Table 3 Phase anomaly trends (P-TATs) with 95\% confidence limits for major diurnal and semidiurnal constituents ${ }^{\mathrm{a}}$.

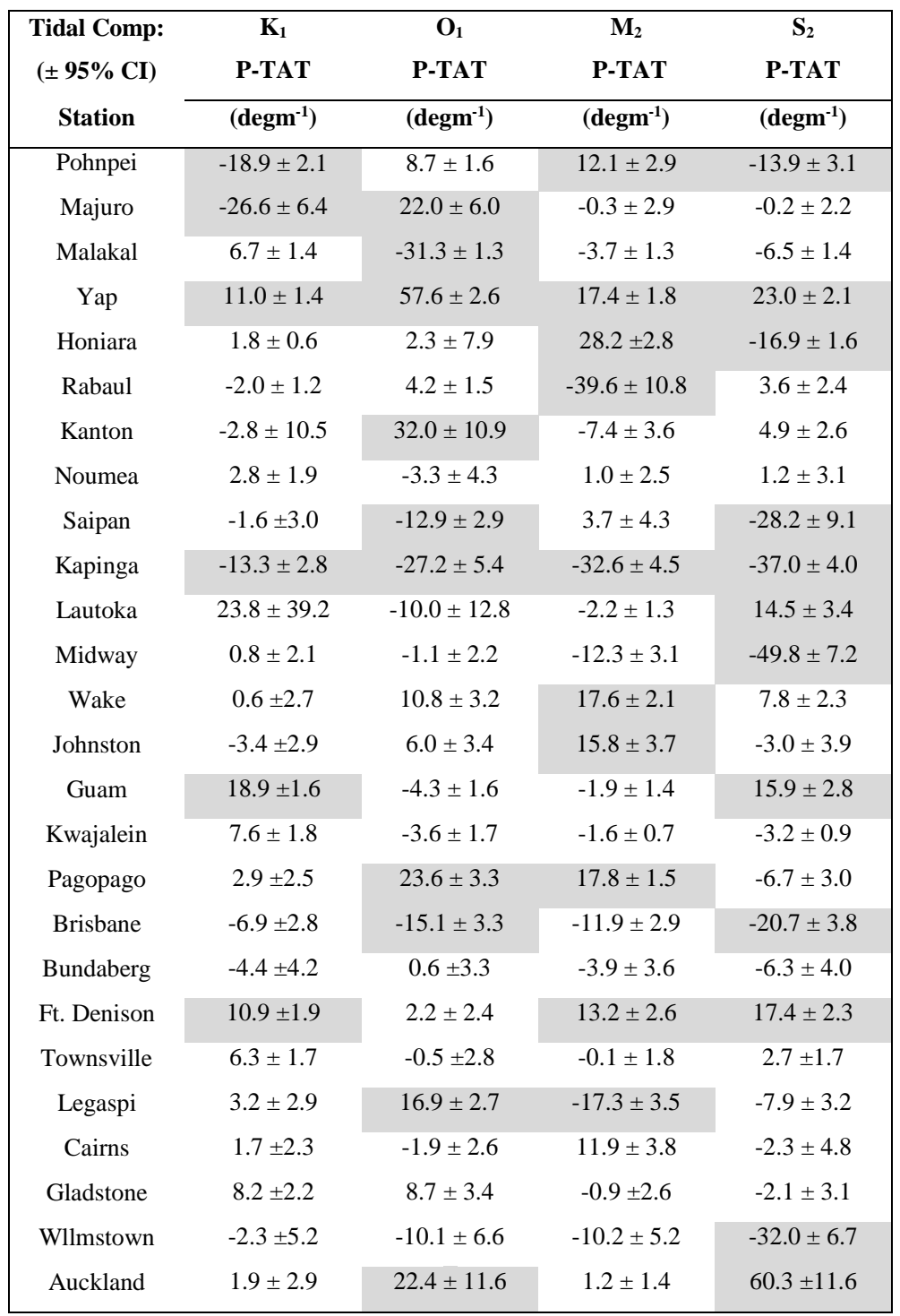

953 a -All values are expressed as degree change in tide per meter rise in MSL (deg/m). Significant values are shaded grey, 954 based on a SNR $>2$, and an absolute magnitude of $>10 \mathrm{degm}^{-1}$. Combined trends have not been calculated for phase 955 anomaly trends, since each forcing frequency has a different period; therefore, cumulative trends may not physical 956 meaningful 
961 Table 4 Phase variances and phase sum variances (of the IMF 4-10 combination) for Honiara and Rabaul. For 962 Honiara, we calculate the variances for the entire time record as well as splitting the record about the year $1993^{\mathrm{a}}$.

\begin{tabular}{|c|c|c|c|c|c|}
\hline Honiara & $\begin{array}{l}\mathbf{K}_{1} \quad \text { phase } \\
\text { variance }\end{array}$ & $\begin{array}{l}\mathrm{O}_{1} \text { phase } \\
\text { variance }\end{array}$ & $\begin{array}{l}\mathbf{M}_{2} \quad \text { phase } \\
\text { variance }\end{array}$ & $\begin{array}{ll}\text { Sum of } \\
\text { variances }\end{array}$ & $\begin{array}{l}\Phi(\tau) \\
\text { variance }\end{array}$ \\
\hline (1974-2012) & 0.49 & 0.62 & 0.71 & 1.06 & 0.42 \\
\hline (1974-1993) & 0.11 & 0.12 & 0.89 & 0.91 & 0.48 \\
\hline (1993-2012) & 0.47 & 0.54 & 0.51 & 0.88 & 0.31 \\
\hline \multicolumn{6}{|l|}{ Rabaul } \\
\hline$(1966-1997)$ & 0.15 & 0.20 & 1.56 & 1.58 & 0.68 \\
\hline
\end{tabular}

963 a- All variances are expressed as a percentage of a full cycle, with $\Phi$ being relative to $\mathrm{K}_{1}$. Values shaded grey in the last column

964 indicate that the variance is less in the combined quantity than in the sum of the individual quantities. 
978 Table 5a Slopes $(\mathrm{m} / \mathrm{\kappa})$ of the dispersion relations of $\mathbf{M}_{2}, \mathbf{K}_{1}$, and $\mathrm{O}_{1}$ at for Honiara for typical values of non979 dimensional $\mathrm{N}$

980

\begin{tabular}{|c|c|c|c|}
\hline $\mathbf{N} / \omega_{m 2}$ & $\begin{array}{l}(m / \kappa) \\
\text { for } M_{2}\end{array}$ & $\begin{array}{l}(m / \kappa) \\
\text { for } K_{1}\end{array}$ & $\begin{array}{l}(m / \kappa) \\
\text { for } O_{1}\end{array}$ \\
\hline 10 & 10.0 & 20.2 & 22.1 \\
\hline 23 & 27.6 & 45.5 & 49.8 \\
\hline 32 & 32.1 & 64.0 & 70.1 \\
\hline 71 & 71.8 & 143.8 & 157.5 \\
\hline 100 & 101.4 & 203.6 & 222.9 \\
\hline
\end{tabular}

981

982

983

984

985

986

987

988

989

990

991

992 
994 Table 5b PSI triad wavenumber estimates for three assumed depths $\mathrm{s}^{\mathrm{a}}$.

\begin{tabular}{|c|c|c|c|c|}
\hline Depth, (m) & $(k, m)$ for $M_{2}$ & $(k, m)$ for $K_{I}$ & $(k, m)$ for $O_{1}$ & $\Delta \mathbf{k}$ \\
\hline 500 & $\left(2.0 \times 10^{-6} \mathrm{~m}^{-1}, \sim 0\right)$ & $\left(-2.7 \times 10^{-5} \mathrm{~m}^{-1}, \pm 1\right)$ & $\left(+2.5 \times 10^{-5} \mathrm{~m}^{-1}, \pm 1\right)$ & $\sim 0$ \\
\hline 5000 & $\left(0.7 \times 10^{-6} \mathrm{~m}^{-1}, \sim 0\right)$ & $\left(-2.7 \times 10^{-5} \mathrm{~m}^{-1}, \pm 1\right)$ & $\left(+2.5 \times 10^{-5} \mathrm{~m}^{-1}, \pm 1\right)$ & $1.3 \times 10^{-6} \mathrm{~m}^{-1}$ \\
\hline 100 & $\left(4.0 \times 10^{-6} \mathrm{~m}^{-1}, \sim 0\right)$ & $\left(-2.7 \times 10^{-5} \mathrm{~m}^{-1}, \pm 1\right)$ & $\left(+2.5 \times 10^{-5} \mathrm{~m}^{-1}, \pm 1\right)$ & $2.0 \times 10^{-6} \mathrm{~m}^{-1}$ \\
\hline
\end{tabular}

995

996

997

998

999

1000

1001

1002

1003

1004

1005

1006

1007

1008

1009

1010

1011 a- Calculations of wavenumbers for the case of a barotropic $\mathrm{M}_{2}$, and a first mode baroclinic $\mathrm{K}_{1}$, and $\mathrm{O}_{1}$ at Honiara, Solomon Islands. Three cases are shown for three depths typical of the region; the mean depth of $500 \mathrm{~m}$ gives an exact triad $(\Delta \mathrm{k})$. For much deeper $(5000 \mathrm{~m})$ and much shallower $(100 \mathrm{~m})$ water, a near-resonant triad is possible Horizontal wavenumbers $(k$ 's, and $\Delta \mathrm{k})$ are dimensional (meters) and mode numbers are non-dimensional. 
Table 5c Baroclinic triad wavenumber estimates.

1013

\begin{tabular}{|l|l|l|l|}
\hline$(\boldsymbol{k}, \boldsymbol{m})$ for $\boldsymbol{M}_{2}$ & $(\boldsymbol{k}, \boldsymbol{m})$ for $\mathrm{K}_{\boldsymbol{I}}$ & $(\boldsymbol{k}, \boldsymbol{m})$ for $\boldsymbol{O}_{\boldsymbol{I}}$ & $\Delta \mathbf{k}$ \\
\hline$\left( \pm 1.1 \times 10^{-4} \mathrm{~m}^{-1}, \pm 2\right)$ & $\left( \pm 8.4 \times 10^{-5} \mathrm{~m}^{-1}, \pm 3\right)$ & $\left( \pm 2.5 \times 10^{-5} \mathrm{~m}^{-1}, \pm 1\right)$ & $1.0 \times 10^{-6} \mathrm{~m}^{-1}$ \\
$\left( \pm 1.1 \times 10^{-4} \mathrm{~m}^{-1}, \pm 2\right)$ & $\left( \pm 2.7 \times 10^{-5} \mathrm{~m}^{-1}, \pm 1\right)$ & $\left( \pm 7.8 \times 10^{-5} \mathrm{~m}^{-1}, \pm 3\right)$ & $5.0 \times 10^{-6} \mathrm{~m}^{-1}$ \\
& & & \\
\hline
\end{tabular}

1014

$1015 \mathrm{a}^{\mathrm{a}}$ - As in Table 5b, this time for the 3-2-1 triad of Lamb (2007) (with a mode $2 \mathrm{M}_{2}$ wave), at Honiara, Solomon Islands. The first of 1016 the two estimates assumes that $\mathrm{K}_{1}$ is mode 3 and $\mathrm{O}_{1}$ is mode 1 ; the second assumes that $\mathrm{K}_{1}$ is mode 1 and $\mathrm{O}_{1}$ is mode 3. 
Figure 1 Bathymetry of the western Pacific Ocean, with tide gauge stations used in this study shown as white dots and bold text for island gauges, and yellow dots and italicized text for coastal gauges; the depth scale is shown at right, in meters

Figure 2 Time series of yearly average MSL (in meters) at Guam, Pago Pago, Kwaljein, Malakal, Yap, Honiara, and Kanton, showing differences in sea level evolution before and after 1993 (indicated by the dashed vertical line)

1024 Figure 3 Amplitude anomaly trends (A-TATs) for Honiara in the Solomon Islands: (a) $\mathrm{K}_{1}$; (b) $\mathrm{O}_{1}$; (c) M; (d) $\mathrm{S}_{2}$; and phase anomaly trend (P-TATs) for (e) $\mathrm{K}_{1}$; (f) $\mathrm{O}_{1}$; (g) $\mathrm{M}_{2}$; and (h) $\mathrm{S}_{2}$. The red bars show $95 \%$ confidence limits on each annual estimate. The green line is the robust linear regression trend, in $\mathrm{mmm}^{-1} \mathrm{or} \mathrm{degm}^{-1}$, as shown as text, with $95 \%$ confidence limits on the anomaly trend. Significance is indicated by correlation $\left(\mathrm{r}_{0}{ }^{2}\right)$ values within each subplot

Figure $4 \mathrm{~K}_{1}$ A-TAT map, showing changes in amplitude (per m MSL rise). Map backgrounds show mean tidal amplitudes (meters) over the entire time record (color scale) and phases (solid lines), from the ocean tidal model of TPXO7.2, (Egbert and Erofeeva, 2002, 2010). Red and blue colored markers show positive and negative A-TATs, respectively. The magnitudes are indicated by color intensity, as shown by legend at the bottom, in units of mm of tidal change per meter of sea level rise $\left(\mathrm{mmm}^{-1}\right)$. To avoid potentially spurious results due to large percentage changes in small constituents, A-TATs are only plotted if the ratio of the $95 \%$ confidence limit of the trends has an SNR > 2. Statistically insignificant values are indicated by white circles

Figure $5 \mathrm{O}_{1}$ A-TAT map, showing changes in amplitude anomaly trends (for a 1 meter MSL rise); symbols are as in Figure 4 , and units are $\mathrm{mmm}^{-1}$

1037 Figure $6 \mathrm{M}_{2}$ A-TAT map, showing changes in amplitude anomaly trends (for a 1 meter MSL rise); symbols are as in 1038 Figure 4 , and units are $\mathrm{mmm}^{-1}$

1039 Figure $7 \mathrm{~S}_{2}$ A-TAT map, showing changes in amplitude anomaly trends (for a 1 meter MSL rise); symbols are as in 1040 Figure 4 , and units are $\mathrm{mmm}^{-1}$

1041 Figure 8 Combined A-TAT map, showing changes in amplitude anomaly trends (for a 1 meter MSL rise); symbols 1042 are as in Figure 4, and units are $\mathrm{mmm}^{-1}$. Tidal magnitudes were added together as complex quantities, and the real 1043 part of the result is what is plotted

1044 Figure 9 Overtide ratios (ORs) for: (a) $\mathrm{M}_{4} / \mathrm{M}_{2}{ }^{2}$; (b) $\mathrm{M}_{6} / \mathrm{M}_{2}{ }^{3}$; (c) $\mathrm{S}_{4} / \mathrm{S}_{2}{ }^{2}$; and (d) $\mathrm{MK}_{3} /\left(\mathrm{K}_{1} \mathrm{xM}_{2}\right.$ ); the background color 1045 scale represents the mean OR on a logarithmic scale. For stations that show a significant change over time in this

1046 ratio, numbers and colored markers indicate change in the ORs, in units of $1 / \mathrm{m},\left(\right.$ or $1 / \mathrm{m}^{2}$ for $\left.\mathrm{M}_{6}\right)$ expressed as 1047 percentage change per year 
Figure 10 Time-series for Honiara (blue line with red error bars) and Rabaul (black line with cyan error bars) of: (a) $\mathrm{M}_{4}$ and (b) $\mathrm{M}_{6}$ overtide ratios; and detrended (c) $\mathrm{M}_{2}$ amplitude; (d) $\mathrm{K}_{1}$ amplitude; and (e) $\mathrm{O}_{1}$ amplitude; and (f) MSL at Honiara (blue) and Rabaul (black); and (g) the Multivariate El Nino Index (MEI). Horizontal lines in (f) indicate approximate threshold values of MSL at the two gauges, vertical lines indicate times of ENSO events (yellow shading), when MSL is forced below this threshold. To standardize to a common water level datum, MSL is expressed as difference from the Revised Local Reference (RLR) datum (for 1983), as defined by the Permanent Service for Mean Sea Level (PSMSL), http://www.psmsl.org/; MSL is $6.232 \mathrm{~m}$ on RLR at Honiara and $6.401 \mathrm{~m}$ at Rabaul

Figure 11 (a) Map of Solomon Islands region, with locations of tide gauges and TAO buoys used for thermocline analyses; (b) time series of $\mathrm{D}_{20}$ at buoys 1-3 in blue, red and green, each about equidistant to Honiara, and the composite average of all three (black dotted line); (c) time series of composite $\mathrm{D}_{20}$ (blue), $\mathrm{M}_{2}$ (green) and $\mathrm{S}_{2}$ (red) amplitude variations at Honiara; (d) time series of $\mathrm{D}_{20}$ (blue) at buoy $4, \mathrm{M}_{2}$ (green) and $\mathrm{S}_{2}$ (red) amplitude variations at Kapingamarangi; and (e) $\mathrm{D}_{20}$ for Pago Pago (blue) and $\mathrm{M}_{2}$ amplitude (green) at buoy 5 . All datasets represent an IMF decomposition of monthly time series, using IMFs \#4-9 out of 10 so that the long term trends are not apparent

Figure $12 \mathrm{~K}_{1}$ TAT map, showing differences in A-TATs and P-TATs between years before 1993 and after 1993 (for a 1m MSL rise); symbols are as in Figure 4-7; values are tabulated in Table 4

Figure $13 \mathrm{M}_{2}$ TAT map, showing differences in A-TATs and P-TATs between years before 1993 and after 1993 (for a 1-meter MSL rise); symbols are as in Figure 4-7; values are tabulated in Table 5

Figure 14 Resonant triad interactions for Honiara (a) and Rabaul (b) in the Solomon Sea region, represented in terms of the IMF decomposition (IMFs \#4-10) of the LHS (blue, $\left.\left|\mathbf{M}_{2}\right|\right)$ and RHS (red, $\beta\left|\mathrm{O}_{1}\right|\left|\mathrm{K}_{1}\right|$ ) of (13). As in Figure 9, stronger ENSO-related fluctuations are highlighted in yellow

Figure 15 Triad interactions for Honiara (a) and Rabaul (b), Solomon Sea region: scatterplots of the IMF decomposition (IMFs \#4-10) of $\left|\mathbf{M}_{2}\right|$ vs. $\left|\mathrm{O}_{1}\right|\left|\mathrm{K}_{1}\right|$ to determine $\beta$ in Eq. (13); 95\% confidence limits and correlation ( $\rho$ ) values are given

1071 Figure 16 Phase-lock condition at Honiara, as in (2b), showing the IMF decomposition (IMFs \#4-10) of the individual 1072 PD variations of $\mathrm{M}_{2}$ (blue), $\mathrm{K}_{1}$ (red), and $\mathrm{O}_{1}$ (green), along with errors. The sum of the phase differences, $\Phi$, is shown 1073 in black 


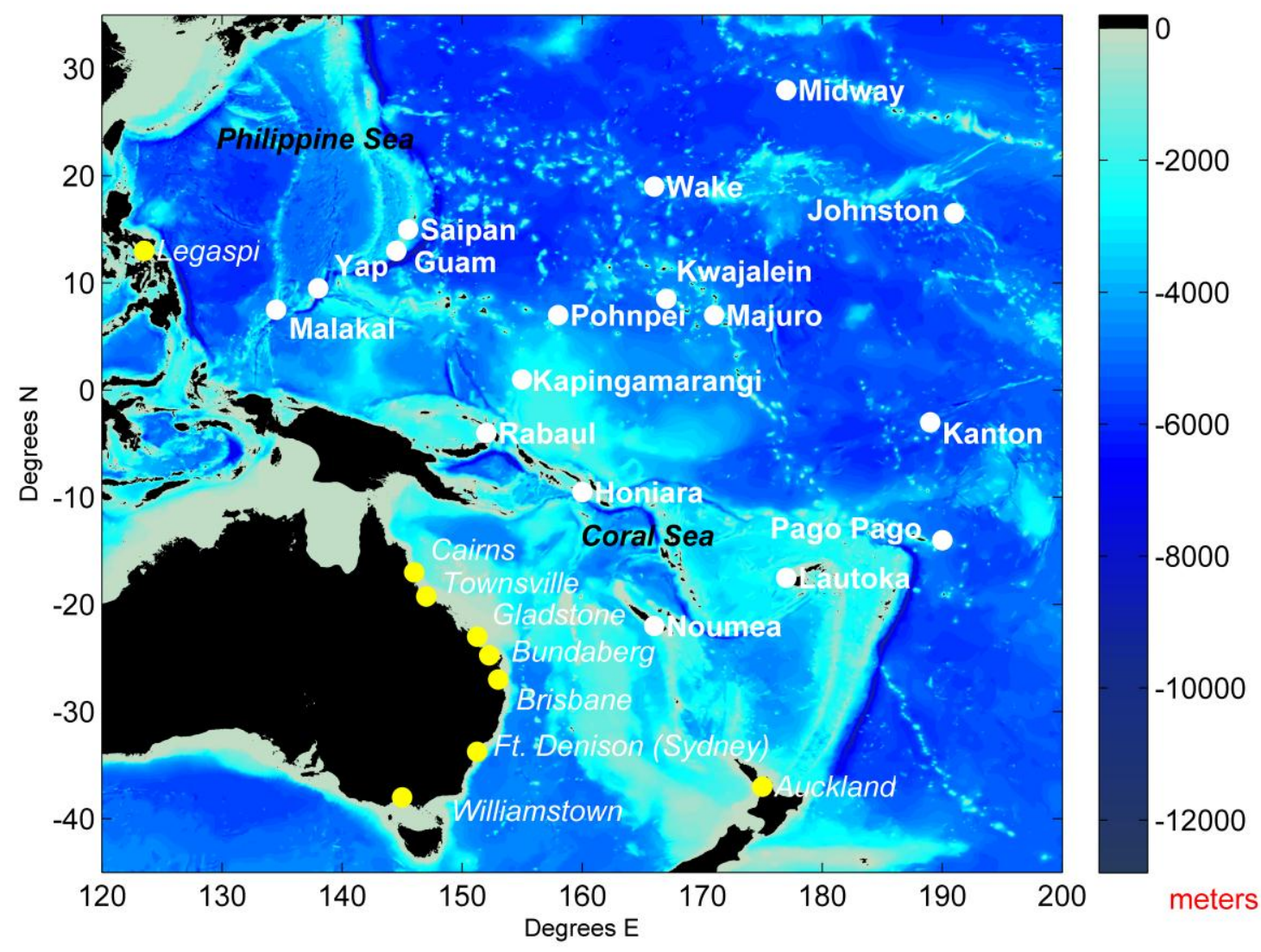

1078

1079 Figure 1 Bathymetry of the western Pacific Ocean, with tide gauge stations used in this study shown as white dots 1080 and bold text for island gauges, and yellow dots and italicized text for coastal gauges; the depth scale is shown at right, 1081 in meters 


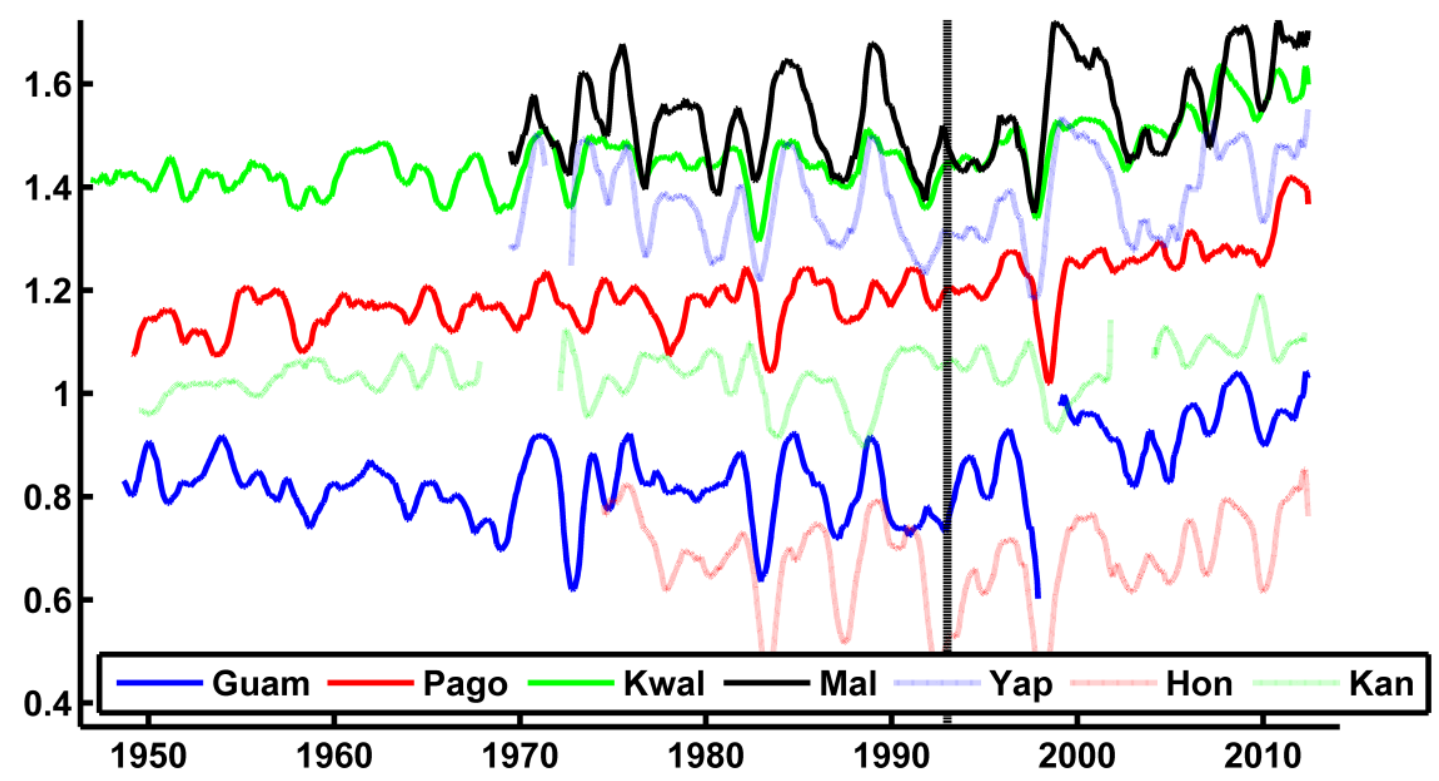

1090

1091

Figure 2 Time series of yearly average MSL (in meters) at Guam, Pago Pago, Kwaljein, Malakal, Yap, Honiara, and 1092 Kanton, showing differences in sea level evolution before and after 1993 (indicated by the dashed vertical line)

1093

1094

1095

1096

1097

1098

1099

1100

1101

1102

1103

1104 

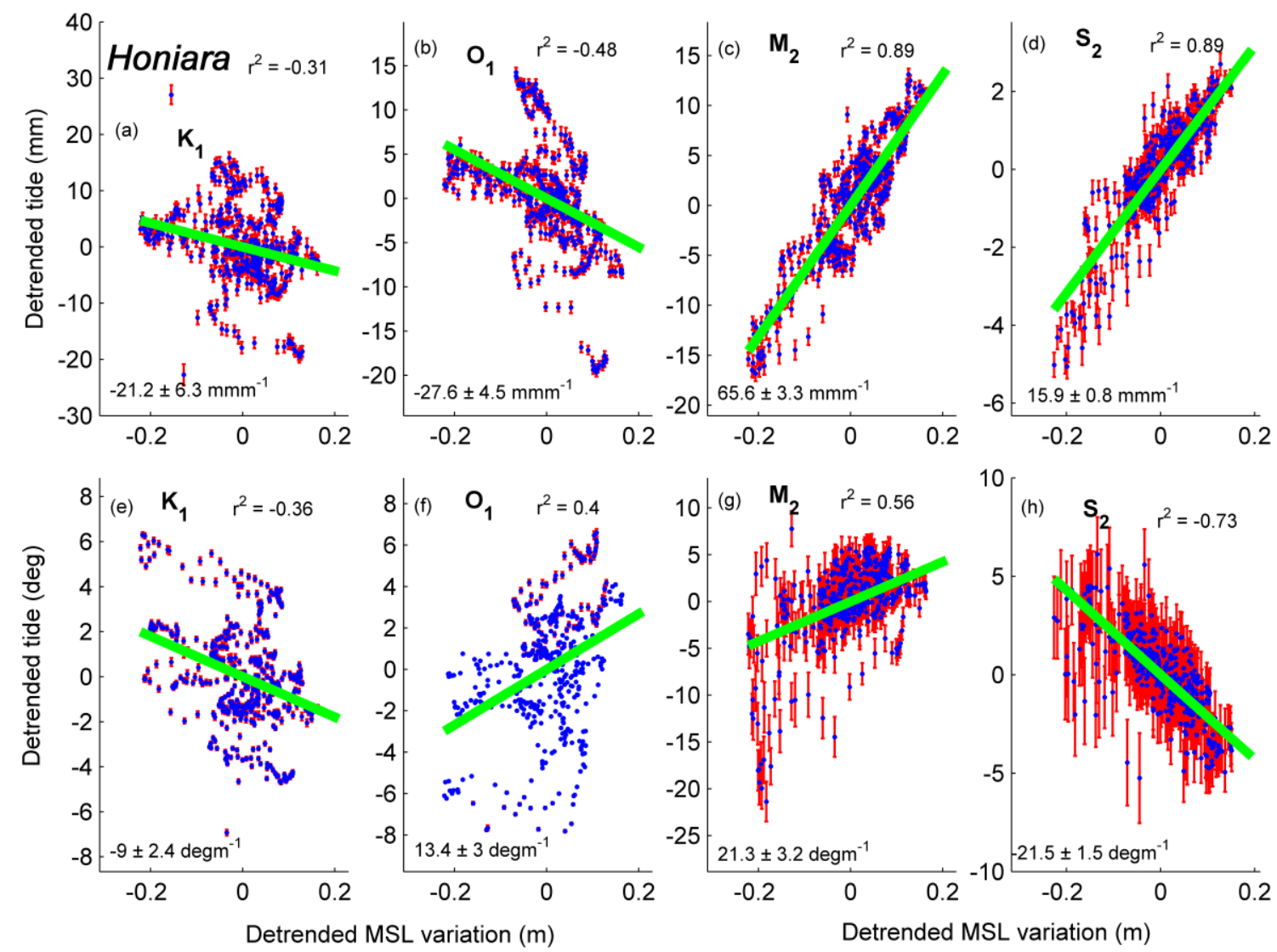

Figure 3 Amplitude anomaly trends (A-TATs) for Honiara in the Solomon Islands: (a) $\mathrm{K}_{1}$; (b) $\mathrm{O}_{1}$; (c) $\mathrm{M}$; (d) $\mathrm{S}_{2}$; and phase anomaly trend (P-TATs) for (e) $\mathrm{K}_{1}$; (f) $\mathrm{O}_{1}$; (g) $\mathrm{M}_{2}$; and (h) $\mathrm{S}_{2}$. The red bars show 95\% confidence limits on each annual estimate. The green line is the robust linear regression trend, in $\mathrm{mmm}^{-1} \mathrm{or} \mathrm{degm}^{-1}$, as shown as text, with 


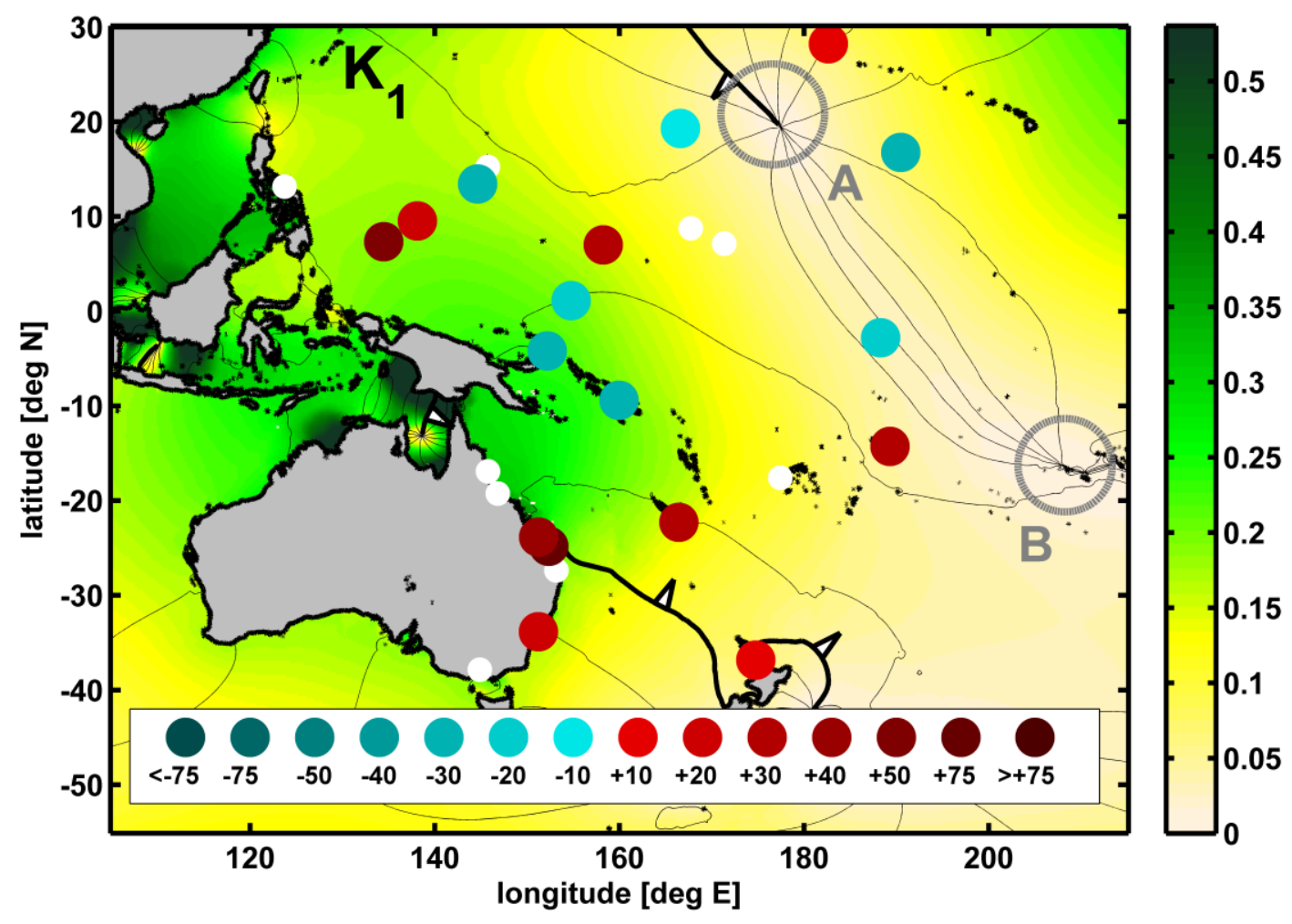

1118 Figure $4 \mathrm{~K}_{1}$ A-TAT map, showing changes in amplitude (per m MSL rise). Map backgrounds show mean tidal 1119 amplitudes (meters) over the entire time record (color scale) and phases (solid lines), from the ocean tidal model of 1120 TPXO7.2, (Egbert and Erofeeva, 2002, 2010). Red and blue colored markers show positive and negative A-TATs, 1121 respectively. The magnitudes are indicated by color intensity, as shown by legend at the bottom, in units of mm of 1122 tidal change per meter of sea level rise $\left(\mathrm{mmm}^{-1}\right)$. To avoid potentially spurious results due to large percentage

1123 changes in small constituents, A-TATs are only plotted if the ratio of the $95 \%$ confidence limit of the trends has an 1124 SNR $>2$. Statistically insignificant values are indicated by white circles 


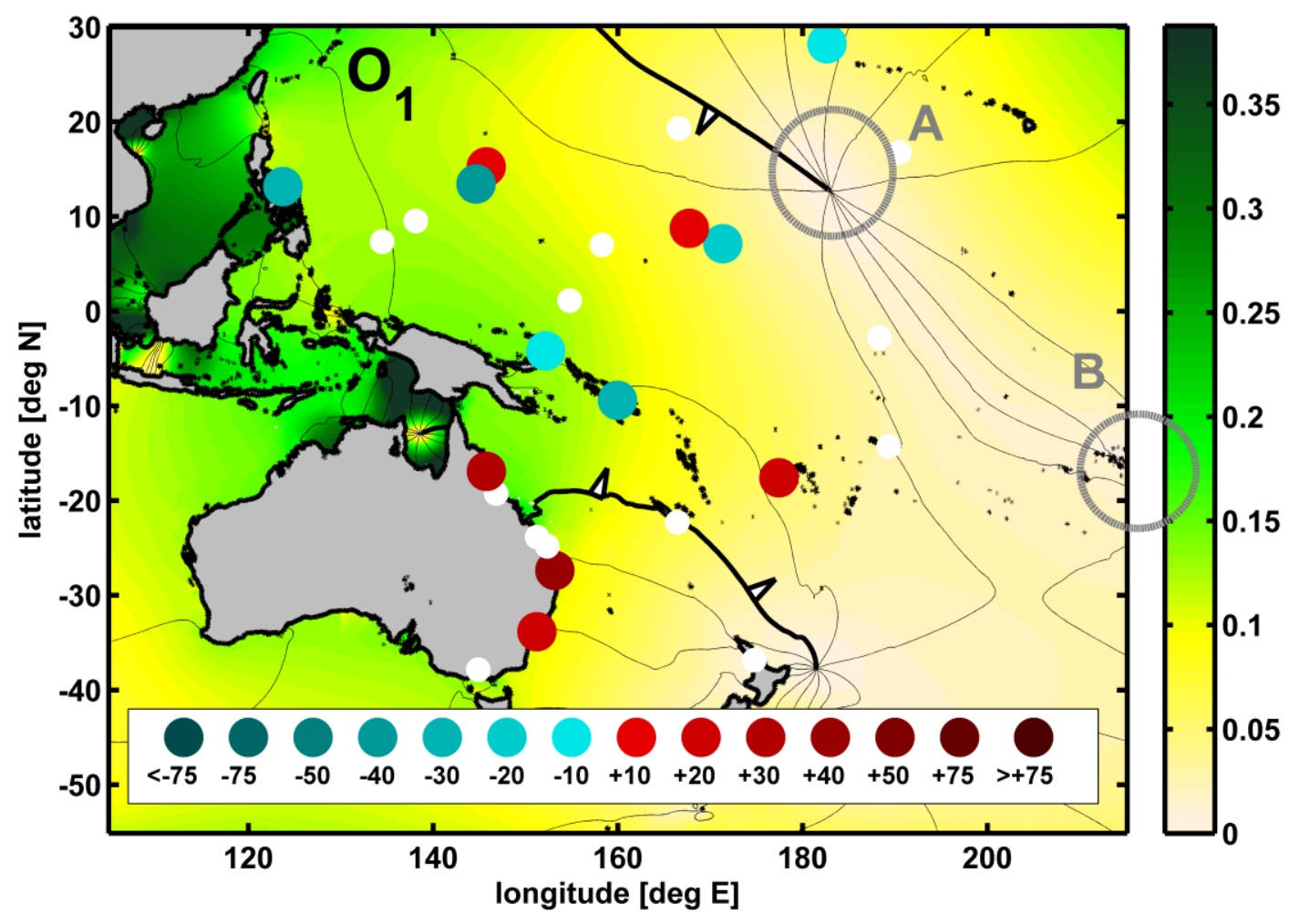

1131

1132 Figure $5 \mathrm{O}_{1}$ A-TAT map, showing changes in amplitude anomaly trends (for a 1 meter MSL rise); symbols are as in 1133 Figure 4 , and units are $\mathrm{mmm}^{-1}$

1134

1135

1136

1137

1138

1139

1140

1141

1142 


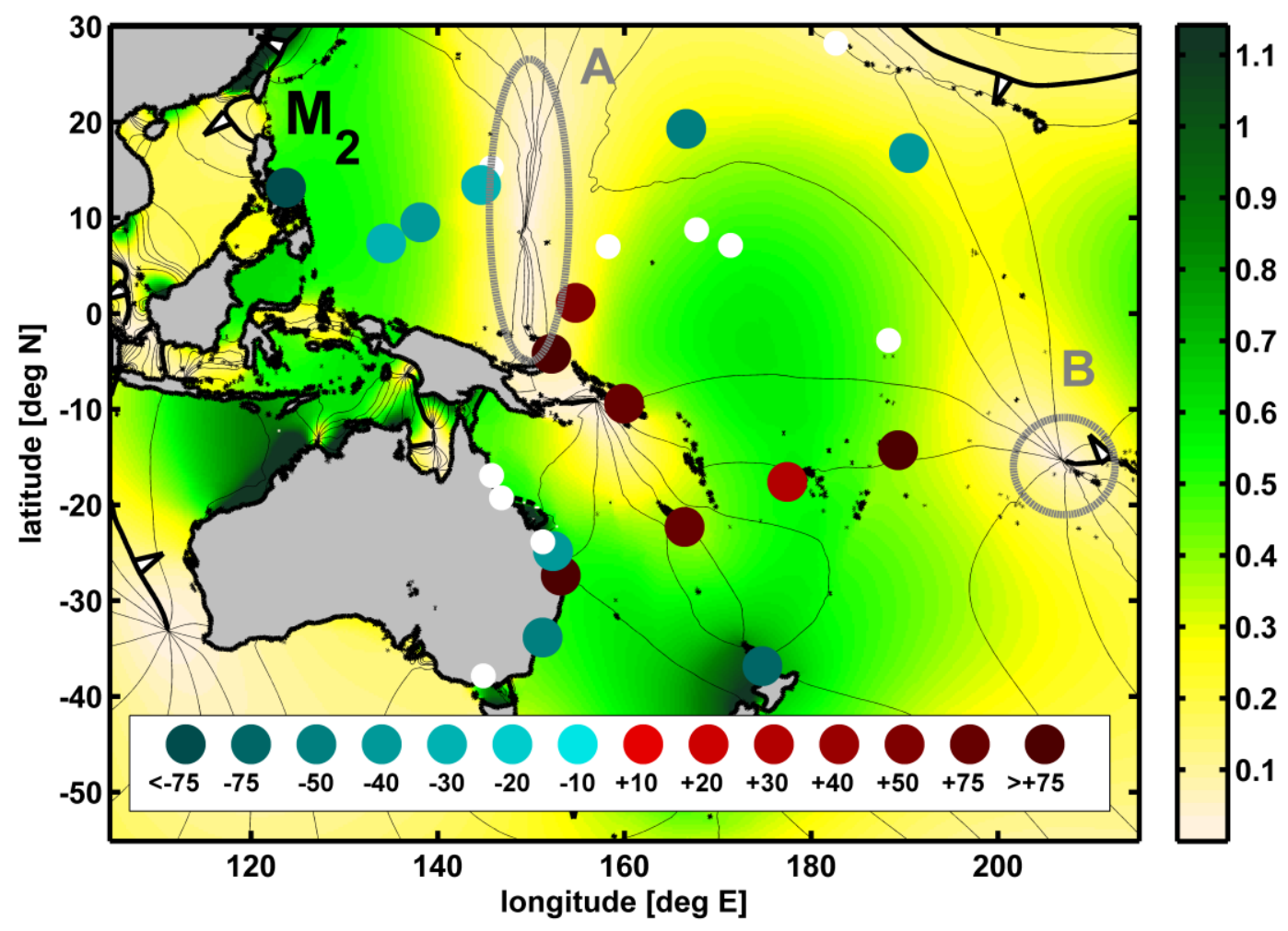

1143

1144 Figure $6 \mathrm{M}_{2}$ A-TAT map, showing changes in amplitude anomaly trends (for a 1 meter MSL rise); symbols are as in 1145 Figure 4, and units are $\mathrm{mmm}^{-1}$ 


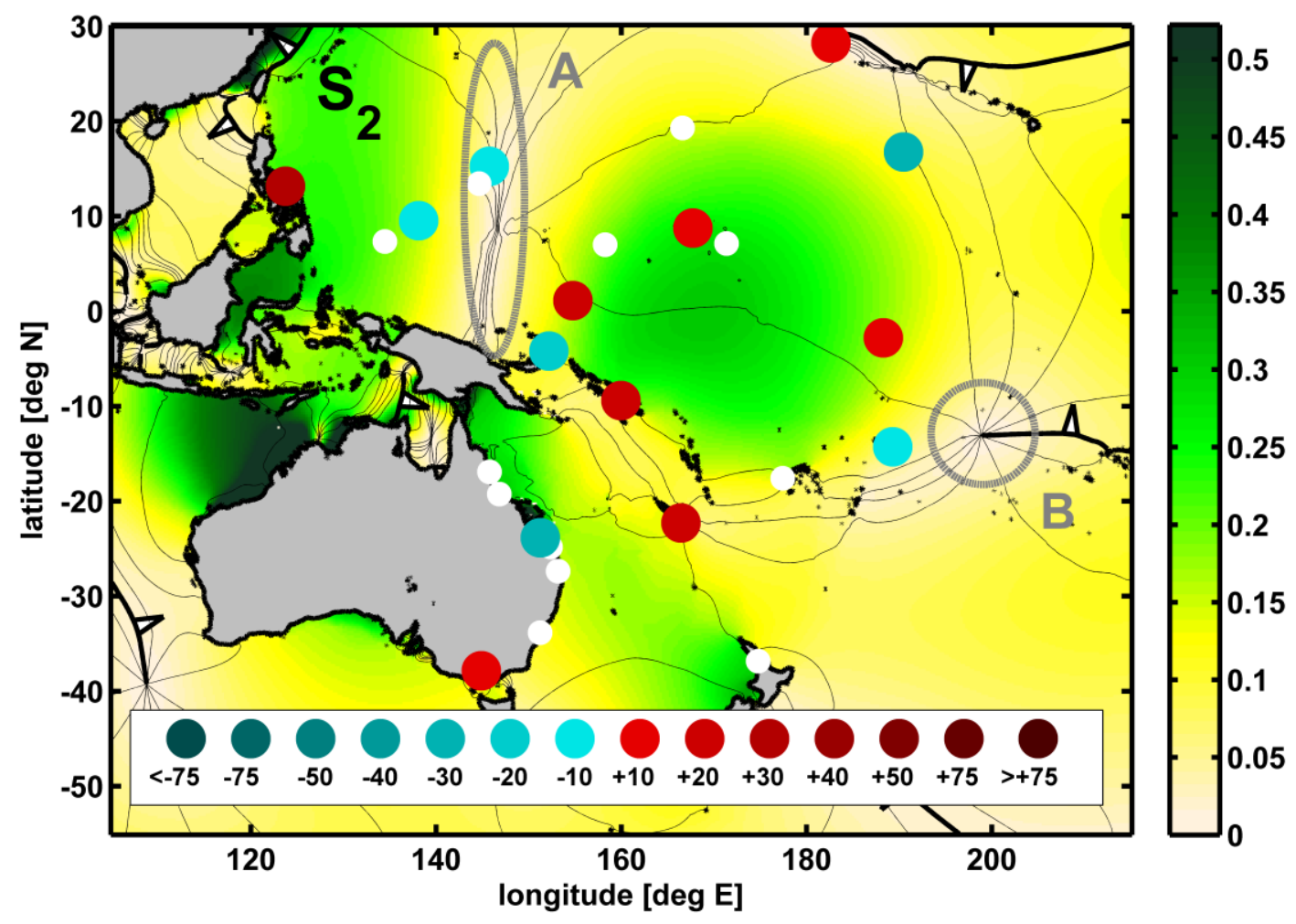

1156 Figure $7 \mathrm{~S}_{2}$ A-TAT map, showing changes in amplitude anomaly trends (for a 1 meter MSL rise); symbols are as in 1157 Figure 4 , and units are $\mathrm{mmm}^{-1}$ 


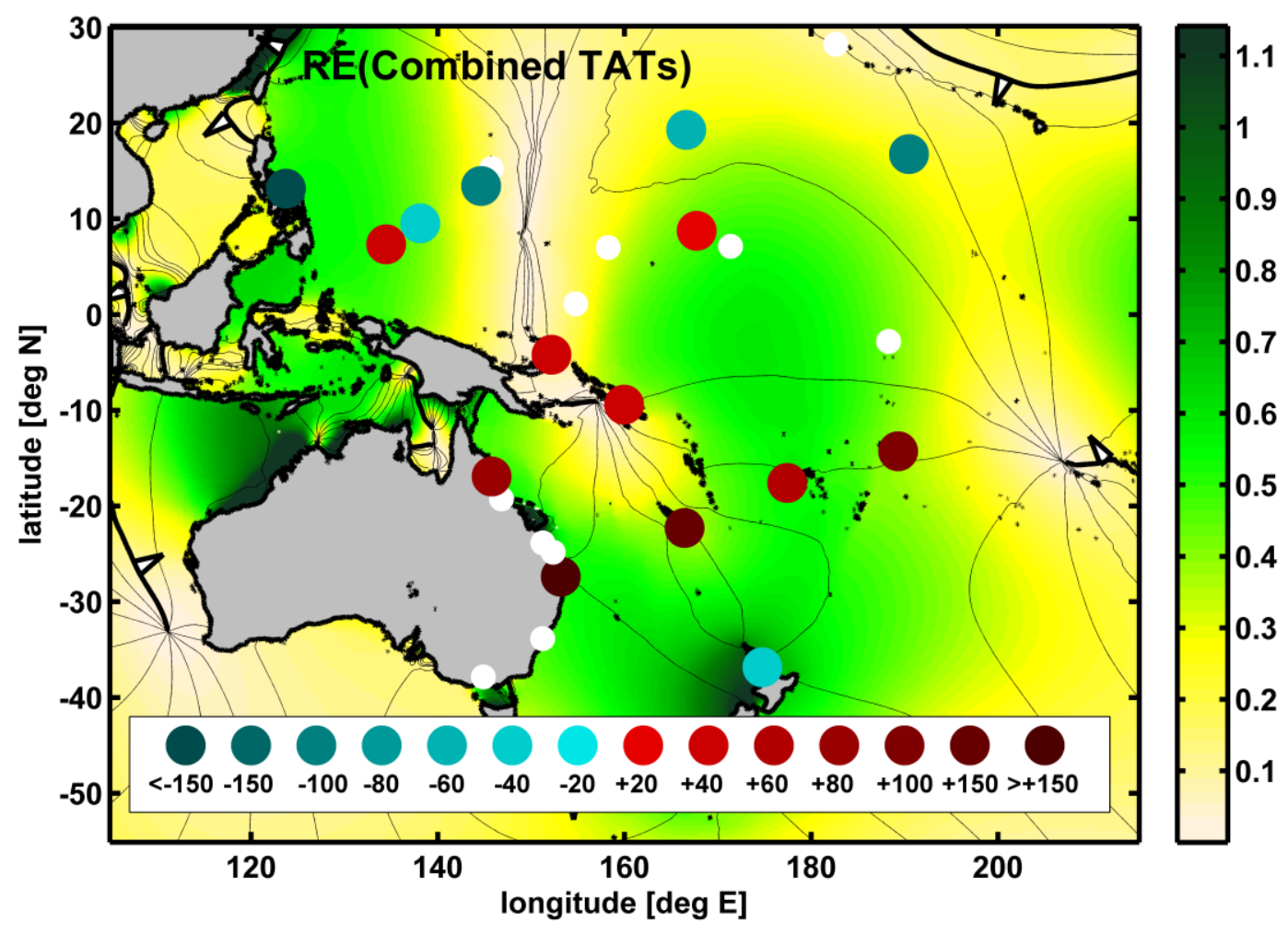

1168 Figure 8 Combined A-TAT map, showing changes in amplitude anomaly trends (for a 1 meter MSL rise); symbols 1169 are as in Figure 4, and units are $\mathrm{mmm}^{-1}$. Tidal magnitudes were added together as complex quantities, and the real 1170 part of the result is what is plotted 

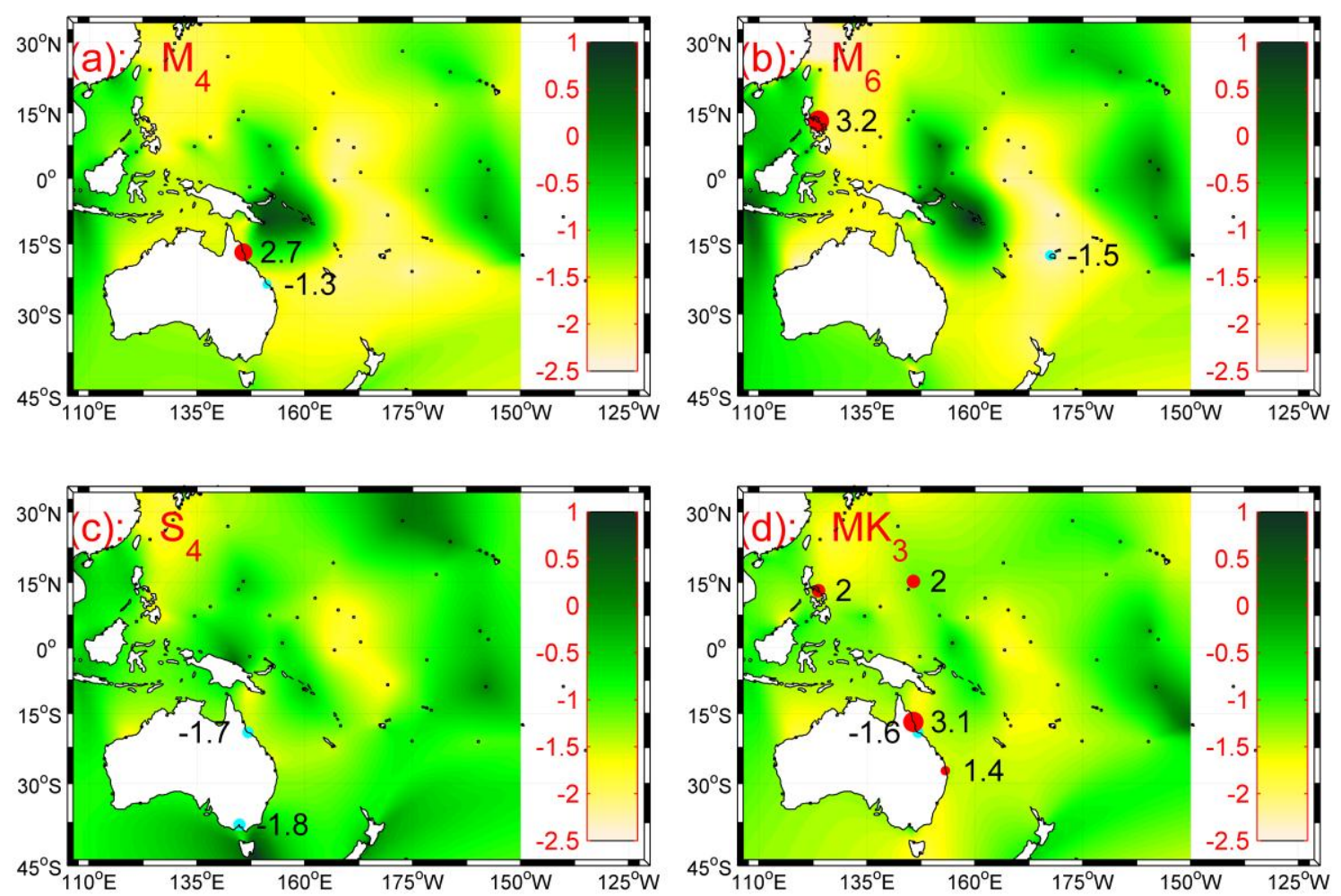

Figure 9 Overtide ratios (ORs) for: (a) $\mathrm{M}_{4} / \mathrm{M}_{2}{ }^{2}$; (b) $\mathrm{M}_{6} / \mathrm{M}_{2}{ }^{3}$; (c) $\mathrm{S}_{4} / \mathrm{S}_{2}{ }^{2}$; and (d) $\mathrm{MK}_{3} /\left(\mathrm{K}_{1} \times \mathrm{M}_{2}\right.$ ); the background color scale represents the mean OR on a logarithmic scale. For stations that show a significant change over time in this ratio, numbers and colored markers indicate change in the ORs, in units of $1 / \mathrm{m}$, (or $1 / \mathrm{m}^{2}$ for $\mathrm{M}_{6}$ ) expressed as percentage change per year 


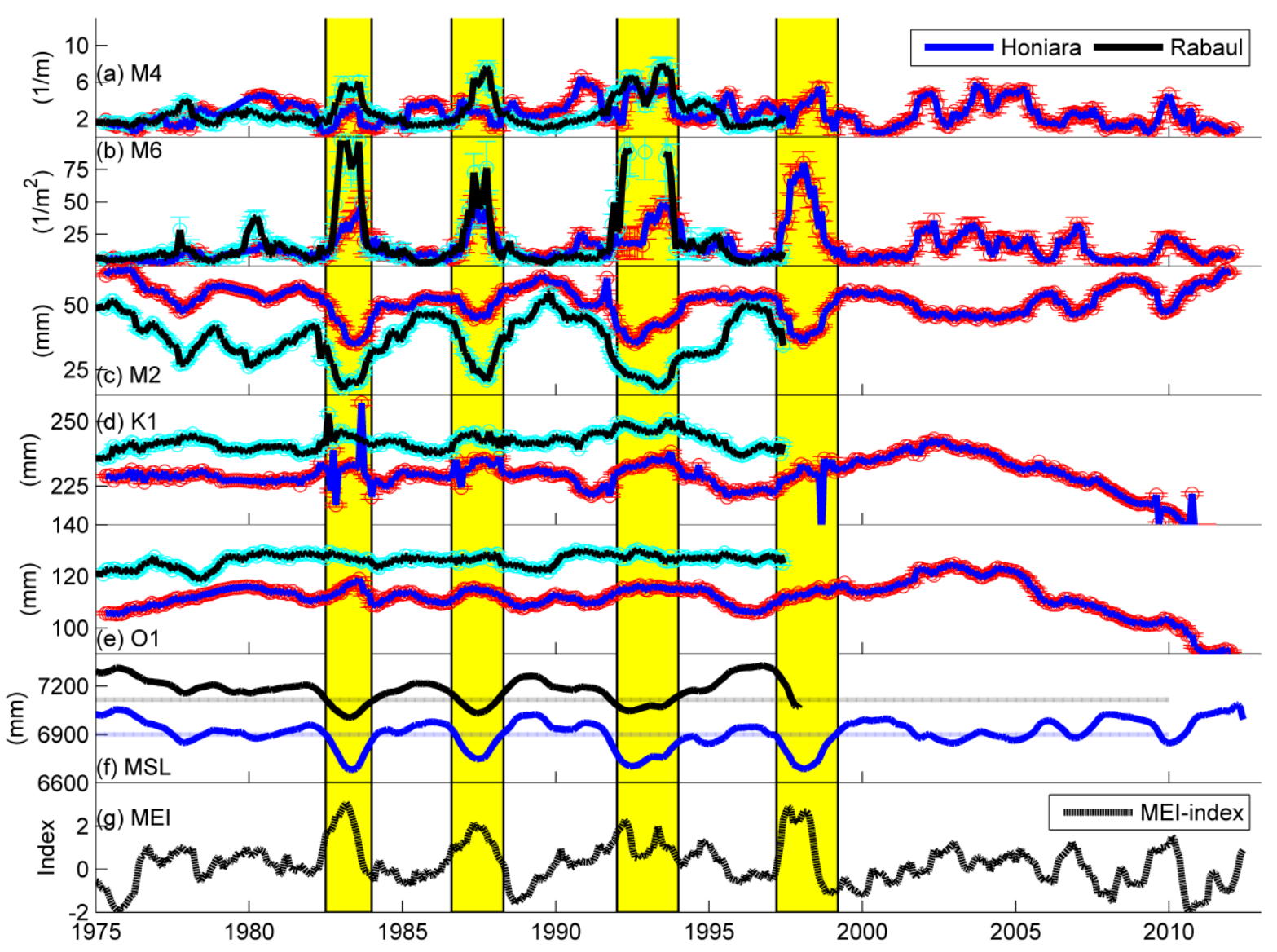

Figure 10 Time-series for Honiara (blue line with red error bars) and Rabaul (black line with cyan error bars) of: (a)

$1193 \quad \mathrm{M}_{4}$ and (b) $\mathrm{M}_{6}$ overtide ratios; and detrended (c) $\mathrm{M}_{2}$ amplitude; (d) $\mathrm{K}_{1}$ amplitude; and (e) $\mathrm{O}_{1}$ amplitude; and (f) MSL 1194 at Honiara (blue) and Rabaul (black); and (g) the Multivariate El Nino Index (MEI). Horizontal lines in (f) indicate 1195 approximate threshold values of MSL at the two gauges, vertical lines indicate times of ENSO events (yellow shading), 1196 when MSL is forced below this threshold. To standardize to a common water level datum, MSL is expressed as difference from the Revised Local Reference (RLR) datum (for 1983), as defined by the Permanent Service for Mean Sea Level (PSMSL), http://www.psmsl.org/; MSL is $6.232 \mathrm{~m}$ on RLR at Honiara and $6.401 \mathrm{~m}$ at Rabaul 

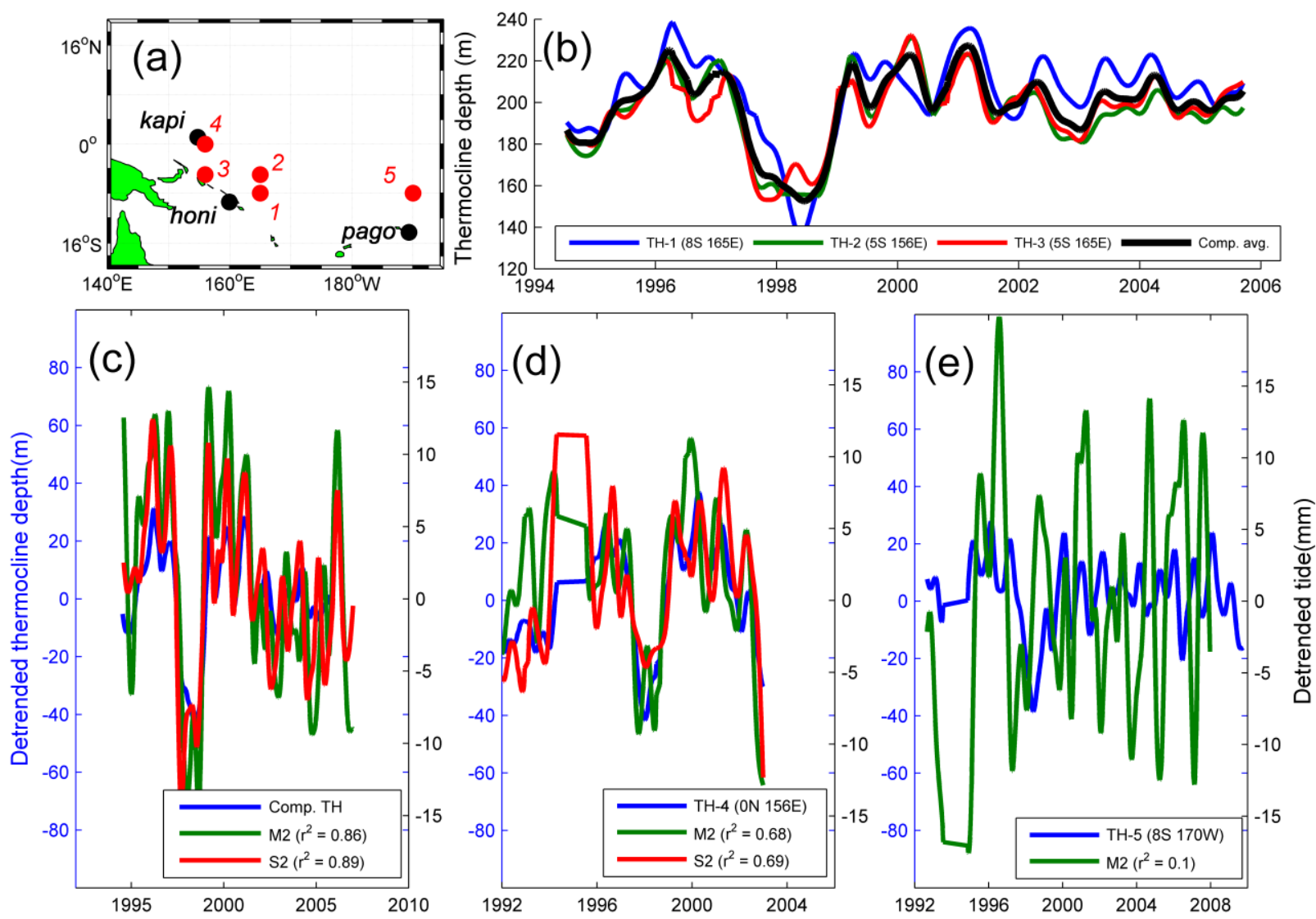

1205

1206

1207

1208

1209

1210

1211

1212

1213

1214

1215

1216

Figure 11 (a) Map of Solomon Islands region, with locations of tide gauges and TAO buoys used for thermocline analyses; (b) time series of $\mathrm{D}_{20}$ at buoys 1-3 in blue, red and green, each about equidistant to Honiara, and the composite average of all three (black dotted line); (c) time series of composite $\mathrm{D}_{20}$ (blue), $\mathrm{M}_{2}$ (green) and $\mathrm{S}_{2}$ (red) amplitude variations at Honiara; (d) time series of $\mathrm{D}_{20}$ (blue) at buoy $4, \mathrm{M}_{2}$ (green) and $\mathrm{S}_{2}$ (red) amplitude variations at Kapingamarangi; and (e) $\mathrm{D}_{20}$ for Pago Pago (blue) and $\mathrm{M}_{2}$ amplitude (green) at buoy 5 . All datasets represent an IMF decomposition of monthly time series, using IMFs \#4-9 out of 10 so that the long term trends are not apparent 


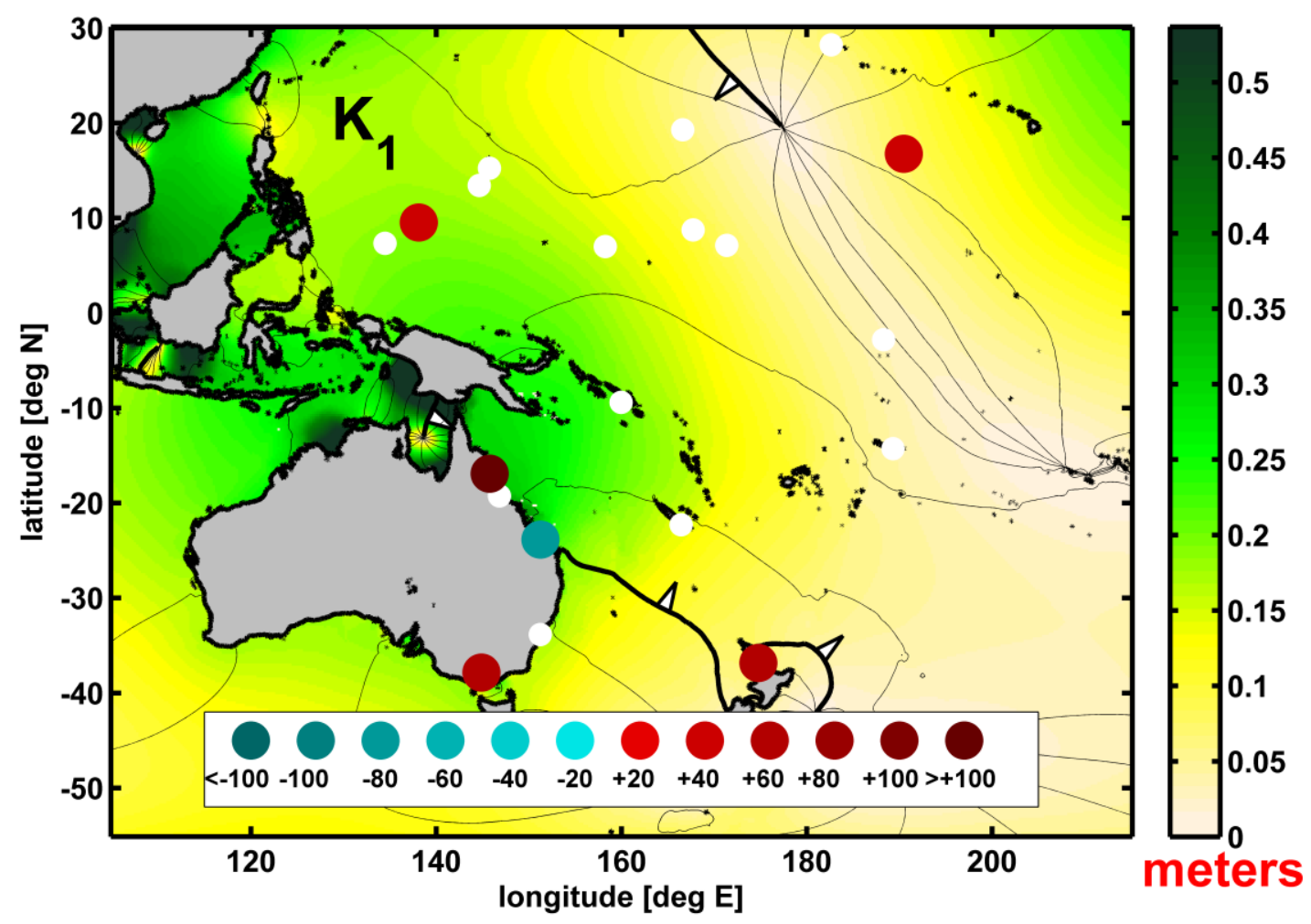

1218 Figure $12 \mathrm{~K}_{1}$ TAT map, showing differences in A-TATs and P-TATs between years before 1993 and after 1993 (for 1219 a 1m MSL rise); symbols are as in Figure 4-7; values are tabulated in Table 4 


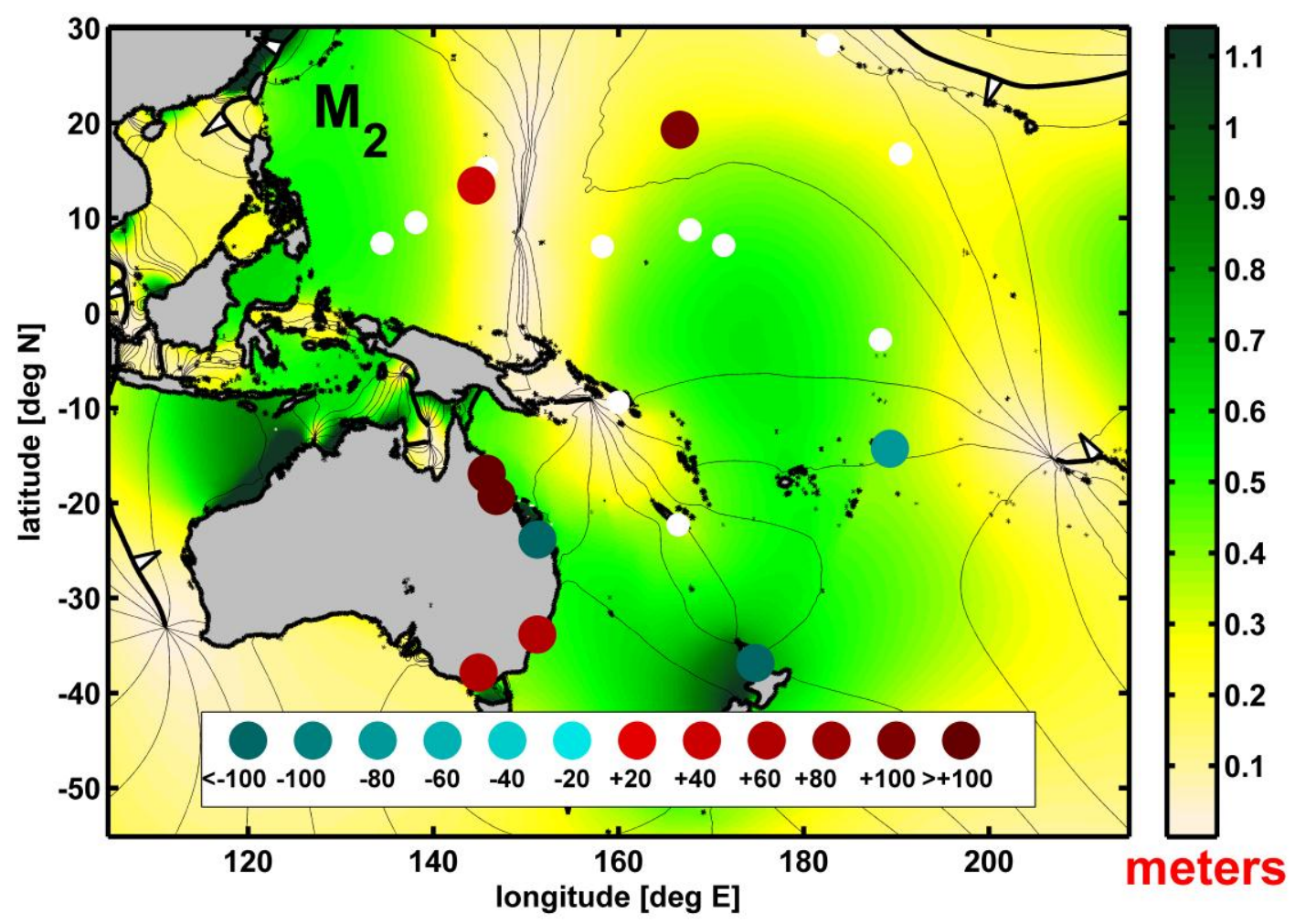

1230 Figure $13 \mathrm{M}_{2}$ TAT map, showing differences in A-TATs and P-TATs between years before 1993 and after 1993 (for 1231 a 1-meter MSL rise); symbols are as in Figure 4-7; values are tabulated in Table 5 

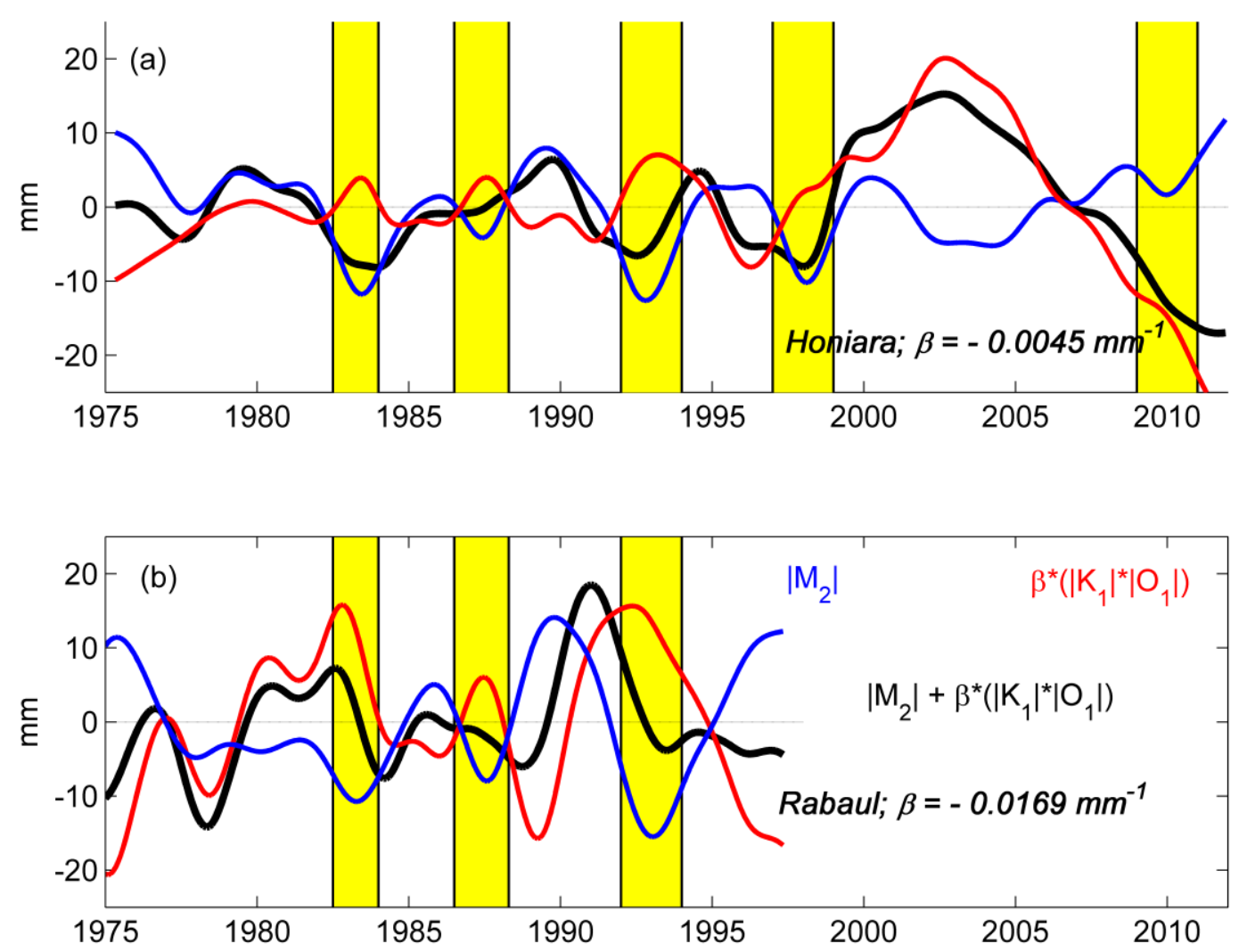

1241

1242

1243

1244

1245

1246

1247

1248

1249

1250

1251

1252

Figure 14 Resonant triad interactions for Honiara (a) and Rabaul (b) in the Solomon Sea region, represented in terms of the IMF decomposition (IMFs \#4-10) of the LHS (blue, $\left|\mathbf{M}_{2}\right|$ ) and RHS (red, $\beta\left|\mathrm{O}_{1}\right|\left|\mathrm{K}_{1}\right|$ ) of (13). As in Figure 9, stronger ENSO-related fluctuations are highlighted in yellow 

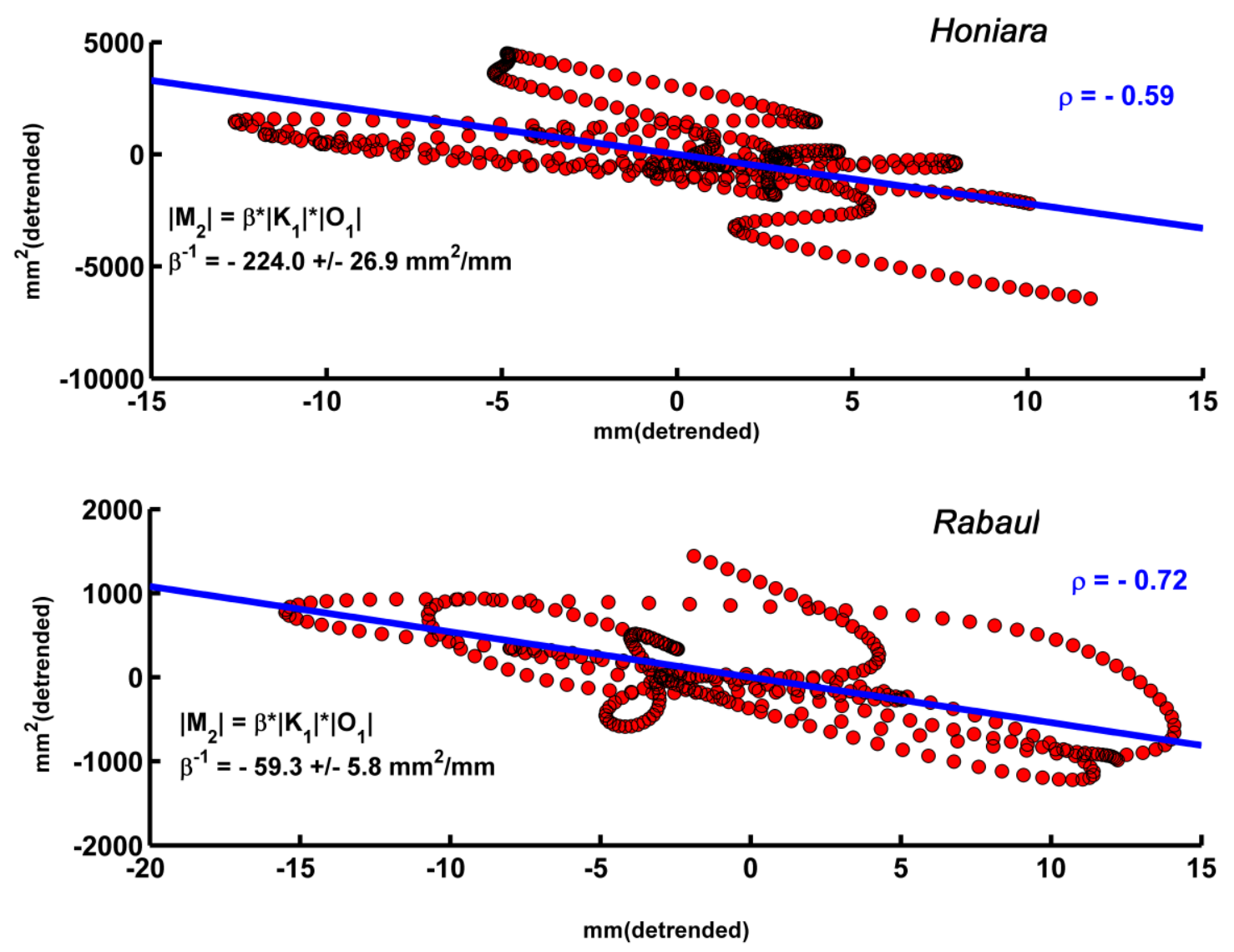

1254 Figure 15 Triad interactions for Honiara (a) and Rabaul (b), Solomon Sea region: scatterplots of the IMF 1255 decomposition (IMFs \#4-10) of $\left|\mathrm{M}_{2}\right|$ vs. $\left|\mathrm{O}_{1} \| \mathrm{K}_{1}\right|$ to determine $\beta$ in Eq. (13); 95\% confidence limits and correlation $(\rho)$ 1256 values are given 


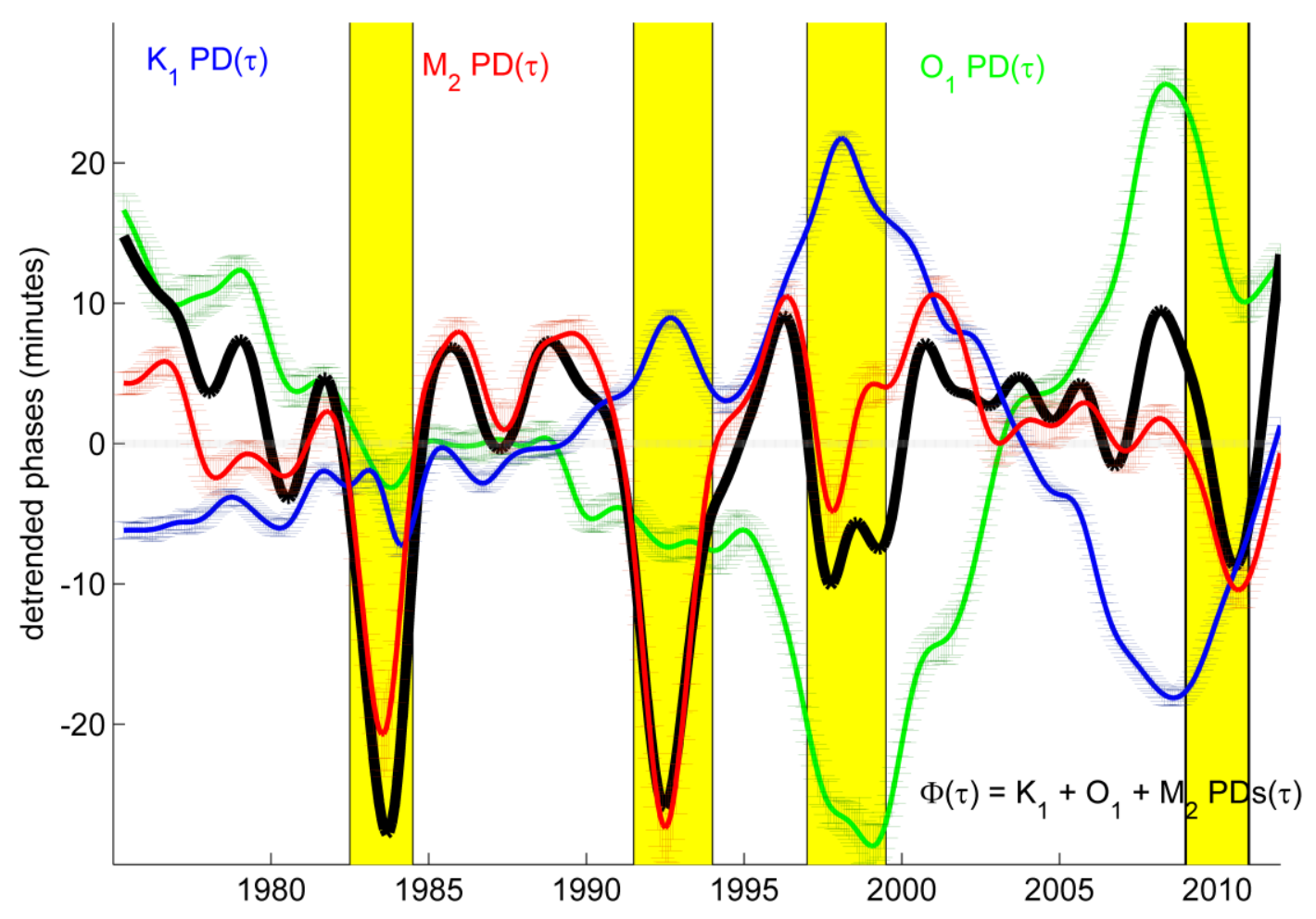

1265

1266

Figure 16 Phase-lock condition at Honiara, as in (2b), showing the IMF decomposition (IMFs \#4-10) of the individual

1267 PD variations of $\mathrm{M}_{2}$ (blue), $\mathrm{K}_{1}$ (red), and $\mathrm{O}_{1}$ (green), along with errors. The sum of the phase differences, $\Phi$, is shown 1268 in black

1269 